\title{
How Firms Respond to Business Cycles: The Role of Firm Age and Firm Size*
}

by

\author{
Teresa C. Fort \\ Tuck School of Business at Dartmouth
}

\author{
John Haltiwanger \\ University of Maryland and NBER
}

\author{
Ron S. Jarmin \\ U.S. Census Bureau
}

Javier Miranda

U.S. Census Bureau

\section{CES 13-30 June, 2013}

The research program of the Center for Economic Studies (CES) produces a wide range of economic analyses to improve the statistical programs of the U.S. Census Bureau. Many of these analyses take the form of CES research papers. The papers have not undergone the review accorded Census Bureau publications and no endorsement should be inferred. Any opinions and conclusions expressed herein are those of the author(s) and do not necessarily represent the views of the U.S. Census Bureau. All results have been reviewed to ensure that no confidential information is disclosed. Republication in whole or part must be cleared with the authors.

To obtain information about the series, see www.census.gov/ces or contact Fariha Kamal, Editor, Discussion Papers, U.S. Census Bureau, Center for Economic Studies 2K132B, 4600 Silver Hill Road, Washington, DC 20233, CES.Papers.List@census.gov. 


\begin{abstract}
There remains considerable debate in the theoretical and empirical literature about the differences in the cyclical dynamics of firms by firm size. This paper contributes to the debate in two ways. First, the key distinction between firm size and firm age is introduced. The evidence presented in this paper shows that young businesses (that are typically small) exhibit very different cyclical dynamics than small/older businesses. The second contribution is to present evidence and explore explanations for the finding that young/small businesses were hit especially hard in the Great Recession. The collapse in housing prices accounts for a significant part of the large decline of young/small businesses in the Great Recession.
\end{abstract}

\footnotetext{
* Tuck School of Business at Dartmouth, University of Maryland and NBER, U.S. Bureau of the Census, and U.S. Bureau of the Census, respectively. We thank participants at seminars at CES, Harvard, and INSEAD, attendees at the IMF ARC Conference and the NBER Entrepreneurship Workshop, Pierre- Olivier Gourinchas, Roberto Fattal Jaef, Ayhan Kose, Giuseppe Moscarini, Robert Strom and two anonymous referees for helpful comments and the Kauffman Foundation for financial support. Any opinions and conclusions expressed herein are those of the authors and do not necessarily represent the views of the U.S. Census Bureau. All results have been reviewed to ensure that no confidential information is disclosed. We thank Ryan Decker for his assistance developing the STATA code used in this paper as well as Inessa Love for the original version of PVAR.
} 


\section{Introduction}

The 2007-2009 recession is one of the two largest cyclical downturns experienced in the U.S. in the post WWII era - the other being the 1982-83 recession. One obvious difference between these two downturns is the subsequent recoveries. Following the 1982-83 recession, the U.S. exhibited a rapid recovery from 1984 through 1986. In contrast, the recovery from the 2007-09 downturn has been relatively anemic. Much commentary and analysis has focused on the differences in the nature of the recessions, especially focusing on the financial crisis in the most recent downturn. A critical feature of the latter is associated with the collapse in housing prices in the U.S.

To explore these issues further, we exploit a recently developed comprehensive longitudinal database of employer businesses in the U.S. that enables us to track employment dynamics by firm size, firm age and geographic location. While the basic facts mentioned above are now well known, we use this rich new data to show that young and small businesses are particularly sensitive to housing price fluctuations and that they were hit especially hard in the 2007 to 2009 recession. Businesses less than five years old and with fewer than 20 employees (young/small) exhibited a decline in net employment growth from 26.6 percent to 8.6 percent from 2006 to 2009 . Over this same period, businesses more than five years old with more than 500 workers (older/large) exhibited a decline in net employment growth from 2.8 percent to -3.9 percent. The net growth rate differential between such young/small businesses and older/large businesses fell from 23.7 percent to 12.5 percent.

Our work is related to an ongoing debate in the literature on how firms of different sizes respond to the business cycle and financial shocks. One strand of the literature suggests that small firms have a disproportionate response, relative to large firms, to financial and monetary policy shocks (Gertler and Gilchrist, 1994 and Sharpe, 1994). Chari, Christiano and Kehoe (2007) caution that the greater cyclicality of small relative to large firms is sensitive to time period and cyclical indicators. In recent work, Moscarini and Postel-Vinay (2012) document large firms have a disproportionate response, relative to small firms, to deviations of the level of unemployment from its (HP-filtered) trend. A careful reading of the above studies suggests that some of the differences stem from differences in the cyclical indicators 
(e.g., contraction/expansion indicators vs. deviations from trend) used and types of shocks measured (e.g., credit market shocks versus demand shocks). But how to fully reconcile these alternative views remains an open question.

One key factor missing from this literature is the distinction between firm size and firm age. Many of the hypotheses about why small firms should be more sensitive to variation to changes in credit conditions are more relevant for startups and young firms. In addition, survey evidence suggests that the appropriate indicators of credit conditions vary across firms by both firm size and firm age. Specifically, startups and young firms don't have access to commercial paper corporate bonds, or perhaps even an established credit record, but rather rely on personal sources of finance, including home equity, to establish credit lines. ${ }^{1}$ In that respect, the pronounced variation in housing prices during the last decade is potentially especially pertinent for startups and young firms.

We investigate how firms of different size and age respond to the cycle by combining data from the Census Bureau's Business Dynamics Statistics (BDS) from 1981 to 2010 with indicators of business cycle and financial market conditions. The BDS permits us to consider differential cyclical dynamics of net job creation, gross job creation and gross job destruction by firm size and firm age. We combine the BDS with standard business cycle indicators such as the unemployment rate, and with state-level housing prices. Our identification strategy exploits the geographic and time variation in the BDS. One limitation of much of the existing literature on the role of either firm size or firm age is that analyses exploit relatively short time series samples with only a limited number of cyclical episodes. This hampers the ability to identify the role played by different types of shocks and the differential response to these shocks across different types of firms. We overcome this limitation by focusing on variation across geography (U.S. states) as well as over time.

Our analysis begins by exploring correlations and simple descriptive regressions to shed new light on the role of firm size and firm age in this context. We find that the differential in the net job

\footnotetext{
${ }^{1}$ See evidence for the Kauffman Firm Survey, the Survey of Small Business Finance, and the Statistics of Business Owners.
} 
creation rate between young/small and large/mature businesses declines in cyclical downturns at both the national and state level. By cyclical downturns, we mean periods of contraction in the economy which we measure using either increases in the unemployment rate or declines in the output growth and net employment growth rate. The data show that distinguishing between small businesses by firm age is of critical importance. That is, older/small businesses respond less to an increase in the unemployment rate than young/small businesses. This focus on firm age helps distinguish our approach from the existing literature. We also find that when housing prices decline, young/small businesses experience a much larger decline in net job creation rates than large/mature businesses.

These descriptive findings motivate the core of our analysis. We employ a panel VAR approach using pooled state-level data across time to achieve identification with a relatively sparse number of variables, while controlling for state and year effects. The latter implies we are controlling for economywide factors in an unrestricted manner (i.e., not tied to any specific type of shock). The panel VAR specification includes indicators of overall state conditions (e.g., the unemployment rate in the state), housing prices in the state, and measures of the differential net growth rates across firms by firm size and firm age.

Even though the specification has a limited number of variables, it captures a rich set of factors. First, we control for unrestricted state and year effects. Second, we use a Cholesky ordering of the variables in the panel VAR to identify and estimate orthogonalized shocks in this system. The state cyclical indicator is first in the causal ordering - this yields the identification of a generic state-specific cyclical shock reflecting state-specific variation in business cycle conditions (from demand, supply or credit markets) as reflected through the state labor market. Housing prices are after the overall state cyclical indicator in the causal ordering so that the identified innovation to housing prices is orthogonal to changes in state-specific business cycle conditions. This approach makes it possible to distinguish between the impact of home price changes and labor market conditions independently of their influence on each other and of the impact of aggregate macro disturbances. 
We find that an innovation to the state-specific cyclical indicator associated with a downturn (e.g., a rise in the state unemployment rate) reduces the differential in the net job creation rate between young/small and large/mature businesses and that the effect persists for a number of years. That is, the net growth rate of young/small businesses falls more in contractions than does the net growth rate of large/mature businesses. We interpret this as evidence that young/small businesses are more vulnerable to business cycle shocks. Similarly, we find that a decline in housing prices in the state, above and beyond the local unemployment rate change, yields a further reduction in the differential in the net job creation rate between young/small and large/mature businesses. This effect is much subdued when examining the differential net job creation rate between mature/small and mature/large businesses. In this regard, we again find it is critical to distinguish between young and mature small businesses.

The panel VAR results also permit us to examine the impact of shocks in specific years and states. For example, we show that the net growth differential between young/small businesses and large/mature businesses fell by about six percentage points in California from 2007 to 2009 . Using the results from the panel VAR, we show that the decline in the orthogonalized housing price shock in California (which was larger than the national decline) accounts for two thirds of this decline in the net growth rate differential over this period. We find similar patterns in other states with especially large declines in housing prices, while such responses to housing prices are absent in states with little or no declines.

There are a number of mechanisms that may be at work in accounting for the greater sensitivity of young and small businesses to local shocks, and local housing price shocks in particular. One of these mechanisms is a housing price/home equity financing channel that, as suggested above, is especially relevant for startups and young businesses. While more data and analysis are needed to confirm this specific channel, our results are consistent with this mechanism. After presenting our empirical results, we discuss this and alternative mechanisms that may be at work.

The paper proceeds as follows. The next section provides a brief background review of the literature. Section III describes the data we use for the analysis. Section IV presents basic facts and some 
simple descriptive regressions. The panel VAR specification is presented in Section V along with results from this analysis. Concluding remarks are in Section VI.

\section{Background}

A number of papers have assessed the differential impact of macroeconomic shocks on firms of different size. In this section, we provide more detail about the measures and methods of these papers to provide guidance and perspective for our analysis. We also tie in relevant literature discussing alternative financing options for large and small/young firms that illustrate both why small and young firms may be more credit constrained, as well how home equity helps alleviate these constraints .

Before turning to a review of the literature on the cyclical dynamics of firms by size and age, it is useful to discuss briefly the conceptual underpinnings of the role of firm size and firm age in firm dynamics. Firm dynamic models incorporate firm-level heterogeneity in profitability and productivity even within a narrowly defined sector (see, e.g., the recent review by Syverson (2011)). High and low profitability firms co-exist because of economies of scope (Lucas (1978)), differentiated products (e.g., Melitz (2003)) or because of adjustment frictions. Firm entry and firm exit go hand-in-hand in these models. Firms exit because they obtain low draws of idiosyncratic profitability shocks and/or learn that they are not sufficiently profitable to continue. Within this context, some posit that new firms enter to exploit an innovation (e.g., Aghion and Howitt (2006)) or to take the place of the firms that exit (e.g., Hopenhayn (1992)). Regardless, it is common to assume that there is considerable heterogeneity and uncertainty among entrants about their prospects in terms of technical efficiency, demand and costs. Further, it takes time for this uncertainty to be resolved so there will be a period of selection and learning dynamics as in Jovanovic (1982). This learning may be not just passive learning about idiosyncratic factors, there might also be active learning by doing. Finally note that changes in ways of doing business may also induce additional rounds of learning (e.g., Ericson and Pakes).

From this perspective, young firms are likely to be very heterogeneous and the evidence supports models predicting an "up or out" dynamic of young firms consistent with selection and learning effects (see, Haltiwanger, Jarmin and Miranda (2013)). Young firms in these models are small due to 
uncertainty and other potential constraints. These constraints likely include limited reputations, in both product and credit markets, leading to challenges of building up a customer base as well as in obtaining credit. Where do small businesses fit into this characterization? Small businesses partly fit in because young businesses will be small. But the models and the evidence support the presence of older, small businesses. Older, small businesses are those that are sufficiently profitable to cover their fixed costs, and given curvature in the profit function from either span of control or differentiated products are not driven out of the market. Moving beyond the standard models, recent research has suggested that many small businesses are driven by non-pecuniary factors (see, Hurst and Pugsley (2011)).

Our focus is on the cyclical dynamics of these different types of firms. While this review of the firm dynamics literature has been necessarily brief, it does highlight that young/small businesses are likely to be quite different from old/small businesses. Moreover, in this class of models, old/large businesses are those that at least in some point in the past were sufficiently profitable and productive to become large. With these remarks as a background, we turn our attention to what we know about the relative cyclicality of these different types of firms.

Much of the literature examining the differential impact of the cycle on firms of different size investigates the financial transmission mechanism. In an influential paper, Gertler and Gilchrist (1994) assess the role of credit market frictions in propagating business cycles. Using firm size as a proxy for capital market access, the authors estimate the response of small versus large manufacturing firms to monetary policy changes while controlling for the business cycle. They find that large and small firms have similar responses to easing credit conditions; however, they show that small firms exhibit much sharper declines in sales and inventories during periods of credit market tightening relative to large firms. Chari, Christiano and Kehoe (2007) extend the Gertler and Gilchrist analysis to include three additional recessions and to compare the effects of monetary shocks and business cycle shocks as captured by NBER recession dates. Chari et al. (2007) confirm the result that small firms are more responsive to the recessions (monetary and NBER) in the original Gertler and Gilchrist timeframe. Results for the three additional recessions, however, suggest that small firms are more responsive to monetary policy shocks, 
while large firms are more sensitive to NBER recessions. These disparate results lead Chari et al. to conclude that there is no particular difference in the response of the sales of small establishments in recessions to generic "aggregate shocks". The story may be more nuanced, however, since their findings are also consistent with the interpretation that different recessions, with potentially different underlying causes, affect small and large firms differently.

There is also evidence about the effects of cyclical changes on employment decisions of firms of different size. Sharpe (1994) assesses the theory that more leveraged firms will hoard labor relatively less when financial markets are tight. Using firm size as a proxy for financial vulnerability, Sharpe instruments for demand and monetary shocks with growth in industrial production and changes in the federal funds respectively. Consistent with Gertler and Gilchrist (1994), Sharpe finds that small firms are quicker to lay off workers during a recession, though not necessarily quicker to hire during an expansion.

These papers are careful in their analysis but rely on datasets that do not cover the entire U.S. economy and in some cases use measures of firm growth that may be sensitive to M\&A activity. ${ }^{2}$ In more recent work, Moscarini and Postel-Vinay (2012) use U.S. economy-wide data from the Census Bureau's Business Dynamic Statistics (BDS) database from 1979-2009 to present evidence about the connection between the level of unemployment and the difference in net job creation at large versus small firms. They obtain a correlation of -0.54 between the differential net job creation rate for large vs. small firms and the Hodrick-Prescott (HP) filtered unemployment rate. ${ }^{3}$ Their focus on the level of unemployment is motivated by a theoretical framework in which large firms poach employees from small firms when labor markets are tight. As will become clear in our discussion below, it is important to

\footnotetext{
${ }^{2}$ Sharpe (1994) uses Compustat data from 1959 through 1985. Gertler and Gilchrist (1994) use the Quarterly Financial Report for Manufacturing Corporations, from 1958:4 through 1991:1. Chari, Christiano and Kehoe (2007) extend the analysis in Gertler and Gilchrist (1994) to cover 1952:1 through 2000:3. Davis, Haltiwanger, Jarmin and Miranda (2007) show the COMPUSTAT data is not representative of the economy as a whole.

${ }^{3}$ Note that Moscarini and Postel-Vinay measure the net difference as the difference between large and small firms. In what follows, we use large/mature firms as the base so all of our differentials are for a group minus the large/mature firms. So in our analysis when we find a positive correlation, for example, between the net differential between old/small and large/older businesses with the unemployment rate, this is the same finding from that in Moscarini and Postel-Vinay. However, as will become clear we find the opposite pattern in our state-level analysis in response to state-specific cyclical shocks.
} 
recognize that periods of above and below trend unemployment only imperfectly correspond to cyclical contractions and expansions of economic activity. In that respect, Moscarini and Postel-Vinay are less about the behavior of large versus small firms in expansions and contractions, but rather about their behavior in periods of high and low unemployment.

Thus far, most of the literature has focused on the role of firm size and the cycle. For Moscarini and Postel-Vinay, firm size is the relevant variable from the theory. For papers addressing the role of financial frictions, firm size is often used as the proxy for differential access to credit across firms even though it is undoubtedly a limited measure. Indeed, many of the papers highlight that firm age would be a preferable proxy but firm age is less readily available. For example, Gertler and Gilchrist (1994) comment that "The informational frictions that add to the costs of external finance apply mainly to younger firms..." (p. 313).

Recent work has emphasized that startups and young firms use different forms of credit than more mature businesses. For example, Mishkin (2008) and Robb and Robinson (2011) emphasize the role of home equity financing for startups and young businesses. But we also note that the Hurst and Lusardi (2004) findings suggest that there is not much relationship between housing prices and the propensity to start a business. The Hurst and Lusardi findings focus on all startups whether the new business hires any workers or not (they use the PSID to identify persons who own a business). In addition, their analysis is about the decision to start a new business while our analysis is about the job creation from young businesses. Haltiwanger, Jarmin and Miranda (2013) and Haltiwanger (2013) highlight that the job creation from young businesses is coming from a relatively small number of high growth young businesses. From our perspective, an open question is the impact of financial conditions on these high growth businesses. This paper does not directly focus on high growth businesses, but we note that such businesses are an important driver in the behavior the young firms that are our focus.

Despite its potential importance, we know very little about how the cycle affects firms of different ages. Recent empirical work examining the size-age growth relationship documents the need to distinguish between firm size and firm age when assessing employment changes at different types of 
firms. Since most firms enter at the bottom of the size distribution, firm size and age are closely related. There are many small firms, however, that are old. Haltiwanger, Jarmin and Miranda (2013) illustrate the potential omitted variables bias that can occur when estimating the effect of firm size without controlling for firm age. They confirm the conventional wisdom that small firms have higher net growth rates than large firms, but show that this relationship disappears once they control for firm age. To the extent that certain macroeconomic factors interact with firm size and age differently, estimates of the role of size will be confounded by the role of age if both variables are not included in the estimation.

There are some papers that have examined the differential cyclical dynamics of businesses by business size and business age. For example, Davis and Haltiwanger (2001) examine employment effects of oil price shocks and credit market shocks on establishments of different size and age within the manufacturing sector. The authors use a VAR approach that is similar methodologically to the approach we take in this paper. They find that industries with a large share of young, small plants are more cyclically sensitive to credit market shocks which they argue is supportive of the evidence in Gertler and Gilchrist (1994). They also find that most of the net response of young, small plants is associated with the response of job creation rather than job destruction.

Given this paper's focus on the local effects of housing price fluctuations, the recent papers by Mian and Sufi $(2010,2011,2012)$ are relevant. They explore the relationship between housing prices, household borrowing, and local economic outcomes. Using exogenous variation in housing prices as an instrument for household borrowing, they find that highly leveraged U.S. counties in 2006 exhibited the largest decreases in consumption and increases in unemployment. In addition, because the relationship between leverage and unemployment is only present in non-tradable sectors, the authors conclude that the household borrowing channel is an important transmission mechanism that works through a consumption channel.

Adelino, Schoar and Severino (2013) use the same Saiz (2010) instrument to document a disproportionate rise in employment at small establishments in areas with large, exogenous housing price 
increases during the same period. ${ }^{4}$ The authors perform various tests to assess whether their results are likely driven by a collateral channel (housing price increases translate to higher collateral values) or by increased local demand (as documented by Mian and Sufi). Our panel VAR approach allows us to identify housing price shocks that are orthogonal to local demand shocks. We still consider the possibility that the Mian and Sufi mechanism plays a role in our findings-but note that the relationship they document between housing prices and household balance sheets suggests that the former are an indicator of credit conditions that is especially relevant for young business activity.

\section{Data Sources and Measurement Methodology}

To conduct our empirical investigation, we use the Census Bureau's Business Dynamic Statistics (BDS). The BDS includes measures of employment dynamics by firm size, firm age, and state as well as other employer characteristics such as industry. ${ }^{5}$ The BDS is based on tabulations from the Longitudinal Business Database (LBD). The LBD covers the universe of establishments in the U.S. nonfarm business sector with at least one paid employee. Employment observations in the LBD are for the payroll period covering the 12th day of March in each calendar year.

Firm size measures in the LBD and BDS are based on the total employment at the enterprise level. The latter is defined by operational control. We use the current average size measures from the BDS (although we show that for our current analysis results are robust to using initial size). ${ }^{6}$ This is the preferred approach to abstracting from regression to the mean issues as described in Davis et al. (1996). Current average firm size is the average of firm size in year $t-1$ and year $t$. Firm age in the BDS is based

\footnotetext{
${ }^{4}$ These authors use the U.S. Census Bureau Country Business Patterns data. These data provide geographic information about employment by establishment, not firm, size.

${ }^{5}$ The BDS is built up from establishment-level data so we know the detailed geographic location of economic activity. The firm characteristics are based on the national firm but the state-level activity is for all establishments in that state in the given firm size and firm age group. The BDS is a public use data base and can be downloaded from http://www.census.gov/ces/dataproducts/bds/index.html.

${ }^{6}$ For a detailed description of differences between this and other sizing methodologies see Haltiwanger, Jarmin and Miranda (2013). We include some analysis below and in the appendix using firm size groups defined by initial size. Our results are robust to using this alternative.
} 
on the age of the oldest establishment of the firm when the firm is created. For firm startups --firms with all new establishments, firm age is set equal to zero. For firms that are newly created as part of M\&A, ownership change or some other form of organizational change, the firm age is initiated at the age of the oldest establishment. From that point forward, the firm ages naturally as long as it exists. ${ }^{7}$ A strength of the BDS firm size and age measures is that they are robust to ownership changes. For a pure ownership change with no change in activity, there will be no spurious changes in firm size or firm age. When there are mergers, acquisitions, or divestitures, firm age will reflect the age of the appropriate components of the firm. Firm size will change but in a manner also consistent with the change in the scope of activity. For further discussion on how our measurement methodology yields patterns of the relationship between net growth, firm size and firm age that are robust to ownership changes and M\&A activity see Haltiwanger, Jarmin and Miranda (2013). Critically, for every establishment in the LBD, we assign the establishment to a given firm size and firm age class in each year.

To simplify the analysis we consider broad firm size and broad firm age groups. Specifically, we consider two firm age groups: firms less than five years old and firms five years old or older. In what follows, we refer to these two groups as young and mature (or sometimes young/older). Using these firm age groups permits us to track employment dynamics in the BDS at the national and state level in a consistent manner from 1981 to 2010. For firm size groups, we consider three groups: less than 20, 20499 and 500+. In what follows we refer to these groups as small, medium and large. While Haltiwanger, Jarmin, and Miranda (2013) consider finer age and size categories, the focus here on assessing how age and size affect cyclical behavior limits the number of groups that can be studied. In addition, the groups here represent much finer categories than those used in most of the existing work.

The use of broad size and age classifications for studying cyclical dynamics is very much in the spirit of Davis and Haltiwanger (2001) and Moscarini and Postel-Vinay (2012). As we discuss in greater

\footnotetext{
${ }^{7}$ If the age composition of establishments in the firm change due to M\&A this does not change firm age.
} 
detail in the measurement appendix, the net growth rate for a given broad size and age class "s" is given by:

$$
g_{s t}=\frac{E_{s t}-E_{s t-1}}{X_{s t}}
$$

where $E_{s t}$ is employment for cell "s" in period t, and $X_{s t}=0.5 *\left(E_{s t}+E_{s t-1}\right){ }^{8}$ In measuring and defining $E_{s t-1}$ it is critical to emphasize that this is the employment in period t- 1 of the establishments that are in cell "s" in period t. That is, the above is consistent with:

$$
g_{s t}=\sum_{e \in S} \frac{X_{e s t}}{X_{s t}}\left(\frac{E_{e s t}-E_{e s t-1}}{X_{e s t}}\right)=\sum_{e \in s} \frac{X_{e s t}}{X_{s t}} g_{e s t}
$$

where "e" indexes establishments. The critical point is that we are tracking a given set of establishments classified into cell "s" between t-1 and t which obviously requires longitudinal establishment-level data. That is, there are no reclassifications of establishments between $\mathrm{t}-1$ and $\mathrm{t}$ for the measurement of $E_{s t}$ and $E_{s t-1} \cdot{ }^{9}$ Another critical issue is that $E_{s t}$ and $E_{s t-1}$ includes the contribution of establishment entry and exit.

The age categories we use group the contribution of firm startups with other young businesses. While distinguishing the role of startups has evident appeal, Haltiwanger, Jarmin and Miranda (2013) show that young firms exhibit a rich "up or out" dynamic - with most startups failing in their first five years but otherwise showing considerable average growth conditional on survival. Thus, our grouping is a way to capture the overall contribution of startups and this up or out dynamic for young firms within

\footnotetext{
${ }^{8}$ This measure of net growth is bounded between $(-2,2)$ and is symmetric around zero. Its desirable properties are discussed extensively in Davis, Haltiwanger, and Schuh (1996).

${ }^{9}$ Note that the level of aggregation "s" that we consider, it is not critical we use the DHS net growth rate at the cell level (e.g., the log difference of $E_{s t}$ and $E_{s t-1}$ yields very similar growth rates as the DHS net growth rate at this level of aggregation - this is not surprising since the DHS net growth rate is a second order approximation to the log first difference). The advantage of the DHS net growth rate approach is the establishment entry and exit are readily integrated into the net growth rate measures.
} 
one category. Of course, this example and discussion highlights that it is of interest to break out the components of the net growth rate of the cell into margins of expansion and contraction of establishments. For that purpose, we consider analysis that distinguishes between the job creation and job destruction margins below. ${ }^{10}$

It is also useful to relate the cell-based net growth rates to the aggregate as shown by:

$$
g_{t}=\sum_{s} \frac{X_{s t}}{X_{t}} g_{s t}
$$

As will become clear in the next section, most of the cyclicality of the aggregate net growth rate reflects the cyclicality within broad size and age class cells rather than changes in the shares at business cycle frequencies.

We supplement our BDS measures of employment dynamics with a variety of business cycle and financial market indicators. At the national and state level, we use unemployment rates from the BLS, real housing prices from the Federal Housing Finance Agency (FHFA), and growth rates in real GDP and real Personal Income from BEA. ${ }^{11}$ When integrating the data across the different sources, we pay careful attention to the timing of the observations. Employment observations in the LBD/BDS are for the payroll period covering the 12th day of March in each calendar year. We measure all of our other variables over the same March-to-March horizon. Details of the measurement of these variables are in the appendix.

\section{Basic Facts About Cyclicality by Firm Size and Firm Age}

A. National Patterns

\footnotetext{
${ }^{10}$ The measurement appendix includes discussion and formulas that show how net and gross job flow rates are calculated for size and age groups.

${ }^{11}$ Real GDP at the quarterly level is available at the national level so we construct annual averages using the retimed data. At the state level, real GDP can be constructed on an annual basis, but not for the properly re-timed year. We use state GDP for robustness purposes, but note that it is off by quarter. We therefore also use real personal income at the state level which we can construct for the re-timed year. Additional details are in the appendix.
} 
Figure 1 shows the share of employment by firm size and firm age from 1981-2008. Even though most firms are small (about 35 percent of firms are young/small and about 50 percent are mature/small), most employment is accounted for by large/mature firms. Figure 1 also shows that the share of employment in young/large firms, those less than five years old and with more than 500 employees, is very small - less than one percent. In what follows, we exclude the young/large firm group from the analysis since they account for such little economic activity. The share of employment at large/mature firms has risen over the last 30 years while the share of young/small and young/medium firms has noticeably fallen. ${ }^{12}$ Despite this trend, Figure 1 shows that the shares are relatively stable over the cycle. The aggregate net employment growth rate is, by construction, the employment share weighted average of the net employment growth rates by firm size and firm age group. Since the shares are relatively stable over time, the fluctuation in the aggregate must be driven by within firm size and firm age group variation in growth rates to which we now turn. ${ }^{13}$

Figure 2 shows net growth rates by firm size and age groups. Net employment growth rates are highest for young/small and young/medium firms and lowest for older/small firms. ${ }^{14}$ All groups exhibit cyclicality but it is striking that net job creation rates for young/small firms and young/medium firms declined sharply in the Great Recession. The decline in this recession for young firms is much larger than in any of the other recessions since 1981. Figure 3 shows that these net growth rate patterns are evident along both job creation and destruction margins. During the 2007-09 recession, job creation for small/young businesses fell substantially, while job destruction for this group rose. For both job creation and destruction margins, young/small exhibited more variation over this period than old/large. The

\footnotetext{
${ }^{12}$ As described in Decker et. al. (2013), this is associated with a secular decline in the firm entry rate over this period of time. See that paper for more analysis and references to the literature on the secular decline in job flows observed over our sample period.

${ }^{13} \mathrm{We}$ also find that the employment shares by firm age and firm size classes are relatively stable at the state-year level which is the focus of much of our analysis.

${ }^{14}$ These first two points echo the findings in Haltiwanger, Jarmin and Miranda (2013).
} 
implication is that at least part of the story for why net differentials for young/small fell so much in this period must be associated with the rise in job destruction for incumbent young/small firms. ${ }^{15}$

Our analysis in what follows focuses on which groups disproportionately account for net and gross job flows. As such, Figures 2, 3 and subsequent analysis focus on net and gross job flow rates for specified firm size and firm age classes. However, as illustrated in Figure 1, almost half of employment is concentrated in large/older employers. This implies that small changes in the net and gross flow rates for large/older businesses can account for substantial changes in the aggregate overall net and gross job flows. In results shown in greater detail in the appendix (see Figures A.1.1 and A.1.2), we find that for the overall decline in net growth of about 8 percent from 2006 to 2009, the large/older group accounts for about 40 percent of this decline while accounting for about 50 percent of employment. Young businesses account for about 22 percent of the decline even though they account for only about 10 percent of employment. Older(small/medium) businesses account for about 38 percent of the overall decline while accounting for about 40 percent of employment. Thus, consistent with our focus, young businesses disproportionately account for the overall decline. We also show in the appendix that businesses less than 10 years old account for 37 percent of the decline in overall net growth while accounting for about 22 percent of employment. This highlights the quantitative importance of young firms that extends beyond five years of age. ${ }^{16}$

Returning to the net growth rate patterns, Figure 2 shows that there are differential cyclical patterns across firm size and firm age groups. It is such differences that are the focus of the remainder of our analysis. For this purpose, we follow Moscarini and Postel-Vinay (2012) by focusing on net growth

\footnotetext{
${ }^{15}$ In unreported results, we have found that the job creation and job destruction patterns reflect consistent movements in the underlying components of job creation from continuers, job creation from entry, job destruction from continuers and job destruction from exit. That is, all margins contribute to the patterns.

${ }^{16}$ The results in Haltiwanger, Jarmin and Miranda (2013) and Foster, Haltiwanger and Syverson (2013) show that the rich dynamics of young businesses extends through the first 10 years following entry. In our analysis, we restrict our attention to very young businesses in order to be able to track young businesses dynamics back to 1981. If we use the definition of young businesses as being 10 years or less then we would have to restrict our analysis to commence in 1987. But it is clear that young businesses so defined contribute very substantially to cyclical dynamics of employment.
} 
rate differentials across firm size groups but extend the approach to also include firm age. We focus on five size-age groups rather than the two size groups (small and large) employed by Moscarini and PostelVinay. As such, we use large/older firms as the base group and focus on net differentials for each of the other four groups with respect to this base group. Figure 4 presents these net growth rate differentials. The net differential for the young/small and young/medium businesses relative to the large/mature group fell substantially in the Great Recession.

Table 1 presents simple correlations of the net differentials of employment growth rates with alternative cyclical indicators. ${ }^{17}$ Our preferred cyclical indicators are indicators reflecting growth or change - that is indicators about whether the economy is expanding or contracting. As such, we use the change in the unemployment rate, the net growth rate of private sector employment, or the growth rate in real GDP. Over our sample period, the correlation between the change in the unemployment rate and the net employment growth rate is -0.84 , and the correlation between the net employment growth rate and real GDP growth is 0.90 . We prefer these indicators for two reasons. First, growth and change indicators are inherently more tied to NBER business cycle turning points since growth measures play a critical role in the determination of such turning points. Second, and of particular importance in this paper, we need our cyclical indicator to be closely related to the changes in the business conditions that influence key variables such as interest rates and housing prices. In the VAR analysis that follows, we use a cyclical indicator as a way to capture unobserved demand, supply and credit factors that in turn may influence housing prices. In the national data, the correlation between real housing price growth and the changes in the unemployment rate, net employment growth, and real GDP is $-0.56,0.55$ and 0.57 respectively.

As indicated earlier, Moscarini and Postel-Vinay (2012) focus on an alternative indicator of the state of the economy - the deviation of the unemployment rate from the (Hodrick-Prescott) trend. Table 1 includes the latter for completeness. The HP-filtered unemployment rate in the national data has quite different properties than the cyclical indicators of expansion and contraction. The correlation between the

\footnotetext{
17 Table A.1 of the appendix presents simple descriptive regressions that shows that all groups net growth is procyclical with young/small businesses being especially procyclical.
} 
HP-filtered unemployment rate and the net employment growth rate, the change in the unemployment rate, and the real GDP growth rates is only $-0.23,0.56$, and -0.37 respectively. Most importantly for our VAR analysis, the correlation between housing price growth and the HP-filtered unemployment rate is 0.10 in the national data. From that perspective, the HP-filtered unemployment rate has limitations in terms of reflecting cyclical shocks that impact both housing prices and changes in the level of economic activity.

Table 1 presents the correlations for two periods: 1981-2010 and 1981-2006. For the entire sample period, we find a negative and significant correlation between the net differential for young/small with the change in the unemployment rate. Similarly, we find a positive and significant correlation between the net differential for young/small and the net employment growth rate as well as the real GDP growth rate. Comparable patterns are also observed for young/medium businesses, although the magnitudes of the correlations are somewhat smaller. For both young/small and young/medium, the correlations are the same sign but are reduced substantially when the post-2006 data are excluded.

For the older/small and the older/medium differentials, we find less systematic patterns with respect to correlations with cyclical indicators of change and growth. The last panel on the right shows the patterns for the HP-filtered unemployment rate. For young/small and young/medium differentials, there are no statistically significant patterns in either sub-period with this indicator. For the older/small and older/medium differentials we find, consistent with the patterns highlighted by Moscarini and PostelVinay (2012), a positive and significant correlation for the overall sample period and the sub-period with post-2006 data excluded. ${ }^{18}$ Relative to their finding at this level of aggregation, our results show that the

\footnotetext{
${ }^{18}$ Moscarini and Postel-Vinay (2012) also note that their result is only robust to considering cyclical indicators based on deviations from trend and not robust to using cyclical indicators of expansions or contractions. We find that when the latter indicators are used, young/small and young/medium businesses are more cyclically responsive than older/large businesses. Moscarini and Postel-Vinay (2012) use initial firm size to classify firms in their analysis. In Appendix Table A.2, we show the results of Table 1 are robust to this alternative so this is not driving differences. Moreover, in Appendix Table A.5 we show that the state by year patterns emphasized in our analysis are robust to using initial firm size to classify firms. We also show in Appendix Figure A.2.7 that the impulse responses to state-specific cyclical and housing price shocks are robust to using initial size to classify firms.
} 
greater sensitivity of large firms relative to small firms to this indicator is being driven by mature firms.

In contrast, the effect they emphasize is insignificant for young/small firms. ${ }^{19}$

What should we make of the varying patterns in Table 1? Perhaps the main conclusion is that statistical inference about the cyclical patterns of net differentials is difficult with only 30 observations. The results in Table 1 are sensitive to both the sample period as well as to the indicator. For the latter, as we have noted, we have a preference for cyclical indicators that track expansions and contractions. The second conclusion from Table 1 is that, at least suggestively, distinguishing between young/small and older/small firms matters. Uniformly in Table 1, young/small firms are more cyclically sensitive than older/small firms. But given the limitations of an analysis with only 30 observations, in subsequent sections we focus not only on variation across time, but also across geography.

\section{B. State-level Patterns}

Table 2 shows simple descriptive regressions at the state-level. We control for both state effects and year effects in virtually all of our analysis at the state-level. The state effects control for any time invariant state-specific factors, while the year effects control for any common (economy-wide) factors in an unrestricted manner in each year. As such, for our state-level analysis, cyclical indicators and shocks should be interpreted as reflecting state-specific variation. We return to the relevance of this point in our discussion of the panel VAR analysis in the next section.

19 One way to emphasize that there is an inherent difference between considering firm size and firm age effects is simply to consider correlations where one focuses on only firm age effects and those where one only focuses on firm size effects. We find that if we use only firm age and consider two age groups where young is $<5$ and mature is $5+$ that the correlation between the change in unemployment rate and the net differential between young and mature is 0.65 (and significant). In contrast, if we only consider firm size with two size groups where small/medium is $<500$ and large is 500+ (and to be similar to Moscarini and Postel-Vinay use initial size classification) then the correlation between the change in the unemployment rate and the net differential between small/medium and large is -0.26 and not significant. Turning to the indicator used by Moscarini and Postel-Vinay we find that the latter correlation is 0.36 and significant. The latter differs some from the correlation emphasized by Moscarini and Postel-Vinay (recall they have the opposite sign convention and so this is equivalent to a -0.36 correlation with their sign convention). We find that this is associated, at least in part, with the specific time series sample. That is, if we use the 1981-2009 sample (closer to what Moscarini and Postel-Vinay use) we obtain a correlation between the HP filtered unemployment rate and the net differential between small and large of 0.54 which is very similar to their highlighted correlation. So even adding/subtracting one year alters this correlation non-trivially. 
The top panel shows bivariate regressions relating the change in unemployment at the state level with the differences in net growth rates at the state level across firm size and firm age groups. All of the differences are expressed as differences with the large/older group. The top panel shows that all net growth differentials relative to large/older businesses decrease when unemployment rises. The largest decrease is for young/small and young/medium businesses. The estimated coefficient for young/small is more than four times as large as the coefficient for older/small. All of these effects are statistically significant at the one percent level.

The lower panel includes as an additional regressor state-level real housing price growth rates. In terms of the cyclicality indicator (the change in the unemployment rate), the quantitative and qualitative patterns are about the same as in the upper panel. In terms of housing prices, we find that an increase in housing prices is associated with a disproportionate response of the younger and smaller businesses relative to older/larger businesses. This is true for all groups but is especially true for the young/small group and interestingly the older/small group. Being very small makes one more responsive to housing prices regardless of age. All of the estimated effects are statistically significant.

We also show in the appendix that the patterns in Table 2 are robust to using alternative cyclical indicators for change and growth including the net employment growth rate, the growth rate in real GDP and the growth rate in Real Personal Income as well as the exclusion of the more recent time period (see appendix Tables A.3, A.6, A.7 and A.8). ${ }^{20}$

Results in the previous section show that the national patterns are sensitive to whether the cyclical indicator is based on a measure of change or growth vs. deviations of levels from trend. In contrast, Table 3 shows that the patterns in Table 2 are robust to using the HP-filtered unemployment rate at the state level. Notably, Table 3 shows that the net differential between older/small businesses and large/older

\footnotetext{
${ }^{20} \mathrm{We}$ also show in Table A.5 that the results in Table 2 are robust to using initial size.
} 
businesses narrows when the unemployment rate in the state is above trend. ${ }^{21}$ We also find that the relationship between net differentials and housing prices is robust to the use of alternative indicators.

The results at the state level using the HP-filtered unemployment rates raise some questions about the findings and interpretation of Moscarini and Postel-Vinay. Their primary result is that large businesses exhibit a greater decline in net employment when unemployment is above the (HP-filtered) trend. The evidence here shows that their finding does not hold using state-level variation and controlling for state and year effects. ${ }^{22}$ We leave further investigation of these issues to future work. For our purposes, we note that our findings are robust to alternative cyclical indicators at the state level.

Whether at the national or state level, the patterns described in this section are only correlations or partial correlations so no causal inferences can be made. In the next section, we exploit the rich joint variation across time and geography in a more structured analysis.

\section{Panel VAR Analysis}

\section{A. Specification}

We now turn to a panel VAR analysis. The specification we consider has the following form:

$$
Y_{s, t}=A(L) Y_{s t}+\text { State }_{s}+\text { Year }_{t}+\varepsilon_{s t}
$$

where $\mathrm{Y}$ is a vector of covariates, $\mathrm{L}$ is a lag operator of length $\mathrm{L}$, and $\mathrm{A}(\mathrm{L})$ a matrix of lagged coefficients, State and Year represent state fixed and year fixed effects and $\varepsilon_{s t}$ is the residual vector of innovations to

\footnotetext{
${ }^{21}$ Like the results in Table 2, we also find that older/small businesses are less cyclically sensitive than young/small businesses as the coefficients are substantially smaller in magnitude for the older/small businesses. But we find that even older/small businesses respond more to the state-specific component of this indicator than large/older businesses (although the estimate for the old/small differential is only significantly different from zero at the 10\% level).

${ }^{22}$ We note that Moscarini and Postel-Vinay (2012) also consider state-level variation. Unlike our analysis, they did not control for state and year effects. We show in Table A.4 that the results in Table 2 using the change in the unemployment rate are robust to not controlling for year effects for young/small and young/medium net differentials. However, in Table A.4 we find that estimated effect for the old/small differential with old/large turns positive and significant when controlling only for state fixed effects. Moreover, in unreported results, we find that when we don't control for year effects but do control for state effects and use the HP filtered unemployment rate that we obtain the Moscarini and Postel-Vinay result for old/small net differentials with large/old businesses but don't find their result for small/young net differentials. Thus, our findings suggest that their results are being driven by old/small businesses relative to old/small and by aggregate variation in their measure and not by state-specific variation in their measure. We also note that in all of these alternative specifications, we always find that young/small businesses are more sensitive to housing price shocks. We find this for the descriptive regressions as well as the panel VAR analysis regardless of the cyclical indicator we use.
} 
each of the covariates. Identification is achieved both by taking into account lags $(\mathrm{A}(\mathrm{L}))$ but also by specifying a relationship between the reduced form innovations and structural innovations. That is, after absorbing the state and year effects we can invert the AR representation to form the MA representation given by:

$$
\widehat{Y}_{s, t}=D(L) \varepsilon_{s t}=B(L) \eta_{s t}
$$

where $\widehat{Y}$ is the variation in $\mathrm{Y}$ after absorbing the state and year effects, $\mathrm{D}(\mathrm{L})$ are the MA coefficients from inverting the AR representation, and $\eta_{s t}$ represents the innovations to each of the orthogonalized "structural" innovations after making some identifying assumptions. The relationship between $\mathrm{D}(\mathrm{L})$ and B(L) can be specified by: $B(L)=B_{o} D(L)$ where $B_{o}$ represents the short run identifying assumptions. We note that in estimating the panel VAR we follow the approach developed by Holtz-Eakin et. al. (1988). ${ }^{23}$ In what follows, we often refer to the innovations as shocks - and in particular to the first two elements of this vector as the cyclical shock and the housing price shock.

For our purposes, we specify $Y=\{$ Change in State-Level Unemployment Rate, State-level Housing Price Growth, Net Growth Differential Young/Small-Older/Large, Net Growth Differential Young/Medium-Older/Large, Net Growth Differential Older/Small-Older/Large and Net Growth Differential Older/Medium-Older/Large\}. For identification, we use a simple lower triangular matrix for $B_{o}-$ i.e., we use a Cholesky causal ordering. In the appendix, we show that all of our results are robust to using alternative cyclical indicators as the first variable in the system including the net employment growth rate, the Real GDP growth rate, the Real Personal Income growth rate and the HP-filtered unemployment rate. ${ }^{24}$

\footnotetext{
${ }^{23}$ We thank Inessa Love for her STATA code (pvar.ado) to implement a panel VAR procedure in STATA. We have modified the code for our application (code available upon request). Consistent with Love and Zicchino (2006) (building on the insights of Arellano and Bover (1995)) we use the Helmert transformation to control for state fixed effects. This forward differencing procedure overcomes the problem that fixed effects and lagged dependent variables are inherently correlated.

${ }^{24}$ The results using the net employment growth rate are in Figures A.2.1-A.2.3, for the HP filtered unemployment rate in Figures A.2.4-A.2.5, for real GDP growth in A.2.14-A.2.16 and for real Personal Income in A.2.17-A.2.19.
} 
Our identification strategy recognizes that many factors drive state-level variation. We address this in several ways. First, we control for state and year effects. The year effects control for economywide factors in an unrestricted fashion. In this context, they control for economy-wide aggregate shocks from demand, supply or credit conditions. Second, we put the change in unemployment rate at the state level first in the causal ordering. Our interpretation of the shock that emerges is that this is an innovation to a generic state-specific cyclical shock. In that respect, this shock captures unobserved state-specific demand, supply and other shocks that affect general business conditions in the state (including general credit conditions). State-level housing price growth is next in the system. The innovation here does not reflect national housing price variation given the year effects. Nor does the innovation here reflect general business conditions in the state - the impact of the latter is accounted for by the Cholesky causal ordering. In other words, when general business conditions decline in a state and housing prices decline endogenously as a result, this identification strategy controls for such variation.

Since the housing price innovation we identify is orthogonal to the local unemployment rate, it does not reflect changes in general business conditions in the state. Instead, the orthogonalized housing price innovation may stem from supply or demand factors affecting housing prices that again are not associated with general business conditions. Mian and Sufi (2011) emphasize the role of geographic variation in household leverage as being important in accounting for geographic variation in housing price declines. Their characterization seems relevant in this case since they highlight that this geographic variation in leverage is being driven by changes in home equity values. ${ }^{25}$ Moreover, their identification approach using the Saiz (2010) housing supply elasticity suggests that there is variation in housing prices across areas due to factors that may not be fully accounted for by local cyclical shocks.

How should we interpret these housing price innovations? It is useful to reiterate what they are not. They abstract from general national shocks, lags of all of variables and contemporaneous state-

\footnotetext{
25 Their approach to identification is to instrument the local leverage ratio with the housing supply elasticity from Saiz (2010). Our approach is to use the panel VAR with the Cholesky decomposition to identify a housing price shock that is orthogonal to general business conditions in the state.
} 
specific cyclical shocks. So by construction they are the state-specific variation in housing prices that cannot be accounted for by these other factors. These other factors are the primary factors that one is concerned about in terms of housing prices reflecting national and local business cycle conditions. So, what is left over? As we show below, there is considerable residual variation in housing prices that in turn has economically and statistically significant effects on young businesses in particular. Moreover, we find that the largest declines in the residual housing price innovations are in Arizona , California, Florida and Nevada. The MSAs with the most inelastic housing supply elasticities from Saiz (2010) are heavily concentrated in these states. Our evidence, along with the existing literature focusing on housing supply elasticities, helps provide guidance about the interpretation of our housing price shocks. They represent the variation in housing prices that is not accounted for by national and general business cycle conditions using the average responses across states. ${ }^{26}$ Our housing price innovations thus may reflect such idiosyncratic responses to other shocks where such idiosyncratic responses may in turn be driven by factors such as those emphasized by Saiz (2010).

We focus our attention on these first two innovations: unobserved state-specific cyclical innovation and the state-specific housing price growth innovation. We are agnostic about the causal ordering of the remaining variables in the system since their ordering has no impact on the impulse response functions for the first two innovations of interest. We note that all of the remaining variables are net differentials. By construction, the VAR is permitting such net differentials to impact all of the variables in the system with a lag. But we do not permit the net differential innovations to affect the change in the unemployment rate or housing price growth contemporaneously. The remaining innovations are interpretable as shocks to the relative outcomes across firm size and firm age groups. In principle, investigation of the properties and consequences of such shocks might be of interest but we leave that for future work. In the appendix we show results for the specification in which housing prices

\footnotetext{
${ }^{26}$ As is typical in the identification of idiosyncratic shocks, it is difficult to distinguish between a true idiosyncratic shock and an idiosyncratic response to a common shock.
} 
are last in the system. ${ }^{27}$ Many of the effects we identify in the main text hold in this alternative specification, but we note that this ordering rules out any contemporaneous impact of housing price innovations on the net growth rate differentials. In our view, the primary concern about housing prices is that they are endogenous with respect to the economic conditions at the national and state level. By including year effects and putting housing prices second in the causal ordering we have taken such effects into account. ${ }^{28}$

Before proceeding, it is worth emphasizing that our empirical specification does not permit identifying asymmetric responses to cyclical and housing price innovations; that is, to expansions vs. contractions. There is a substantial literature focusing on the asymmetric nature of business cycles. This would be an interesting area for future research.

\section{B. Results on Net Differentials at the State-Level}

Figures 5.1-Figure 5.4 report the impulse response functions from the panel VAR in terms of responses to the unobserved state-specific cyclical innovation (that reflects the innovation to the change in unemployment) and the state-specific housing price growth innovation. ${ }^{29}$ Figure 5.1 shows the response of housing prices to these two innovations. As expected, the left panel shows that an innovation to the state-specific cyclical shock yields a decline in housing prices. A one standard deviation shock yields a decline in housing prices immediately with the peak effect in 3 years. While housing prices exhibit variation consistent with being endogenous to state-specific cyclical shocks, the right panel shows that there is substantial residual variation in housing prices. The right panel shows that a housing price innovation generates a persistent increase in housing prices.

Turning to the primary effects of interest, we find in Figure 5.2 that the state-specific cyclical shock yields a decline in the net differential between young/small and large/old. The effect is largest on impact but persists for a number of years. These findings echo the basic results in the prior section. In a

\footnotetext{
${ }^{27}$ See Figures A.2.6.a and A.2.6.b.

${ }^{28} \mathrm{We}$ also note that examination of the impulse response functions with respect to these net differential shocks shows only modest dynamic impact on the change in unemployment and housing price growth.

${ }^{29}$ All figures include 95 percent confidence bands.
} 
state-specific cyclical downturn, the differential between young/small and large/old narrows. Turning to housing prices, we find that a positive housing price innovation widens the net differential between young/small and large/old. Put in terms of a decline, a decrease in housing prices narrows the net differential growth rate between young/small and large/old. The effects in the right panel of Figure 5.2 are changes over and above changes from the unobserved cyclical shock. That is, the right panel reflects responses to the orthogonalized housing price innovation.

Figures 5.3 through 5.5, show similar qualitative patterns for the remaining net differentials. For young/medium, small/old, and small/medium we find the net differential with large/old tends to narrow during the cyclical downturns in the state. However, the magnitude of the effects varies systematically across these groups. The largest effect is for the young/small followed by the young/medium. The smallest effects are for the old/small and old/medium. In other words, it is especially the young (whether small or medium) that respond to the cyclical shock. Similar remarks apply to the housing price innovations. This is consistent with the idea that, on average, young firms are a particularly vulnerable population of businesses. For all groups, housing price innovations tend to (at least on impact) increase the differential with the base group - the large/old firms. But again the largest quantitative effects are for the young/small and young/medium. ${ }^{30}$ Still, we note that even old/small and old/medium businesses are more sensitive to housing price shocks than old/large firms.

In results reported in the appendix (see appendix Figures A.2.8-A.2.11), we also show that the greater sensitivity of young/small and young/medium businesses to cyclical and housing price shocks holds for both job creation and job destruction margins. These patterns indicate that one should not interpret the effects for young firms as only reflecting the responsiveness of startups, but rather the young

\footnotetext{
${ }^{30}$ We show in Appendix Figure A.2.12 that we obtain our main results if we focus only on firm age (ignoring firm size) so that we focus on the net differential between young and mature. In Appendix Figure A.2.13, we show that if we instead had focused on firm size only (ignoring firm age) we would obtain substantially mitigated effects of both the local cyclical shock and the local housing price shock. These results are a way of emphasizing that the critical factor for obtaining our results is to distinguish across firms by firm age and not firm size. A simple way of thinking about this and consistent with the results throughout the paper is that young firms are small and medium size (essentially no young/large firms) while small firms are both young and mature. The results throughout the paper show that old/small firms behave quite differently than young/small and young/medium firms.
} 
firms effects reflect the combined contribution of startups, job creation of incumbent young firms and job destruction of incumbent young firms.

\section{The Quantitative Contribution of Housing Price Innovations in the Great Recession}

Our findings indicate that young/small businesses are the most cyclically sensitive to generic cyclical shocks as well housing price shocks. The reported impulse response functions show the response to one standard deviation shocks from the pooled state by year data. We know that there are some years and some states with especially large variation in housing prices. To see this, Figure 6 shows the real housing price change in years 1981-2010 at the national level and in three different states: California (CA), Florida (FL) and North Dakota (ND). As is well-known, housing prices rose rapidly in the post2000 period especially in CA and FL and then plummeted in the Great Recession, especially in some states such as CA and FL. In contrast, ND exhibited much milder fluctuations in housing prices. We can use the results from the panel VAR to quantify the impact of such different patterns of housing price changes on the net growth rate differentials that are the focus of this study.

Figure 7 presents the results from such an exercise for selected states. The top panel shows the results from our baseline estimation that includes year effects. We find that in states such as Arizona (AZ), California (CA), Florida (FL), Nevada (NV), New Jersey (NJ) and New York (NY), the actual change in the differential between small/young and large/old fell substantially from 2007-09. For example, in CA the differential fell from 0.18 to 0.12 over this period. In some states, such as ND, the differential actually rose over this same period. Using the impulse response function (IRF) from Figure 5.2 along with the estimated structural housing price innovations from the panel VAR for these years and for these states, we can generate the responses to state-specific innovations in housing prices. Figure 7 shows the results of this exercise with the bar labeled "Due to Housing Price Changes". In AZ, CA, FL and NV, the state-specific housing price declines account for a substantial fraction (about two thirds on average) of the observed decline in the differential. These are all states with large state-specific declines in housing prices over this period. Interestingly, the state-specific housing price increase in ND helps account for the observed increase in the differential (about one third). There are states with notable 
declines in the net differential for young/small that are not accounted for by housing prices - such as NJ and NY. Both of those states exhibited housing price declines, but the top panel using the baseline specification with year effects only captures the responses from the state-specific variation in housing prices. In Texas (TX), there was a modest decline in the young/small net differential but housing prices fell much less than the national prices, so in TX the state-specific component predicted an increase in the net differential.

The top panel of Figure 7 is arguably a lower bound estimate of the impact of housing prices on the net differential since the impact of the national variation in housing prices is not included in these calculations. For something closer to an upper bound estimate, we re-estimate our panel VAR without year effects. Even in this case, housing price innovations represent the variation in housing prices that cannot be accounted for by the cyclical shock which in this case reflects both state and national variation and are also orthogonal to lags in all of the variables. The lower panel shows the results of the same exercise as in the upper panel but in this specification inclusive of national variation in all variables (so it is still a panel VAR using state-year data but without year effects). These upper bound estimates show that more than 100 percent of the decline in the net differential in states such as AZ, CA, FL and NV is accounted for by housing prices. But there are still states such as NJ and NY with substantial declines in the net differential where even with these upper bound estimates housing prices don't account for all of the net decline (although interesting a substantial fraction - in NY, 67 percent and in NJ, 54 percent). ${ }^{31}$

Figure 7 highlights that housing prices are quite important in accounting for the cross-state variation in the net differential for young/small during the 2007/09 period. But we know there are other factors at work over this same period. In addition, it is of considerable interest to determine how different

\footnotetext{
${ }^{31}$ An additional calculation of interest for the upper bound estimates is the overall fraction of the decline in the net differential for young/small that can be accounted for housing prices in the 2007-09 period. Weighting the states by employment, the average overall contribution is 60 percent. Note that this calculation is not applicable for the baseline estimates with year effects since by construction with year effects the average overall effect in any given year from state-specific variation in housing prices is zero. That is, in the baseline specification we are focusing on identifying and accounting for state-specific variation in the net differentials. We focus on the latter in Table 4 and in the accompanying discussion.
} 
the 2007-09 period is from other periods. To explore these issues, we consider the pooled annual changes in the net differential for young/small across all years and all states. For any given year or for groups of years, we can compute the actual and predicted changes in the net differentials. By predicted changes, we mean the predicted annual changes from specific orthogonal shocks. For this purpose, we focus on the cyclical shock (the change in the state unemployment rate) and the housing price shock. We compute the standard deviations of the predicted and actual annual changes for specific years and groups of years. Note that this exercise is the generalization of what we are showing in Figure 7 -rather than just showing actual and predicted components from 2007 to 2009 for selected states, this exercise uses the same type of variation for all states and all years in our sample.

Table 4 reports the ratio of the standard deviation from the predicted components to the standard deviation from actual changes for specific years and groups of years. ${ }^{32}$ We show these calculations for the baseline lower bound estimates and the upper bound estimates associated with the exercise illustrated in the lower panel of Figure 7. It is apparent that the 2007-10 period is an outlier in terms of the contribution of housing price shocks. For the pooled 1983-2006 period the lower bound estimates imply that the ratio of predicted standard deviations to actual is 0.13 and increases to 0.29 for the upper bound estimates. In contrast, for the $2007-10$ period the lower bound ratio is 0.24 and the upper bound ratio is 0.48. Moreover, in 2009 when the full two years of the housing price declines in the Great Recession have kicked in, the lower bound ratio is 0.48 and the upper bound ratio is 0.78 . Table 4 also shows the contribution of cyclical shocks. In the 1983-2006 period, the lower bound ratio using the cyclical shock is 0.18 while the upper bound ratio is 0.79 . In the $2010-10$ period, there is also substantial contribution of the cyclical shock but the ratios are lower than those for housing price shocks. In the period of the rapid run up in housing prices in the 2004-06 period, we find that housing price shocks account for a relatively

\footnotetext{
${ }^{32}$ It would be of interest to highlight the difference in the role of housing prices in the 2007-09 recession relative to the 1981-83 recession. Our sample period is from 1981-2010 and we exploit variation from the 1981-83 period in our estimation but with a panel VAR with 2-years of lags our first period of predicted values is in 1983. Note that we start our sample in 1981 given that the LBD starts in 1976 and our focus on identifying the contribution of young businesses. Given left censoring in firm age, we can consistently measure the contribution of young firms less than five years old and five years or more from 1981.
} 
larger share of the variation in the net differential for young/small than in other periods. Still, the period with the largest contribution of housing prices is clearly the 2007-109 period. In sum, the evidence in Figure 7 and in turn the evidence in Table 4 highlights the special role of housing prices in accounting for the sharp decline in young/small businesses in the Great Recession.

\section{Results by Sector}

The focus of this analysis has been on the differential response to cyclical and housing price shocks by firm size and firm age. Variation by firm size and firm age may reflect many factors. One factor may be variation within and between industries. Different industries use different technologies and business models that translate into well-known differences in the firm size and firm age distributions across industries. It may be, for example, that our findings are related to differential responses across as well as within industries at the national or local level. The findings in Mian and Sufi (2012) suggest one possible linkage. They find that employment in non-tradeables sectors is much more sensitive to the type of local cyclical shocks that we have been exploring (and in particular much more sensitive to the local variation in household leverage, instrumented by exogenous variation in housing prices). Firms in tradable sectors such as manufacturing tend to be older and larger than in non-tradable sectors like the retail sector (although appropriate caution is required here in terms of distinguishing between establishment and firm size and age - note our focus is intentionally on firm size and firm age). Thus, it is possible that our results reflect differential responses across industries.

In this section, we estimate our panel VAR specification separately for each broad sector. For the sake of brevity, we focus on the responses of the net differential for young/small relative to the old/large firms in each sector. Moreover, we focus on the responses to the state-specific cyclical shocks and state-specific housing price shocks. ${ }^{33}$

\footnotetext{
${ }^{33}$ Analogous to the concerns expressed for the analysis of job creation and job destruction, one concern in comparing results across specifications that differ by sector is that the identified state cyclical shocks and housing price shocks and their respective dynamics vary across specifications. In practice, each of these sectoral specifications yields very similar state specific cyclical shocks and state specific housing price growth shocks.
} 
The broad sectors we use are defined in a consistent manner from the 1981-2010 period. Specifically, the broad sectors are defined in a manner consistent with the SIC broad sectors by reallocating industries that switched broad sectors under NAICS back to their original SIC broad sectors. For example, this implies that we have switched Restaurants and Bars back into the Retail Trade sector during the NAICS (post-1997) period. We note that Mian and Sufi (2012) consider four broad sectors Non-tradables, Tradables, Construction and Other industries. They define the Non-tradable sector as essentially the NAICS Retail Trade sector with Restaurants and Bars added back in (although they also consider a more narrow definition based on restaurants and grocery stores), the Tradable sector is mostly Manufacturing, the Construction sector is the building trades and the building materials components of Manufacturing, and their Other sector is everything else. Thus, our broad sectors provide a reasonable correspondence to their categories with our breaking out the other into the various broad sector components.

The impulse response functions for the net differential for young/small relative to old/large for each of the broad sectors are reported in Figures 9.a-Figure 9.g. We find that for all broad sectors, the state-specific cyclical shock decreases the net differential between young/small and old/large. That is, in all sectors, an increase in the unemployment rate in the state is associated with a decline in the net differential between young/small and old/large. We think it is noteworthy that even the Manufacturing sector ("Tradables") exhibits a large decline in the net differential of young/small relative to the old/large with respect to a state-specific cyclical downturn. Apparently, young/small businesses are vulnerable to local downturns in all sectors. ${ }^{34}$

\footnotetext{
${ }^{34}$ In unreported results, we have explored the net responses of all groups rather than the net differential responses to cyclical and housing price shocks. We find that all firm size/age groups in all sectors experience a decline in net employment growth in response to an increase in the state-specific unemployment rate. Consistent with our findings, we find that the magnitude of the response is largest for the young/small firms. The point is that the net differential responses are associated with all firm size and age groups experiencing a decline in local cyclical downturns but young/small experiencing the larger and that this pattern holds for all sectors. In response to housing price shocks, similar remarks apply but with the largest magnitude being for the young/small in the Construction, Retail Trade, FIRE and Service sectors.
} 
While our results on cyclical shocks are fairly robust within all sectors, the results on housing price shocks vary substantially by sector. In Construction, Retail Trade, Finance, Insurance and Real Estate (FIRE), and Services, we find that when housing prices decline the net differential between young/small businesses and old/large businesses declines. For Manufacturing, Wholesale Trade, and Transportation and Public Utilities, the estimated effects of housing price shocks on this same net differential are mostly small and insignificant, though for Manufacturing and Wholesale, they are negative rather than positive. Note that in general these are sectors with higher startup and fixed costs and as such one might expect home equity to play a smaller role if any. ${ }^{35}$

Our finding that the net differential impact on young/small businesses holds within sectors such as Construction, Retail Trade, FIRE and Services indicates that our main results are not being driven by composition effects across industries. That is, our main results in section V.B, cannot be interpreted as suggesting that only some sectors are responsive to the local shocks and they happen to be sectors dominated by young/small businesses. Rather we find that in all sectors, young/small businesses are more sensitive to local shocks. We do find that the sensitivity to housing price shocks varies across sectors which is something we discuss in the next section.

\section{E. Discussion}

Our results highlight that young/small businesses respond more to state-specific cyclical and housing price shocks than do large/mature businesses. Both findings are of interest for understanding how firms of different size and age respond to business cycles. Moreover, we find that housing price shocks in some states and years (e.g., California in the 2007-09 period) account for a substantial fraction of the large reduction in the net differential between young/small and large/mature businesses over this period of time. These results point to the collapse of housing prices as being a major factor in the disproportionate decline of young/small businesses in the Great Recession.

\footnotetext{
${ }^{35}$ Adelino et al. (2013) similarly find smaller effects in these sectors and suggest this is consistent with a financial transmission channel for home equity.
} 
We find that the large decline of young/small businesses in the Great Recession is associated with not only an especially large decline in job creation for such businesses, but also an especially large increase in job destruction for such businesses. Moreover, we find that the greater responsiveness to state-specific cyclical shocks for young/small businesses holds within all of the broad sectors we consider. In contrast, the greater responsiveness to housing price shocks, are driven by greater responsiveness in the Construction, Retail Trade, FIRE and Services industries.

Our findings demonstrate that young/small businesses are more vulnerable to local cyclical shocks as well as to local housing price shocks. While we do not identify the specific mechanisms driving our results, the results themselves highlight the importance of these shocks on the more vulnerable populations for understanding the decline in economic activity in the Great Recession.

There are a number of mechanisms that may be underlying our results. It is beyond the scope of this paper to differentiate fully between them, but the remainder of this sub-section discusses these possible mechanisms. We think it is useful to consider the two main results in turn. First, we consider possible mechanisms that account for young businesses being more sensitive to cyclical shocks. Several factors may be at work here. Young firms may not have the customer base of older firms and thus are more vulnerable to downturns in local demand. Foster, Haltiwanger and Syverson (2012) show that even in the manufacturing sector for commodity goods like ready mix concrete, it takes significant time and investment in customer relationships by young businesses to grow and survive. In a related fashion, young/small businesses inherently have a customer base that is more local. In that respect, young/small businesses are more likely to be producing goods and services that are "non-tradables" in the sense of a limited geographic reach for such businesses (e.g., the small restaurant or store in the neighborhood).

The greater responsiveness of young/small businesses to local cyclical shocks may also reflect greater credit market imperfections facing such businesses. Young/small businesses that are more credit constrained can be more sensitive to shocks as downturns in activity make it more difficult for them to obtain financing, and given reduced cash flow from the downturn such businesses are less able to finance their activities from internal funds. 
We note as well that we find that even old/small businesses are more sensitive to local cyclical shocks than old/large businesses. In discussing related results above, we note that these results are not consistent with the Moscarini and Postel-Vinay (MPV) (2012) hypothesized poaching mechanism. The findings in Figure A.2.4 reinforce this conclusion since those results use the HP-filtered unemployment rate as the cyclical indicator (the measure favored by MPV) and still show that old/small businesses are more cyclically sensitive than large/old businesses. In drawing these inferences, we are focusing on the responsiveness to local cyclical shocks.

Turning to the results on housing prices, we think there are alternative possible mechanisms but they typically rely on some form of credit channel. One possible mechanism is a collateral channel for young/small businesses. The literature described in Section II documents the reliance on home equity as a source of credit for startups and young businesses. The local decline in housing prices is associated with a large decline in home equity implying direct home equity financing is less available for startups and young businesses. If this is the channel, then reconciling it with the findings of Hurst and Lusardi (2004) is important. Our conjecture is that such reconciliation may be through distinguishing between the typical startup/young business that does not grow and the high growth young businesses that disproportionately contribute to job creation. Our findings are about the response of job creation so such high growth businesses are inherently relevant. Exploring these issues should be a high priority for future research.

Our results are consistent with the home equity financing channel, but we recognize that other mechanisms could account for our findings. One alternative is the potential impact on consumption by households that is the focus of Mian and Sufi (2012). They find that areas with higher household leverage (which tend to be areas with greater run-up in housing prices), show bigger decreases in local consumption and also in employment in the tradable sectors. The Mian and Sufi mechanism therefore highlights the importance of housing prices on households' balance sheets, but points to its effect on local consumption rather than its role in facilitating financing options for young/small businesses. 
Mian and Sufi's findings are relevant, but additional channels beyond the household balance sheet/consumption channel are necessary to account for our results on young/small differential responses to local cyclical shocks and local housing price shocks. First, we find that the greater response to young/small businesses to local cyclical shocks holds in all sectors - both tradable and non-tradable. In as much as the cyclical shock affects local consumption, then their local aggregate demand channel should already be captured at least in part by our local cyclical shock. ${ }^{36}$ Second, we find that the greater response to young/small businesses to housing price shocks holds within non-tradable sectors. That is, some other mechanism other than the household balance sheet/consumption channel must be accounting for why young/small businesses within non-tradeables are especially impacted. The Mian and Sufi mechanism also fails to explain all our results on the differential impact of housing prices on young/small businesses across sectors. The result that the net differential effect of housing prices on young/small businesses is large in magnitude in the Construction and FIRE industries suggests that one part of the explanation may be the impact of housing prices on the local industries that are directly tied to housing i.e., Construction and FIRE. But again, it is important to emphasize that our findings are not simply that these are industries hit hard when housing prices fall. A mechanism must also explain why it is the young/small businesses within these industries that are the most adversely affected. We think an obvious candidate is the home equity financing channel for young/small businesses.

Whether operating through the collateral channel or the balance sheet channel, both mechanisms inherently point to the variation in housing prices as impacting the credit conditions faced by households. In that respect, we think that our findings on housing prices should be interpreted as reflecting some form of credit channel. But as Mian and Sufi emphasize, a critical question is what households do with home equity, and more specifically, how households responded to their decreased home equity when housing prices collapsed. Identifying the use of home equity as a financing channel for young businesses will

\footnotetext{
${ }^{36}$ Pushing on this point further, our housing price shocks are orthogonal to the local cyclical shock. If the latter captures changes in local aggregate demand, then the variation in housing prices we exploit is orthogonal to local demand effects. We note that, in this regard, our results are robust to using a variety of indicators of local cyclical conditions including real GDP growth and real Personal Income growth.
} 
require more evidence on the extent to which such financing varies by sector (since our results indicate the sensitivity to housing price shocks varies by sector) and the extent to which the usage of such financing changed when housing prices collapsed.

\section{Concluding Remarks}

We combine data from the Census Bureau's Business Dynamics Statistics (BDS) from 1981 to 2010 with indicators of business cycle and financial market conditions to examine the cyclical job dynamics of firms of different size and age. We exploit unique state and time variation in these data to identify the relative impact of business cycle and housing price shocks. We show that young, small businesses experienced especially large declines in net employment growth and job creation in the 200709 recession. We show that they also experienced large increases in job destruction over the same period.

Large and mature businesses also experienced substantial declines in net employment growth over this period, and since such firms account for most employment it follows that they account for a larger share of job loss. However, we find that young/small businesses are more cyclically sensitive so that the relative decline in this period is greater for young and small businesses than for large and mature businesses.

Since young firms disproportionally contribute to job creation in any given year, our results further indicate that the disproportionally large decline of young and small businesses is important for understanding not only the depth of the recession, but also the slow recovery. Research has shown that startups and young fast-growing U.S. businesses are important not only for U.S. jobs, but also for productivity growth. In as much as this recession has had a negative impact on a cohort of businesses that would otherwise have been born, the impact of the Great Recession has yet to be fully understood.

Why was the impact on young and small businesses especially large in this period? The evidence in this paper points to the collapse in housing prices as a potential critical factor. In states where housing prices declined the most (and after controlling for the endogenous impact of local business conditions on those prices), we find that there has been an especially large decline in the net employment growth for young and small businesses. 
The mechanism(s) that accounts for the greater vulnerability of young and small businesses to cyclical shocks and housing price shocks is an open question. We think there are a number of channels possibly at work that make young and small businesses more vulnerable in general to cyclical shocks and to housing prices in particular. One possible channel of interest is a home equity financing of startups and young businesses. Research has shown that startups and young businesses are much more likely to use home equity for financing. An open question is whether this is the mechanism that yielded the tight connection between the decline in housing prices and the decline in net growth for young and small businesses. Our findings also indicate that the impact of the collapse of housing prices on young and small businesses is concentrated in the Construction, Retail Trade, FIRE and Service sectors. As such, for the home equity financing channel of young businesses to be at work, we would need evidence that home equity financing of young businesses is especially important in these sectors. We think our findings suggest exploring this and alternative mechanisms should be an active area for future research but we recognize that this will likely require additional data to help us sort out the possible alternatives.

The challenges for investigating these questions stem not only from data limitations but also from related conceptual questions. As emphasized by Hurst and Pugsley (2011) and Haltiwanger (2013), most new businesses either fail or don't grow. Despite this fact, young businesses still contribute disproportionately to job creation. To reconcile these seemingly alternative views, it is critical to model and study the role of high growth young businesses. Haltiwanger (2013) shows that high growth (incumbent) businesses contribute about 50 percent of job creation and startups account for about 20 percent of job creation. Moreover, high growth businesses are disproportionately young businesses. For the questions of this paper, this implies that what might be especially important is what makes high growth young businesses more vulnerable to cyclical shocks and financial conditions including housing price shocks. Thus, future research should focus not so much on the impact of the cycle and financial conditions on the typical young business, but rather the impact of those in the right tail of the productivity and profitability distribution. 


\section{References}

Adelino, Manuel and Antoinette Schoar and Felipe Severino, 2013, "House Prices, Collateral and Self-Employment," mimeo.

Aghion, Philippe and Peter Howitt, 2006, "Appropriate Growth Policy: A Unifying Framework" Journal of European Economic Association, April-May 2006 4(2-3):269-314.

Arellano, M., \& Bover, O, 1995, "Another look at the instrumental variable estimation of error component models," Journal of Econometrics, 68, 29-51.

Bartelsman, Eric J., and Mark Doms, 2000, “Understanding Productivity: Lessons from Longitudinal Microdata.” Journal of Economic Literature, 38(3):569-94.

Becker. Randy A., John Haltiwanger, Ron S. Jarmin, Shawn D. Klimek and Daniel J. Wilson, 2006, "Micro and Macro Data Integration: the Case of Capital", in A New Architecture for the U.S. National Accounts, (Jorgenson, Landefeld and Nordhaus eds), NBER/University of Chicago Press.

Bernanke, Ben and Mark Gertler, 1989, "Agency Costs, Net Worth and Business Fluctuations," The American Economic Review, 79 (1), 14-31.

Bernanke, Ben, Mark Gertler, and Simon Gilchrist, 1999, "The Financial Accelerator in a Quantitative Business Cycle Framework," Handbook of Macroeconomics.

Chari, V.V., L. Christiano and P. Kehoe, 2007, "The Gertler-Gilchrist Evidence on Small and Large Firm Sales," mimeo.

Davis, Stephen J., and John Haltiwanger, 2001, "Sectoral Job Creation and Destruction Responses to Oil Price Changes and Other Shocks." Journal of Monetary Economics, December.

Davis, Stephen J., John Haltiwanger and Scott Schuh ,1996, Job Creation and Destruction, MIT Press.

Davis, Stephen J., John Haltiwanger, Ron Jarmin and Javier Miranda, 2007. "Volatility and Dispersion in Business Growth Rates: Publicly Traded versus Privately Held Firms," NBER Chapters, in: NBER Macroeconomics Annual 2006, Volume 21, pages 107-180 National Bureau of Economic Research, Inc.

Decker, Ryan, John Haltiwanger, Ron Jarmin and Javier Miranda, 2013, “The Secular Decline in Business Dynamism in the U.S.”, mimeo.

Fazzari, Stephen, R. Glenn Hubbard, and Bruce Peterson,1988, "Financing Constraints and Corporate Investment," Brookings Papers on Economic Activity, 1, 141-95.

Foster, Lucia, John Haltiwanger, and Chad Syverson, 2012, “The Slow Growth of New Plants: Learning about Demand," NBER Working Paper No. 17853.

Gertler, Mark and R. Glenn Hubbard, "Financial Factors in Business Fluctuations," in Financial Market Volatility: Causes, Consequences, and Policy (Kansas City: Federal Reserve Bank of Kansas City), 33-71.

Gertler, Mark and Simon Gilchrest, 1994, "Monetary Policy, Business Cycles, and the Behavior of Small Manufacturing Firms,” The Quarterly Journal of Economics, 109 (2), 309-340. 
Gilchrist, Simon and Vladimir Yankov and Egon Zakrajsek, 2009, "Credit Market Shocks and Economic Fluctuations: Evidence from Corporate Bond and Stock Markets," NBER, Working Paper: 14863, April 2009.

Haltiwanger, John, 2010, “The Changing Cyclical Dynamics of U.S. Labor Markets,” mimeo.

Haltiwanger, John, 2013, "What is the Contribution of Entrepreneurs to Jobs and Productivity?", mimeo.

Haltiwanger, John, Ron Jarmin and Javier Miranda, 2009, "Business Dynamic Statistics: An Overview" Marion Ewing Kauffman Foundation BDS Briefs.

Haltiwanger, John and Ron Jarmin and Javier Miranda, 2013, "Who Creates Jobs? Small vs. Large vs. Young," Review of Economics and Statistics. 95(2), 347-361.

Holtz-Eakin, Douglas, Whitney Newey and Harvey S. Rosen, 1988, "Estimating Vector Autoregressions with Panel Data," Econometrica, Vol. 56, No. 6, pp. 1371-1395.

Hopenhayn, H, 1992, "Entry, exit, and firm dynamics in long run equilibrium”, Econometrica, Vol. 60, No. 5, pp. 1127-1150.

Hurst, Erik and Anna Maria Lusardi, 2004, "Liquidity Constraints, Household Wealth, and Entrepreneurship" Journal of Political Economy, Vol. 112, No. 2, pp. 319-347

Hurst, Erik and Benjamin Pugsley, 2012. "What Do Small Businesses Do?”, Brookings Papers on Economic Activity. vol. 43(2 (Fall)), pages 73-142.

Jarmin, Ron S., and Javier Miranda, 2002, “The Longitudinal Business Database," CES Working Paper 02-17.

Jovanovic, B, 1982, "Selection and the evolution of industry", in Econometrica, Vol. 50, No. 3, pp. 649-670.

Krainer, John, 2004, "What Determines the Credit Spread?," FRBSF Economic Letter, 36.

Love, Inessa and Lea Zicchino, 2006, "Financial development and dynamic investment behavior: Evidence from panel VAR", The Quarterly Review of Economics and Finance, 46 (2006) 190210.

Lucas, R.E., 1978, “On the size distribution of business firms", in The Bell Journal of Economics, Vol. 9, No. 2, pp. 508-523.

Mach, Traci and John Wolken, 2006, "Evidence from the 2003 Survey of Small Business Finances," Federal Reserve Bulletin, 92, A167-A195.

Melitz, M.,2003, "The impact of trade on intra-industry reallocations and aggregate industry productivity", in Econometrica, Vol. 71, No. 6, pp. 1695-1726.

Mian, Atif and Amir Sufi, 2010, "Household Leverage and the Recession of 2007-09", IMF Economic Review, (58) 74-116.

Mian, Atif and Amir Sufi, 2011, "House Prices, Home Equity-Based Borrowing, and the U.S. Household Leverage Crisis", American Economic Review, 101, 2132-2156.

Mian, Atif and Amir Sufi, 2012, "What Explains High Unemployment? The Aggregate Demand Channel" mimeo. 
Mishkin, Frederic S., 2008, “Small Business Lending,” Testimony before the Committee on Small Business and Entrepreneurship, U.S. Senate, April 2008.

Moscarini, Guiseppe and Fabien Postel-Vinay, 2008," "The Timing of Labor Market Expansions: New Facts and a New Hypothesis," in D. Acemoglu, K Rogoff, and M. Woodford., eds, NBER Macroeconomics Annual, 23, 1-51.

Moscarini, Guiseppe and Fabien Postel-Vinay, 2012, "The Contribution of Large and Small Employers to Job Creation in Times of High and Low Unemployment", American Economic Review. 102(6), 2509-2539

Mueller, Philippe, 2009, "Credit Spreads and Real Activity,” mimeo.

Robb, Alicia and David Robinson, 2011, “The Capital Structure Decisions of Startup Firms," Review of Financial Studies, forthcoming.

Robb, Alicia and John Wolken, 2002, "Firm, Owner, and Financing Characteristics: Differences between Female- and Male-owned Small Businesses," Federal Reserve Board Finance and Economics Discussion Series Paper.

Saiz, Albert Saiz, 2010, "The Geographic Determinants of Housing Supply," Quarterly Journal of Economics, 125(3), 1253-1296.

Sharpe, Stephen, 1994, "Financial Market Imperfections, Firm Leverage, and the Cyclicality of Employment," American Economic Review, 84(4), 1060-74.

Stock, James H. and Mark W. Watson, 2003, "Forecasting Output and Inflation: The Role of Asset Prices," Journal of Economic Literature, 41(3), 788-829.

Syverson, Chad, 2011, "What Determines Productivity?" Journal of Economic Literature. 49(2), 326-365.

Tornqvist, Leo, Pentti Vartia and Yrjo Vartia, 1985, "How Should Relative Changes Be Measured?" American Statistician, February, 39:1, pp. 43-46. 


\section{Measurement and Data Appendix}

\section{A1: Measurement of Net and Gross Job Flows}

Our measures are taken from the Business Dynamic Statistics. The net job creation and gross job flow measures are based on the methodology of Davis, Haltiwanger and Schuh (1996). In the BDS, establishments are classified by their parent firm's size and firm age. This is based on the parent firm for the establishment. Firm size is available using both current average size (the average size of the parent firm in the prior and current year) and initial size (the size of the parent firm in the prior year). Firm age is based on the age of the oldest establishment when a new firm is started and then ages naturally thereafter. It is based on the parent firm in the current year. As noted in the text we collapse the available firm size and firm age categories into broad firm size and firm age categories. For any given cell "s" defined by a firm size and firm age category is equal to:

$$
g_{s t}=\frac{E_{s t}-E_{s t-1}}{X_{s t}}
$$

where $E_{s t}$ is employment for cell "s" in period t, $X_{s t}=0.5 *\left(E_{s t}+E_{s t-1}\right){ }^{37}$ In measuring and defining $E_{s t-1}$ it is critical to emphasize that this is the employment in period t-1 of the establishments that are in cell "s" in period t. That is, this is based on the same set of establishments in period t-1 and $\mathrm{t}$ (and this is not subject to the "size distribution fallacy" discussed in Davis, Haltiwanger and Schuh (1996) wherein misleading inferences can be generated by considering cell based totals of establishments classified by firm size (or firm age) across years as establishments can change firm size and firm age classifications). Another way of making this point is to note that that the growth rate for the cell can be equivalently generated by:

$$
g_{s t}=\sum_{e \in S} \frac{X_{e s t}}{X_{s t}}\left(\frac{E_{e s t}-E_{e s t-1}}{X_{e s t}}\right)=\sum_{e \in s} \frac{X_{e s t}}{X_{s t}} g_{e s t}
$$

The net growth rate for the cell can be decomposed into the contribution of job creation and destruction as follows. Define job creation and job destruction for the cell as:

$$
\begin{aligned}
J C_{s t} & =\sum_{e \in s} \frac{X_{e s t}}{X_{s t}} \max \left(g_{e s t}, 0\right) \\
J D_{s t} & =\sum_{e \in s} \frac{X_{e s t}}{X_{s t}} \max \left(-g_{e s t}, 0\right)
\end{aligned}
$$

By construction, net employment growth for the cell can be decomposed into:

$$
g_{s t}=J C_{s t}-J D_{s t}
$$

${ }^{37}$ This measure of net growth is bounded between $(-2,2)$ and is symmetric around zero. Its desirable properties are discussed extensively in Davis, Haltiwanger, and Schuh (1996). 
Note that the cells for young firms include establishments of new firms (firm age $=0$ ). All such establishments have DHS net growth rates at the establishment level equal to 2 . For the young firm cell, when there is a decrease in the share of young firm employment accounted for by new firms, the cell based growth rate will decline. But the net growth rate for the young firm cells will also reflect the job creation of firms older than firm age $=0$ as well as the job destruction of firms older than firm age $=0$.

\section{A2: Cyclical variable construction}

Unemployment rate: The national unemployment rate is based on quarterly data from the Bureau of Labor Statistic's (BLS) Current Population Survey for 1979-2010 . The state-level unemployment data are also quarterly and come from the BLS regional and state-level data releases available on FRED. We construct yearly data for the regression analysis by averaging the unadjusted, quarterly data over the retimed year. We calculate the yearly change as: $\delta U_{t}=U_{t}-U_{t-1}$, where $t$ represents the re-timed year. We also HP filter the unemployment as an alternative measure that captures deviations from the longterm trend.

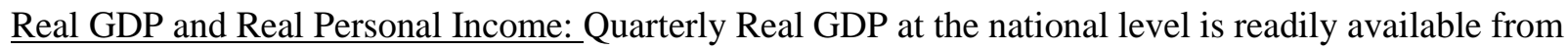
the BEA (Real GDP is nominal GDP deflated by the GDP implicit price deflator). We take time averages for the retimed year and compute log first differences. At the state level, nominal GDP is available on an annual basis but not for the re-timed year. Since the re-timed year is only off by a quarter we use this in our analysis with appropriate caution. We deflate the state level nominal GDP with the national implicit price deflator and then compute growth rates with log first differences. At the state level, a related alternative measure is available quarterly - personal income. The latter is income from all sources available to households. We deflate the latter on a quarterly basis with the national implicit price deflator, take averages for the re-timed year and then compute growth rates with log first differences.

Housing Prices: The housing price measure is based on the Federal Housing Finance Agency (FHFA) House Price Index. The HPI is a weighted, repeat-sales index. It measures the average price changes in repeat sales or refinancings on the same properties. The information for the HPI is obtained from repeat mortgage transactions on single-family properties whose mortgages have been purchased or securitized by Fannie Mae or Freddie Mac since January 1975.

We use unadjusted HPI data that are quarterly, by state. We divide the HPI by the BLS Urban Consumer Price Index for all items so that the data are in real terms. We then average the quarterly index over the re-timed year and calculate the log first difference in home prices. 
Table 1 Correlations Between Cyclical Indicators and Net Differential Employment Growth Rates

\begin{tabular}{|c|c|c|c|c|c|c|c|c|}
\hline & \multicolumn{2}{|c|}{ Change in Unemp Rate } & \multicolumn{2}{|c|}{ Net Emp. Growth Rate } & \multicolumn{2}{|c|}{ Real GDP Growth } & \multicolumn{2}{|c|}{ HP Filtered Unemp Rate } \\
\hline & $1981-2010$ & $1981-2006$ & $1981-2010$ & $1981-2006$ & $1981-2010$ & $1981-2006$ & $1981-2010$ & $1981-2006$ \\
\hline \multirow[t]{2}{*}{ Young/Small-Older/Large } & -0.452 & -0.292 & 0.551 & 0.279 & 0.527 & 0.305 & 0.239 & 0.215 \\
\hline & $(0.012)$ & $(0.148)$ & $(0.002)$ & $(0.168)$ & $(0.003)$ & $(0.130)$ & $(0.203)$ & $(0.292)$ \\
\hline \multirow[t]{2}{*}{ Young/Medium-Older/Large } & -0.342 & -0.263 & 0.507 & 0.329 & 0.475 & 0.344 & 0.125 & -0.057 \\
\hline & $(0.064)$ & $(0.194)$ & $(0.004)$ & $(0.101)$ & $(0.008)$ & $(0.085)$ & $(0.512)$ & $(0.782)$ \\
\hline \multirow[t]{2}{*}{ Older/Small-Older/Large } & 0.283 & 0.342 & 0.146 & -0.258 & -0.171 & -0.242 & 0.608 & 0.620 \\
\hline & $(0.130)$ & $(0.087)$ & $(0.441)$ & $(0.204)$ & $(0.367)$ & $(0.233)$ & $(0.000)$ & $(0.001)$ \\
\hline \multirow[t]{2}{*}{ Older/Medium-Older/Large } & -0.218 & -0.075 & 0.403 & 0.267 & 0.313 & 0.162 & 0.391 & 0.551 \\
\hline & $(0.247)$ & $(0.715)$ & $(0.027)$ & $(0.188)$ & $(0.092)$ & $(0.429)$ & $(0.033)$ & $(0.004)$ \\
\hline
\end{tabular}

Note: P-values in parentheses. 
Table 2 Descriptive Regressions at State Level (Controlling for State and Year Fixed Effects) - Using State-Level Change in Unemployment Rate as Cyclical Indicator

Bivariate

\begin{tabular}{|l|c|c|c|c|}
\hline & $(1)$ & $(2)$ & $(3)$ & $(4)$ \\
\hline & diff_net_rate_11 & diff_net_rate_21 & diff_net_rate_12 & diff_net_rate_22 \\
\hline Chg_UR_st & $-2.207^{* * *}$ & $-1.432^{* * *}$ & $-0.570^{* * *}$ & $-0.479^{* * *}$ \\
\hline & $(0.212)$ & $(0.248)$ & $(0.142)$ & $(0.140)$ \\
\hline
\end{tabular}

Multivariate

\begin{tabular}{|l|c|c|c|c|}
\hline & $(1)$ & $(2)$ & $(3)$ & $(4)$ \\
\hline & diff_net_rate_11 & diff_net_rate_21 & diff_net_rate_12 & diff_net_rate_22 \\
\hline Chg_UR_st & $-1.916^{* * *}$ & $-1.347^{* * *}$ & $-0.484^{* * *}$ & $-0.437^{* *}$ \\
\hline GR_HPrice_st & $(0.213)$ & $(0.253)$ & $(0.144)$ & $(0.143)$ \\
\hline & $0.183^{* * *}$ & 0.054 & $0.054^{* *}$ & 0.026 \\
\hline$N$ & $(0.027)$ & $(0.032)$ & $(0.018)$ & $(0.018)$ \\
\hline
\end{tabular}

The dependent variable is the differential net employment growth rate for the group specified. Note 11=Young/Small, 21=Young/Medium, 12=Old/Small, 22=Old/Medium. All net differentials are with respect to Old/Large. Ch_UR_st is the state unemployment growth rate; GR_HPrice_st is the growth rate of the state's real FHFA housing price index. Standard errors in parentheses. ${ }^{*} p<0.05,{ }^{* * *} p<0.01,{ }^{* * *} p<0.00$. 
Table 3 Descriptive Regressions at State Level (Controlling for State and Year Fixed Effects) - Using HP Filtered StateLevel Unemployment Rate as Cyclical Indicator

Bivariate

\begin{tabular}{|l|c|c|c|c|}
\hline & $(1)$ & $(2)$ & $(3)$ & $(4)$ \\
\hline & diff_net_rate_11 & diff_net_rate_21 & diff_net_rate_12 & diff_net_rate_22 \\
\hline HP_UR_st & $-2.406^{* * *}$ & $-0.914^{*}$ & $-0.885^{* * *}$ & $-0.456^{*}$ \\
\hline & $(0.347)$ & $(0.401)$ & $(0.227)$ & $(0.225)$ \\
\hline
\end{tabular}

Multivariate

\begin{tabular}{|l|c|c|c|c|}
\hline & $(1)$ & $(2)$ & $(3)$ & $(4)$ \\
\hline & diff_net_rate_11 & diff_net_rate_21 & diff_net_rate_12 & diff_net_rate_22 \\
\hline HP_UR_st & $-1.731^{* * *}$ & -0.657 & $-0.708^{* * *}$ & -0.353 \\
\hline & $(0.355)$ & $(0.417)$ & $(0.236)$ & $(0.234)$ \\
\hline GR_HPrice_st & $0.195^{* * *}$ & $0.074^{*}$ & $0.051^{* *}$ & 0.030 \\
\hline & $(0.028)$ & $(0.033)$ & $(0.019)$ & $(0.019)$ \\
\hline$N$ & 1530 & 1530 & 1530 & 1530 \\
\hline
\end{tabular}

The dependent variable is the differential net employment growth rate for the group specified. Note 11=Young/Small, 21=Young/Medium, 12=Old/Small, 22=Old/Medium. All net differentials are with respect to Old/Large. HP_UR_st is the HP-filtered state unemployment rate; GR_HPrice_st is the growth rate of the state's real FHFA housing price index. Standard errors in parentheses. ${ }^{*} p<0.05,{ }^{* *} p<0.01,{ }^{* * *} p<0.001$

Table 4: Ratio of Cross State Std Deviations of Forecasted to Actual for Two Year Changes in the Net Differential for Young/Small with Large/Old (Diff_Net_Rate_11)

\begin{tabular}{|c|c|c|c|c|}
\hline \multicolumn{5}{|c|}{ Accounted For By: } \\
\hline \multirow[t]{2}{*}{ Year(s) } & \multicolumn{2}{|c|}{ Housing Prices } & \multicolumn{2}{|c|}{ Change in Unemployment Rate } \\
\hline & $\begin{array}{c}\text { Only State- } \\
\text { Specific Variation }\end{array}$ & $\begin{array}{c}\text { With National } \\
\text { Variation }\end{array}$ & $\begin{array}{c}\text { Only State-Specific } \\
\text { Variation }\end{array}$ & $\begin{array}{c}\text { With National } \\
\text { Variation }\end{array}$ \\
\hline 1991 & 0.12 & 0.22 & 0.19 & 0.39 \\
\hline 2002 & 0.11 & 0.22 & 0.26 & 0.79 \\
\hline 2009 & 0.41 & 0.78 & 0.28 & 0.44 \\
\hline $1983-2006$ & 0.13 & 0.29 & 0.18 & 0.79 \\
\hline $2007-2010$ & 0.24 & 0.48 & 0.21 & 0.46 \\
\hline 2004-2006 & 0.27 & 0.59 & 0.28 & 0.87 \\
\hline
\end{tabular}

Notes: Reported statistics are the ratio of the cross state standard deviation of the forecasted two year change in Diff_Net_Rate_11 from housing price shocks and changes in unemployment rate shocks, respectively, to the cross state standard deviation of the actual two year change in Diff_Net_Rate_11. Standard deviations are computed using state-year employment weights. 
Figure 1

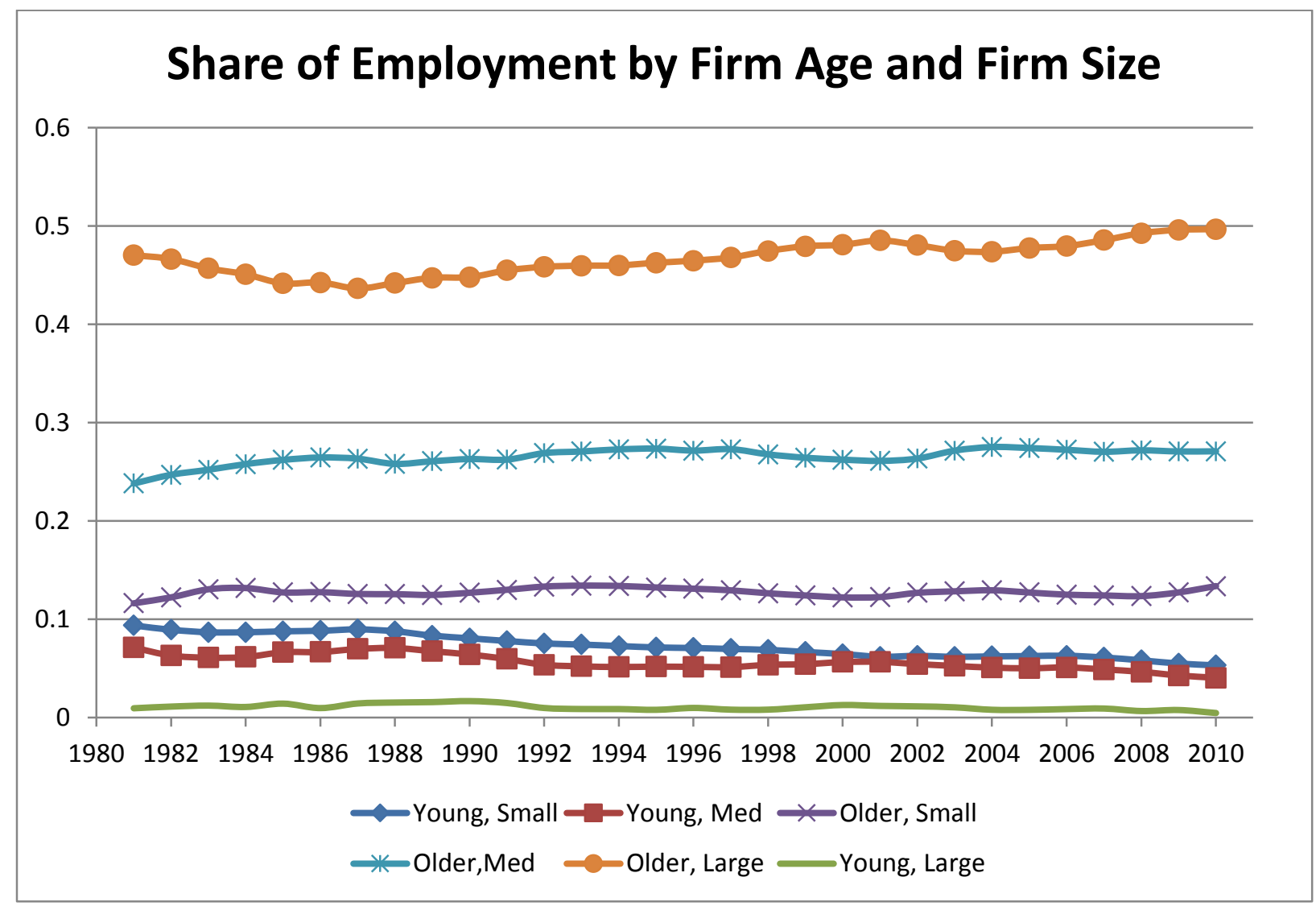

Notes: Tabulations from the Business Dynamic Statistics (BDS). See text for definitions of young, older, small, medium and large. 
Figure 2

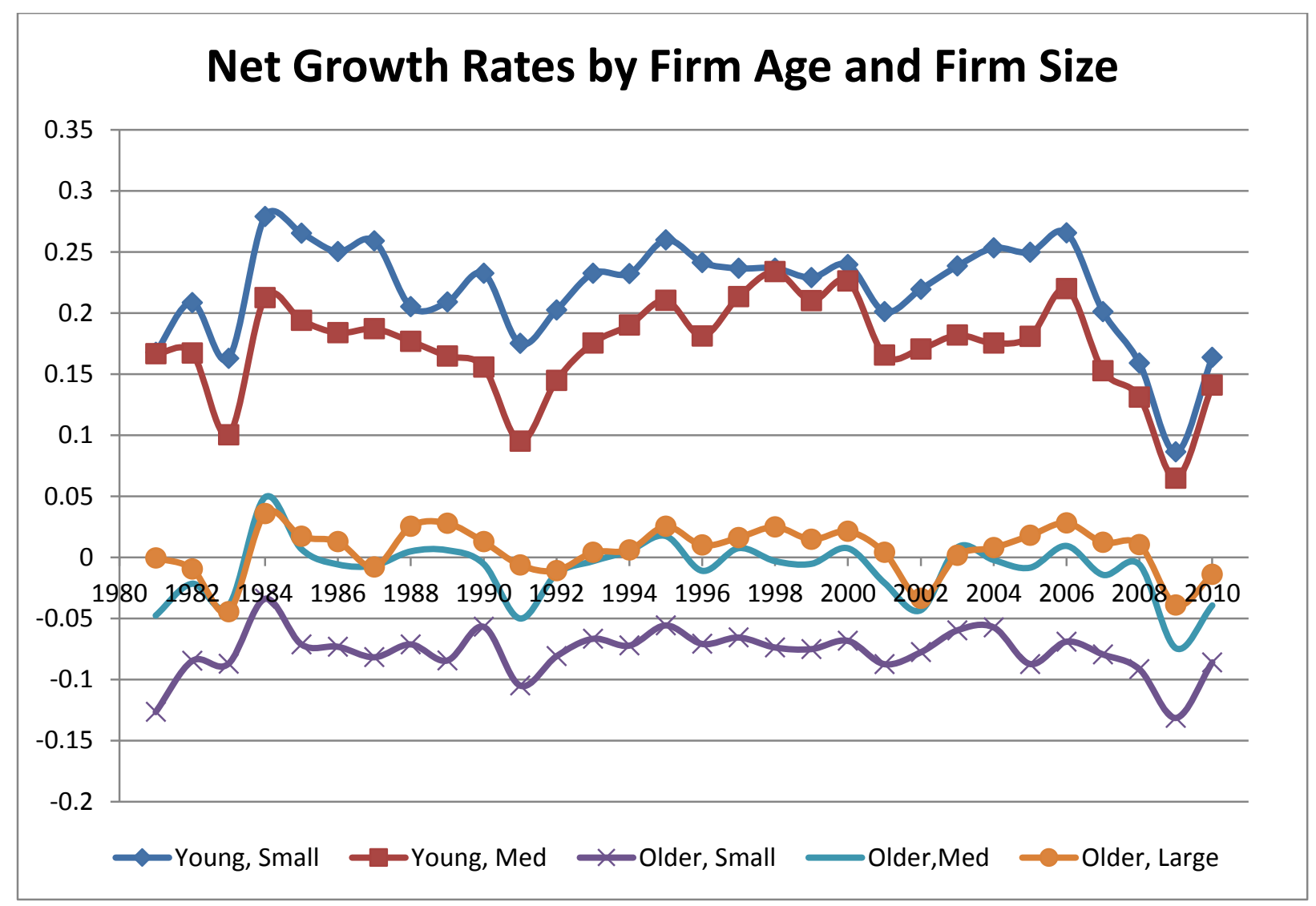

Notes: Tabulations from BDS. See Notes to Figure 1. 
Figure 3.a

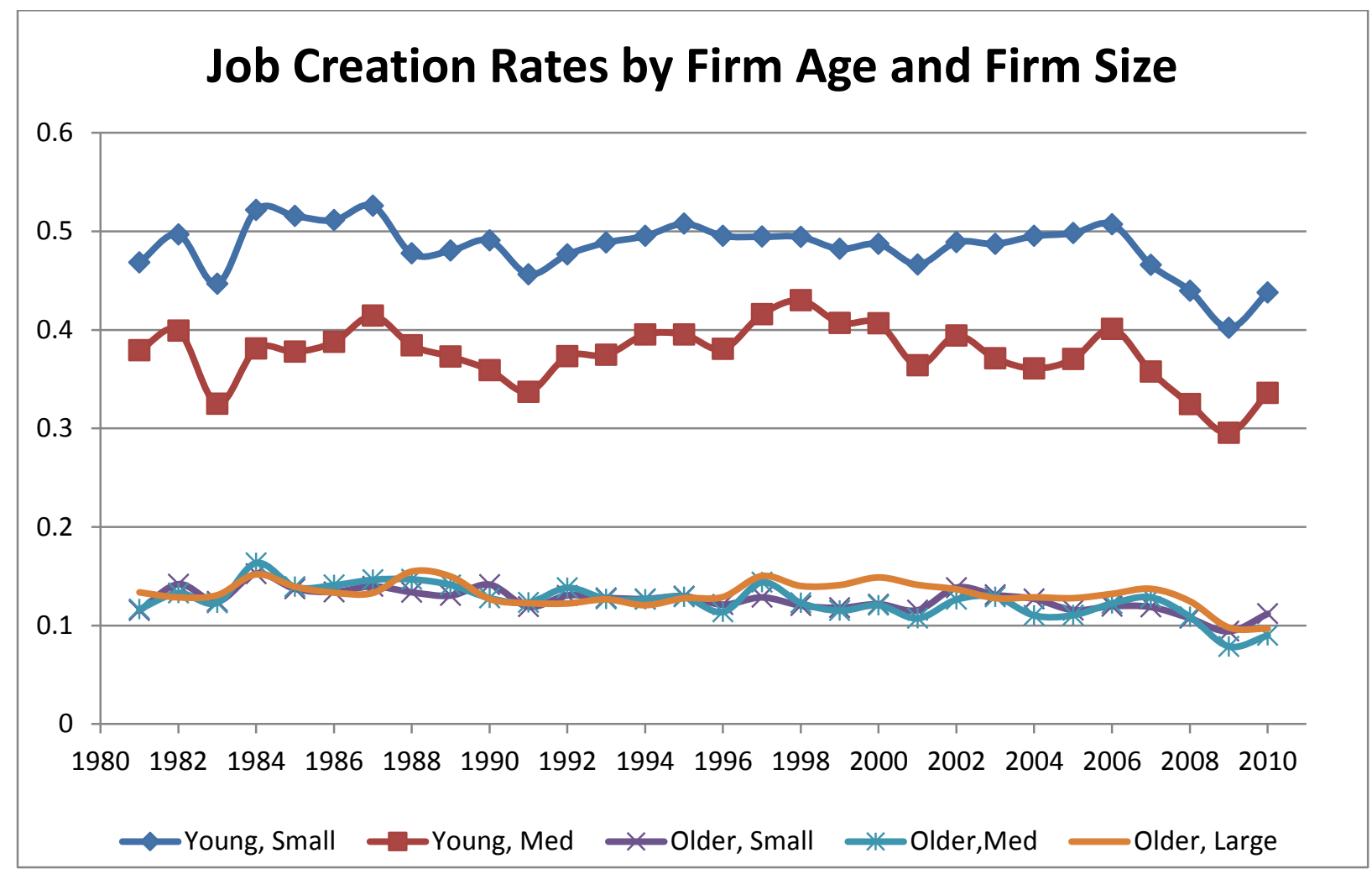

Figure 3.b

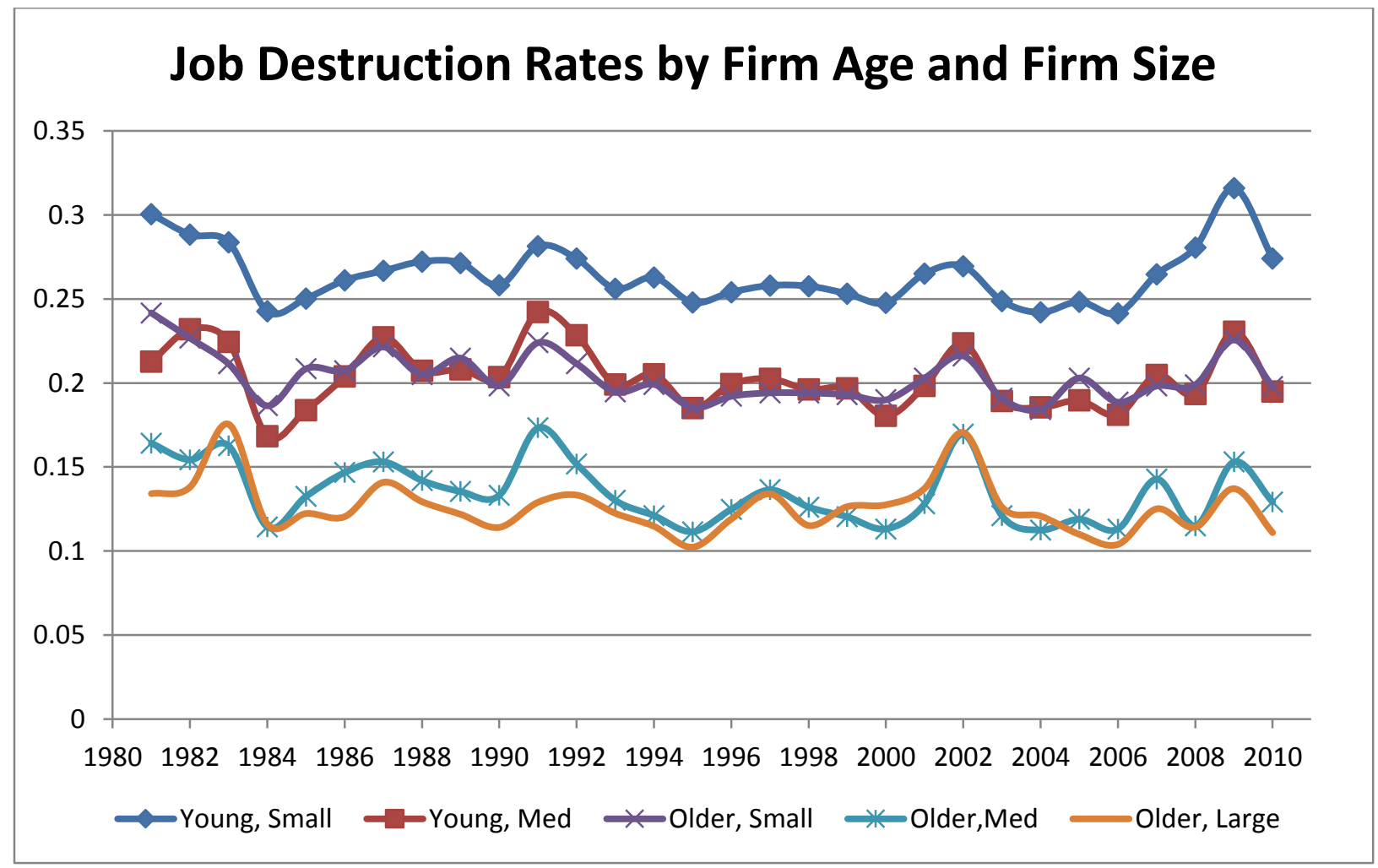

Notes: Tabulations from BDS. See Notes to Figure 1. 
Figure 4

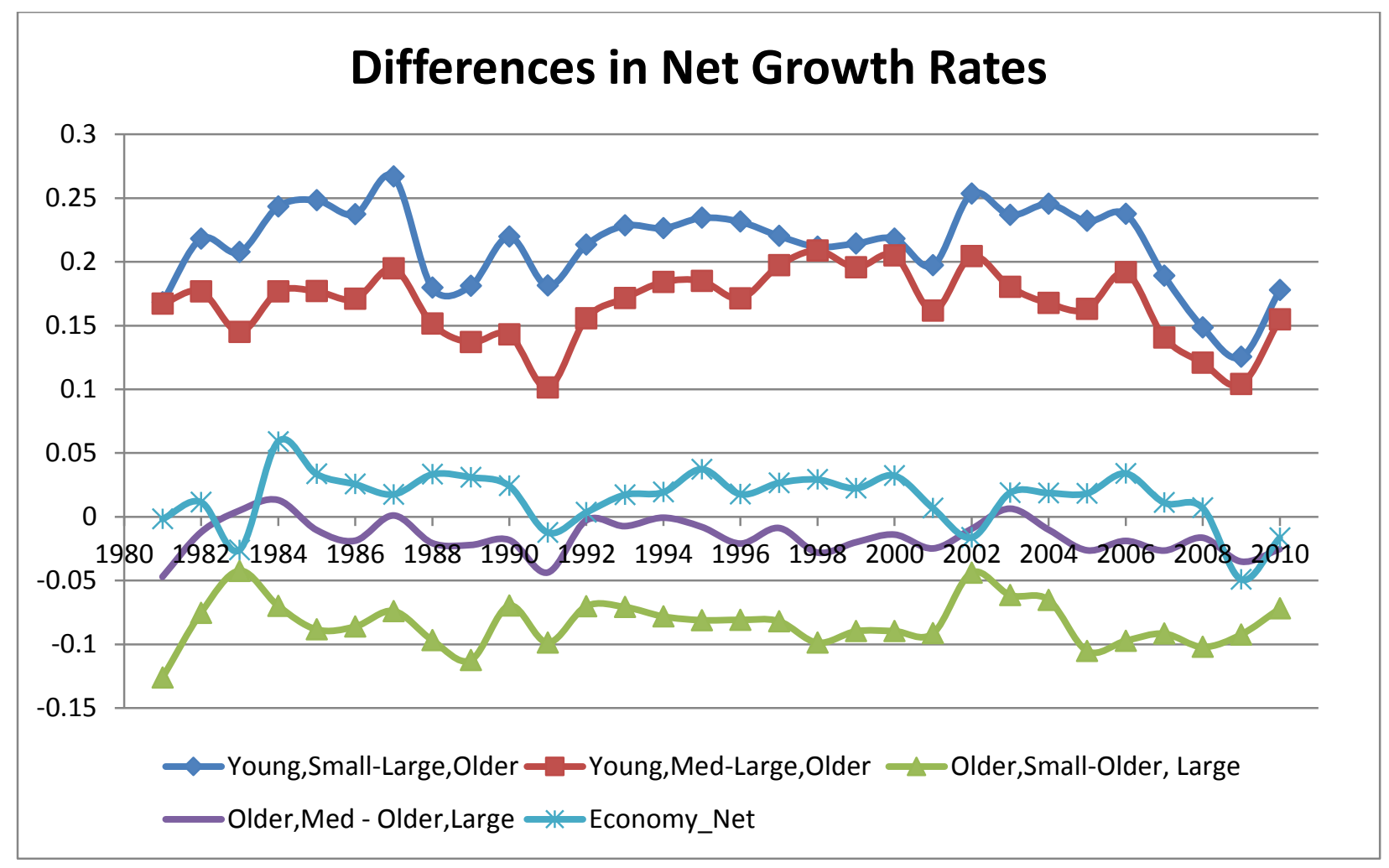

Notes: Tabulations from BDS. See Notes to Figure 1. 
Figure 5.1

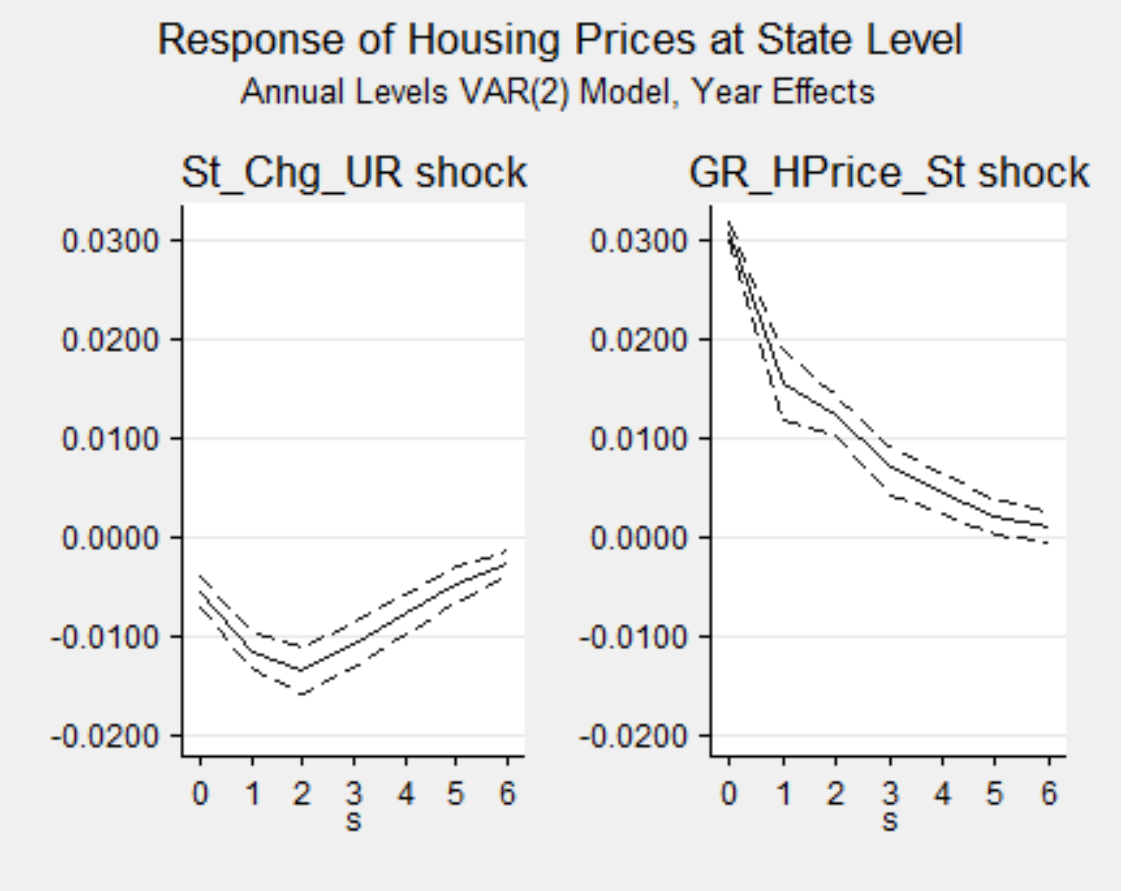

Notes: Tabulations by authors. St_Chg_UR shock is the innovation to the state-specific changes in unemployment rate. GR_HP_St shock is the innovation to state-specific housing price growth.

Figure 5.2

Response of Difference of Young/Small with Large/Old Net Annual Levels VAR(2) Model, Year Effects
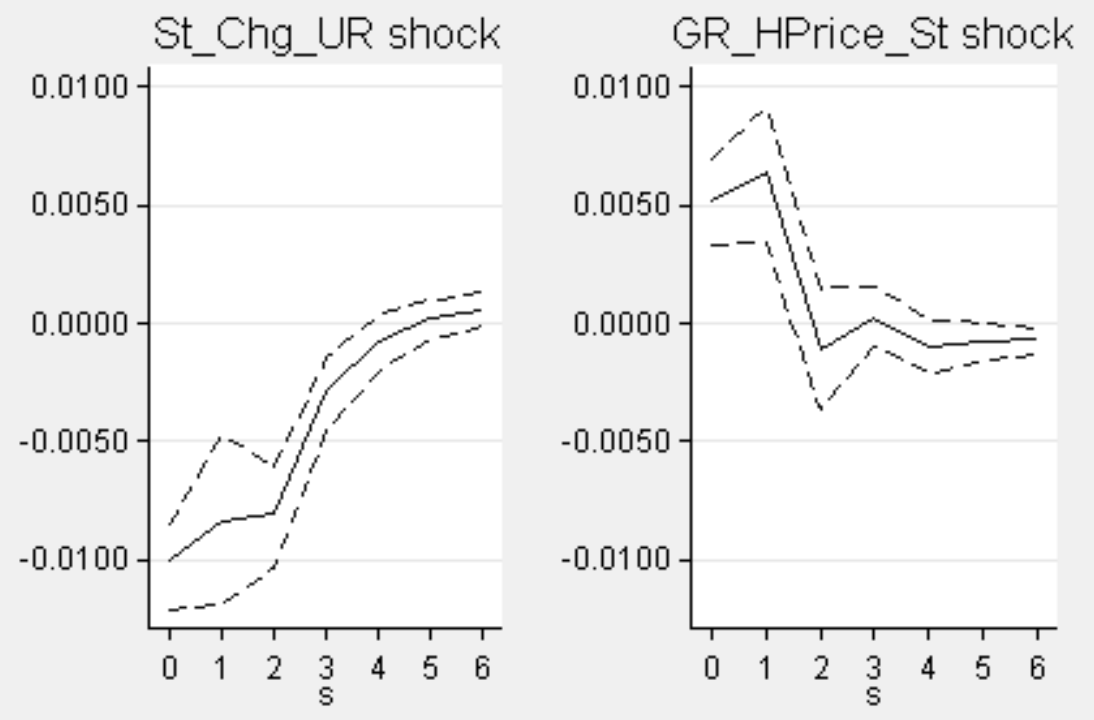

Notes: See Notes to Figure 5.1 
Figure 5.3

Reponse of Difference of Young/Medium with Large/Old Net Annual Levels VAR(2) Model, Year Effects
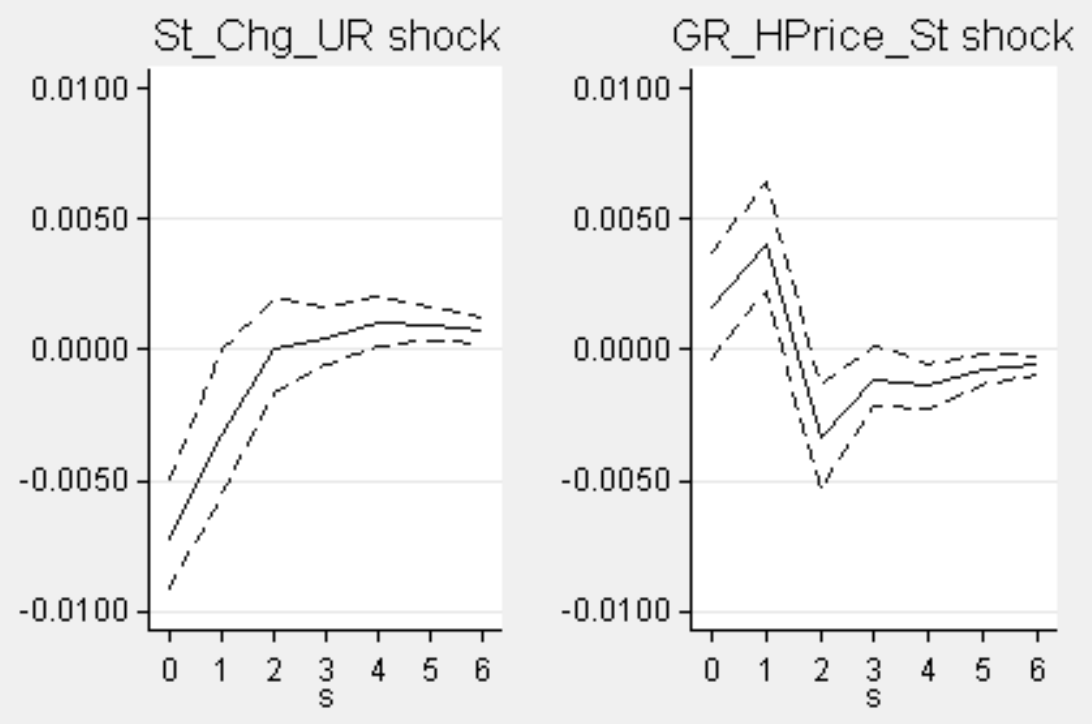

Notes: See Notes to Figure 5.1

Figure 5.4

Response of Difference of Old/Small with Large/Old Net Annual Levels VAR(2) Model, Year Effects
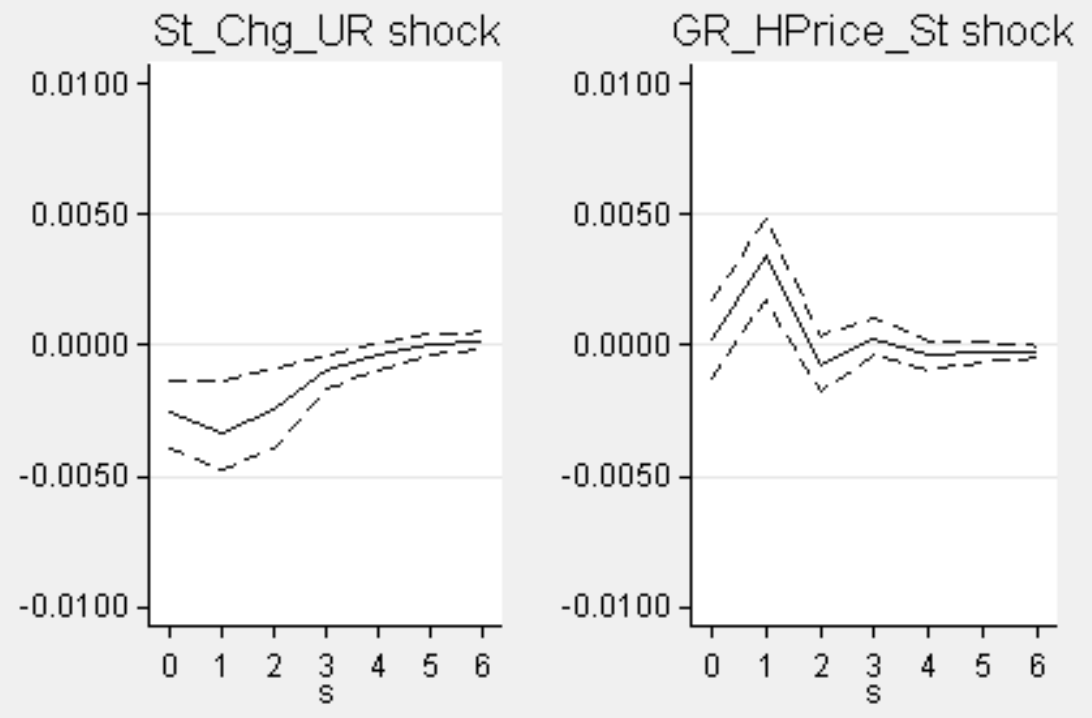

Notes: See Notes to Figure 5.1 
Figure 5.5

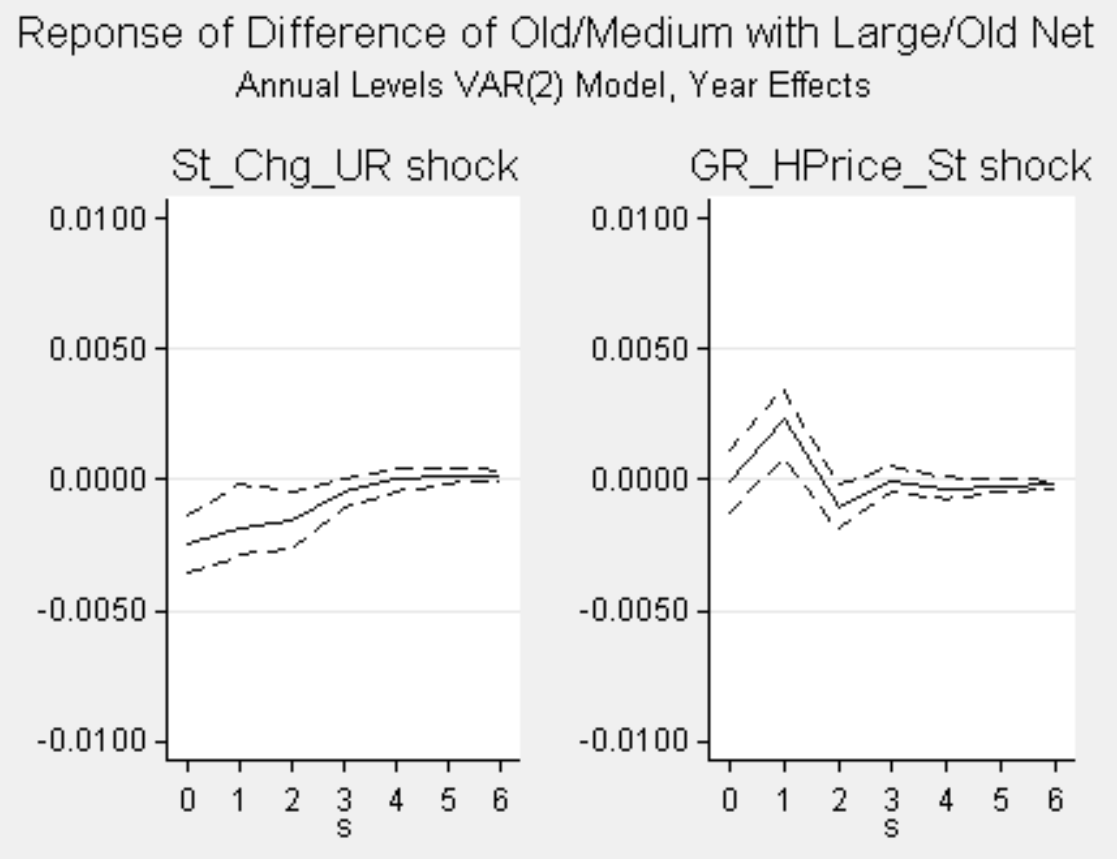

Notes: See Notes to Figure 5.1 
Figure 6

\section{Growth in Real Housing Prices}

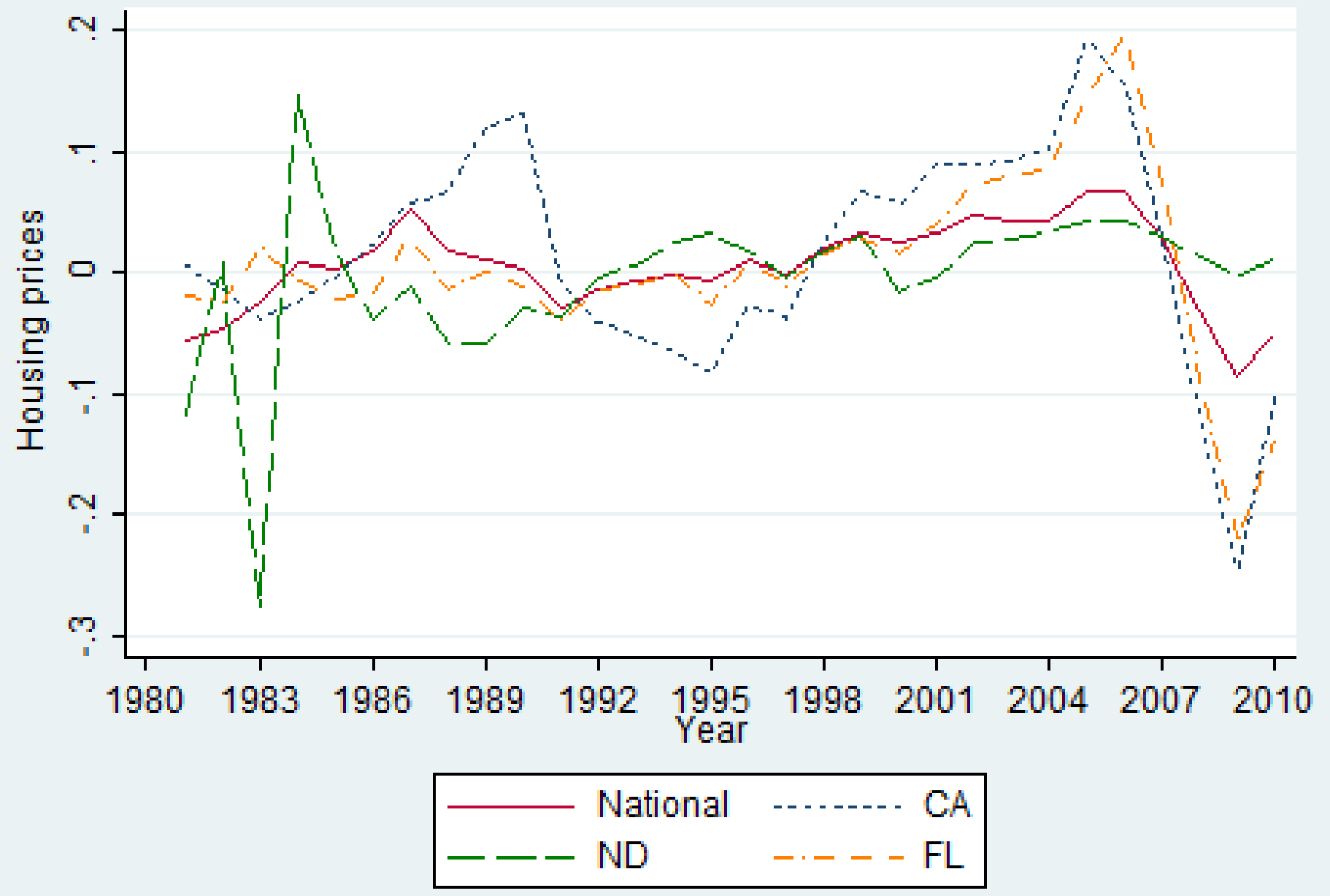

Notes: Tabulations by author from FHFA housing prices. 
Figure 7a

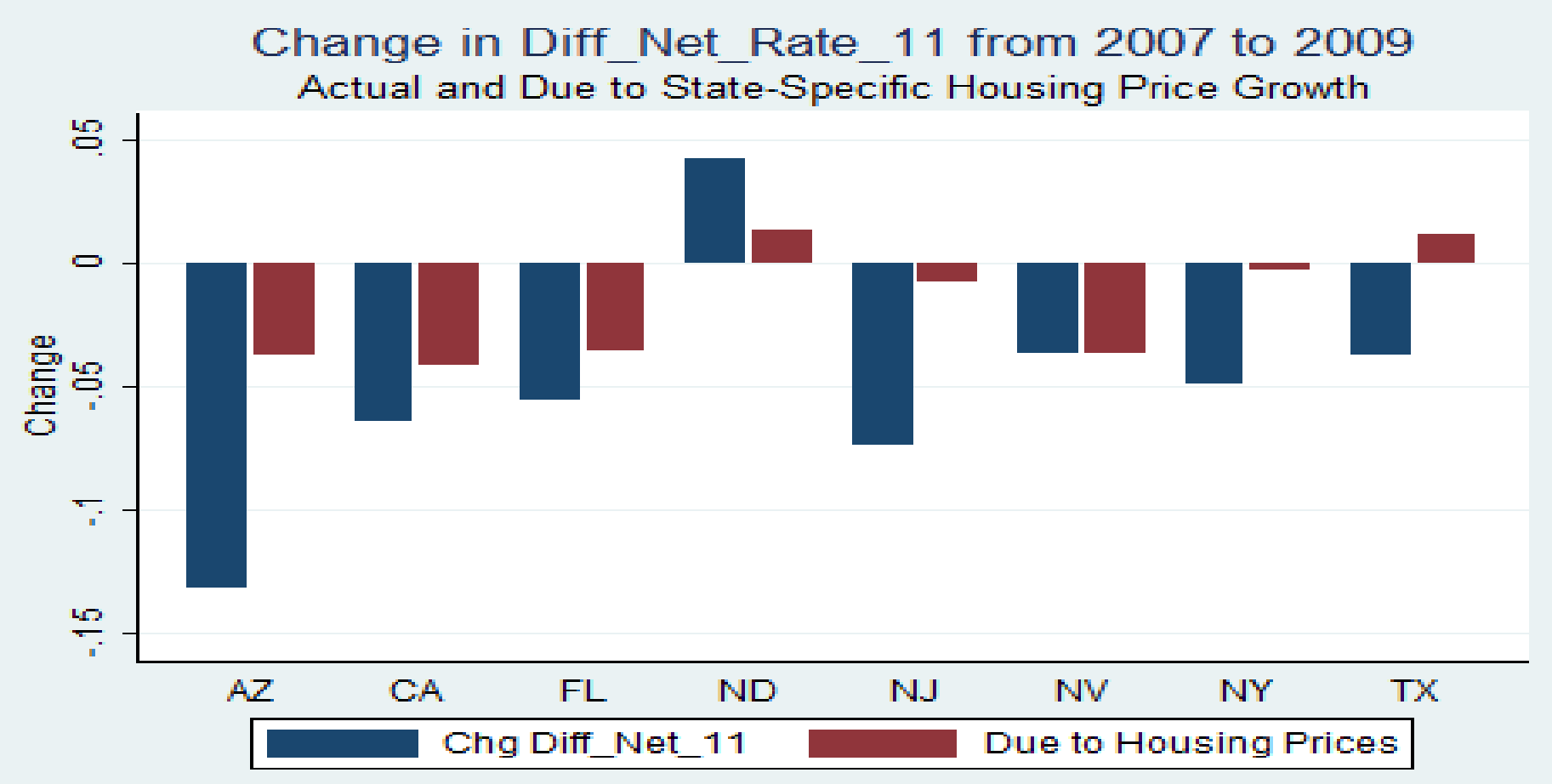

Figure $7 b$

Change in Diff_Net_Rate_11 from 2007 to 2009 Actual and Due to Housing Price Growth Including National Variation

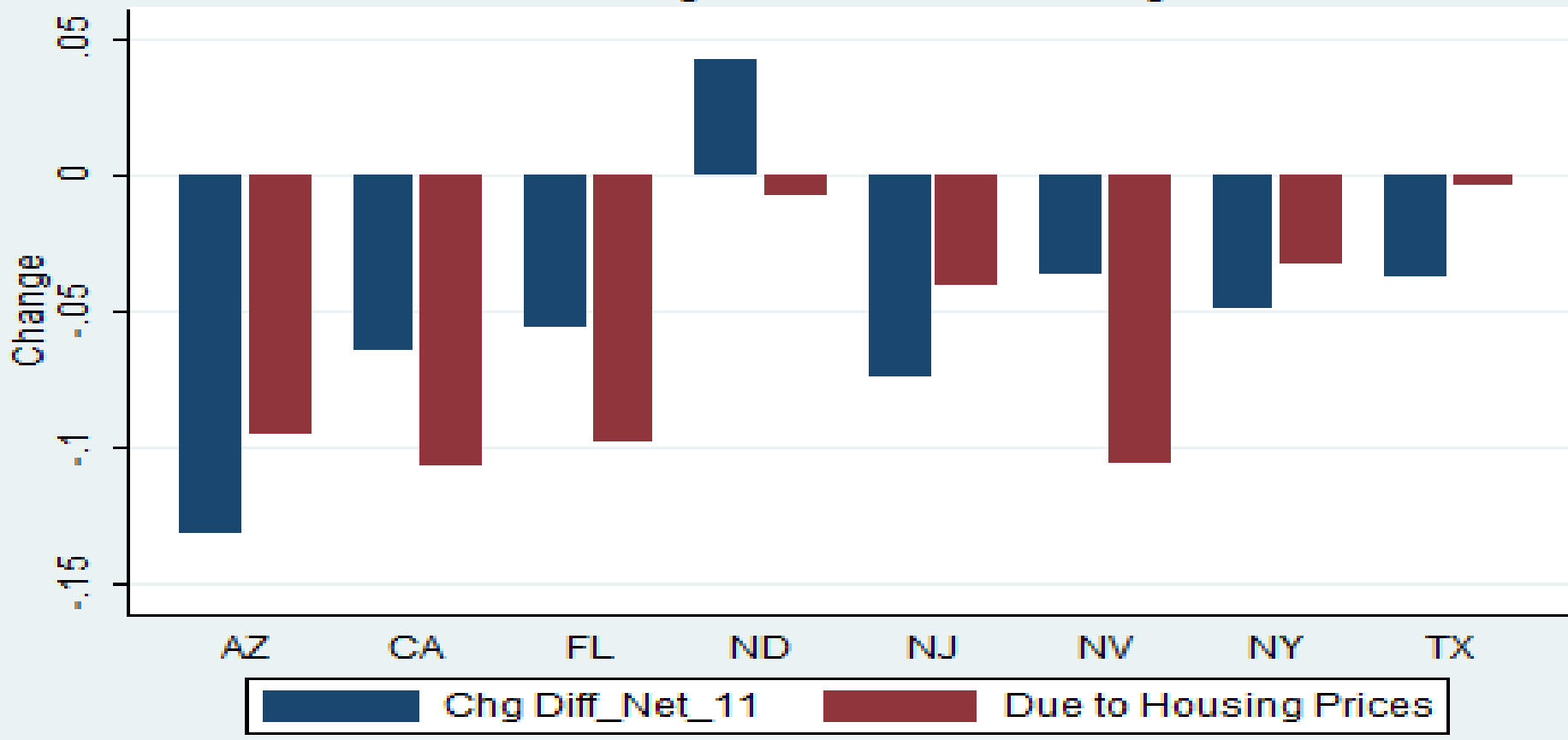

Notes: Tabulations by authors. 
Figure 9.a. Net Differential Response for Construction

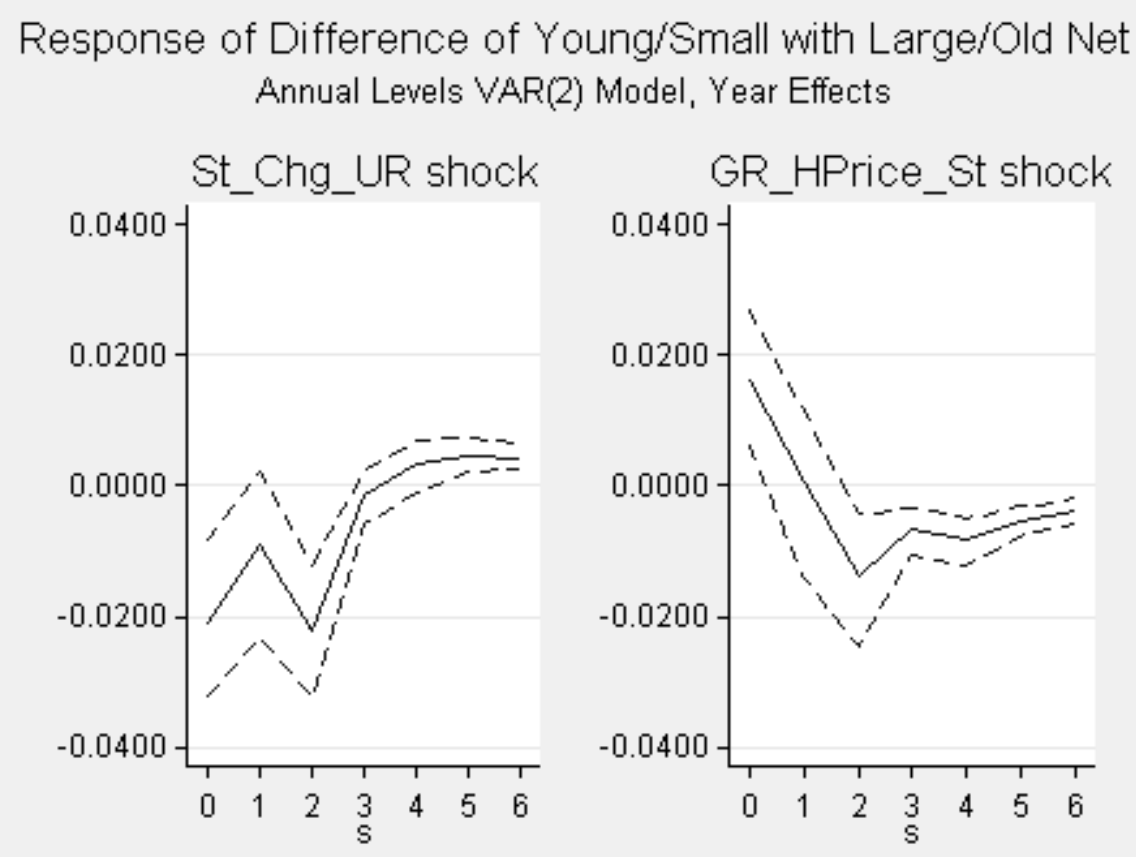

Notes: See Notes to Figure 5.1

Figure 9.b Net Differential Response for Manufacturing

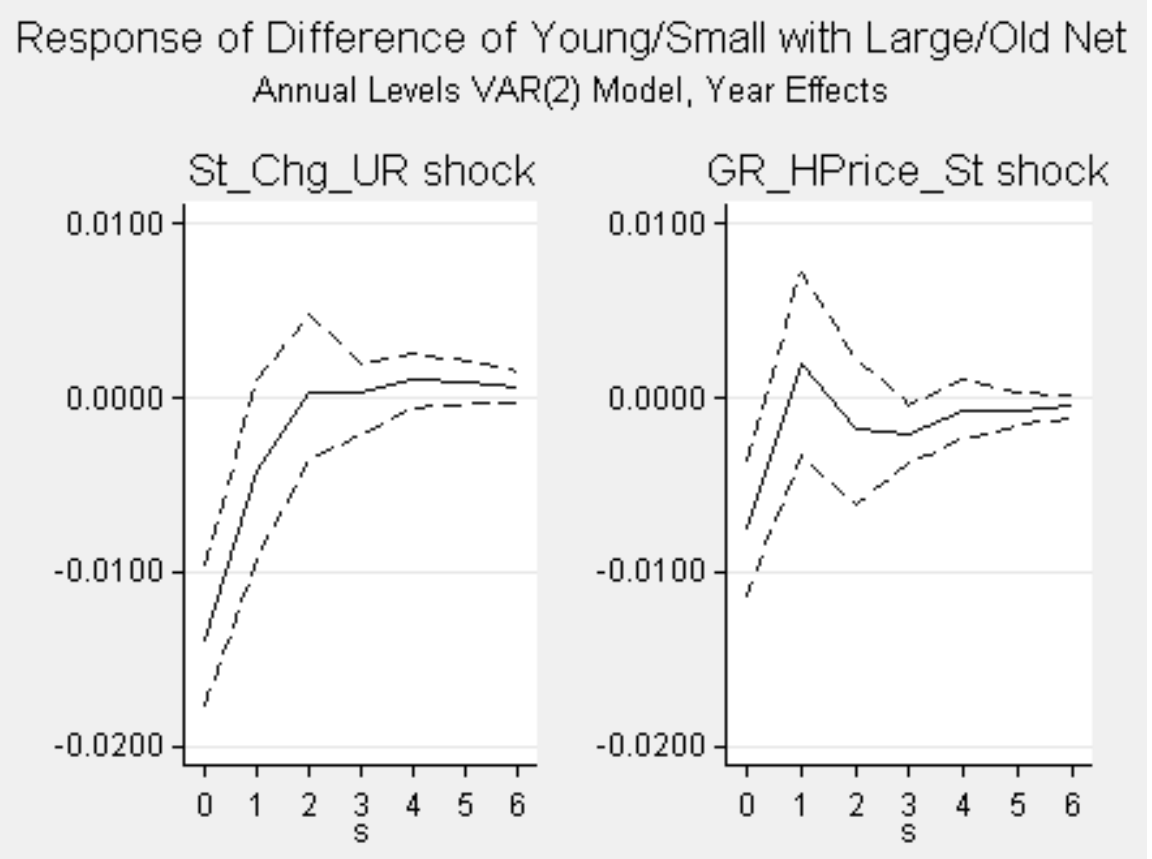

Notes: See Notes to Figure 5.1 
Figure 9.c Net Differential Response for Retail Trade

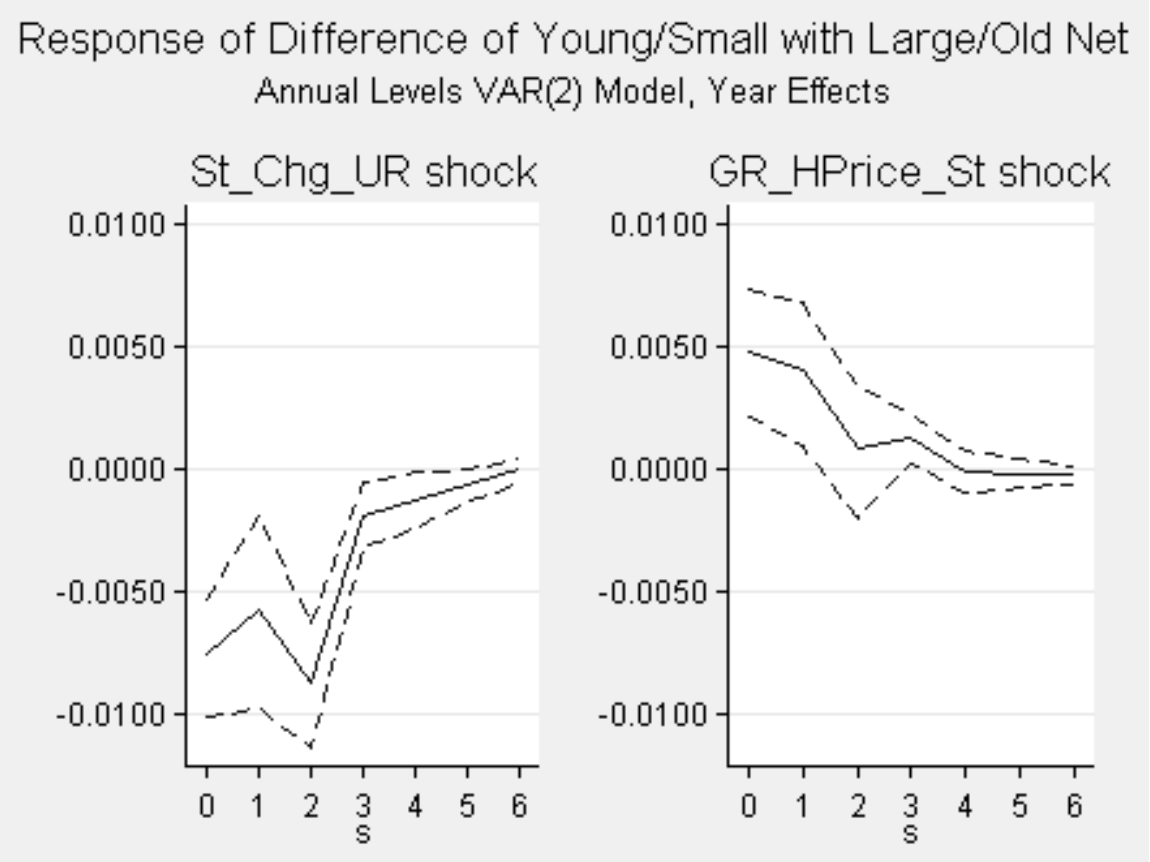

Notes: See Notes to Figure 5.1

Figure 9.d Net Differential Response for Wholesale Trade

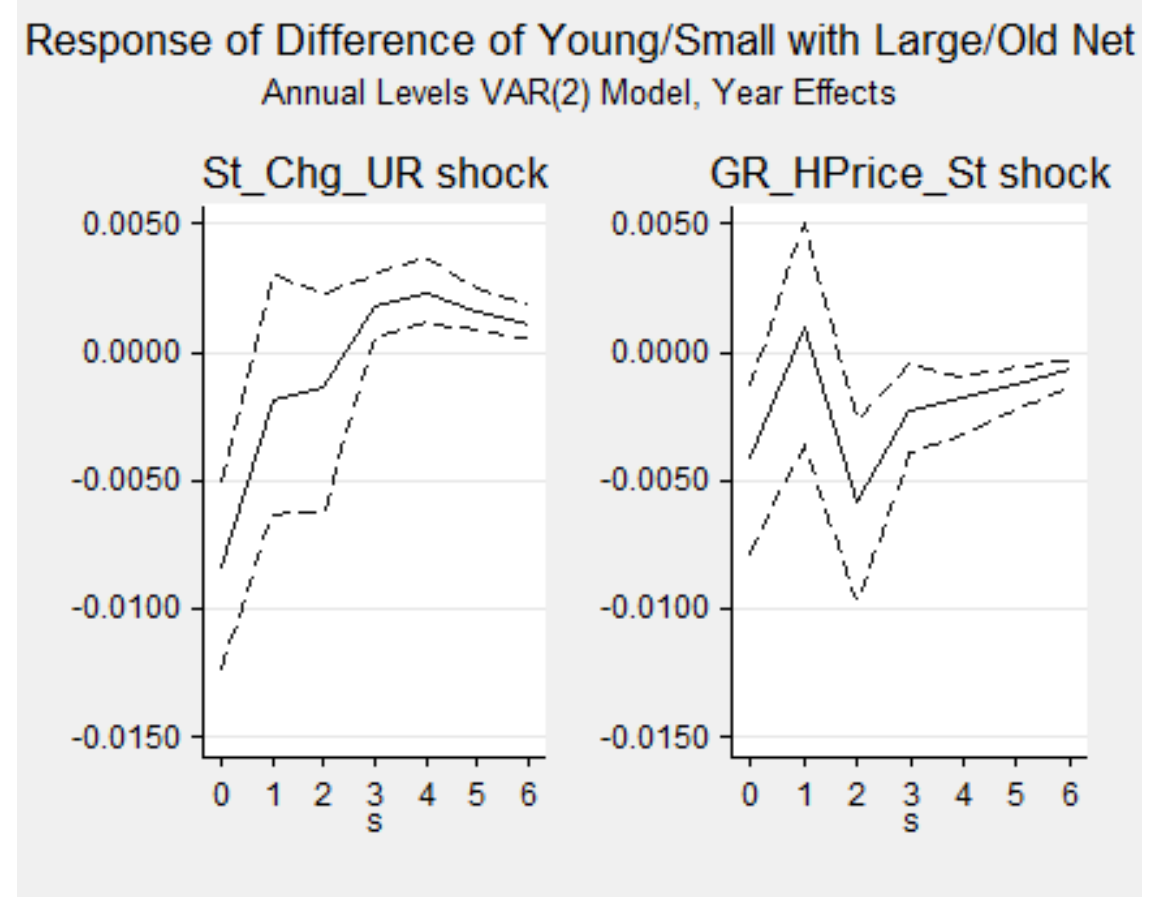

Notes: See Notes to Figure 5.1 
Figure 9.e Net Differential Response for FIRE

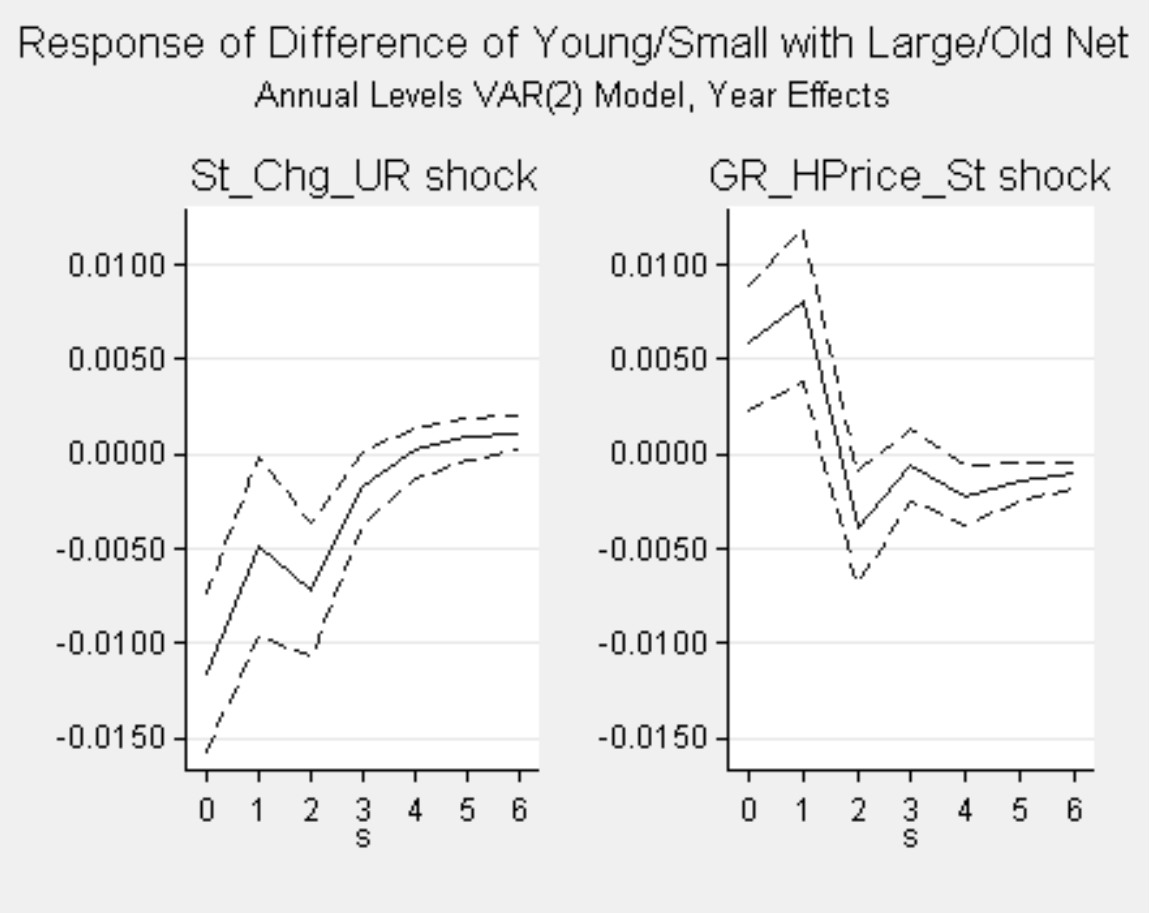

Notes: See Notes to Figure 5.1

Figure 9.f Net Differentials for Services

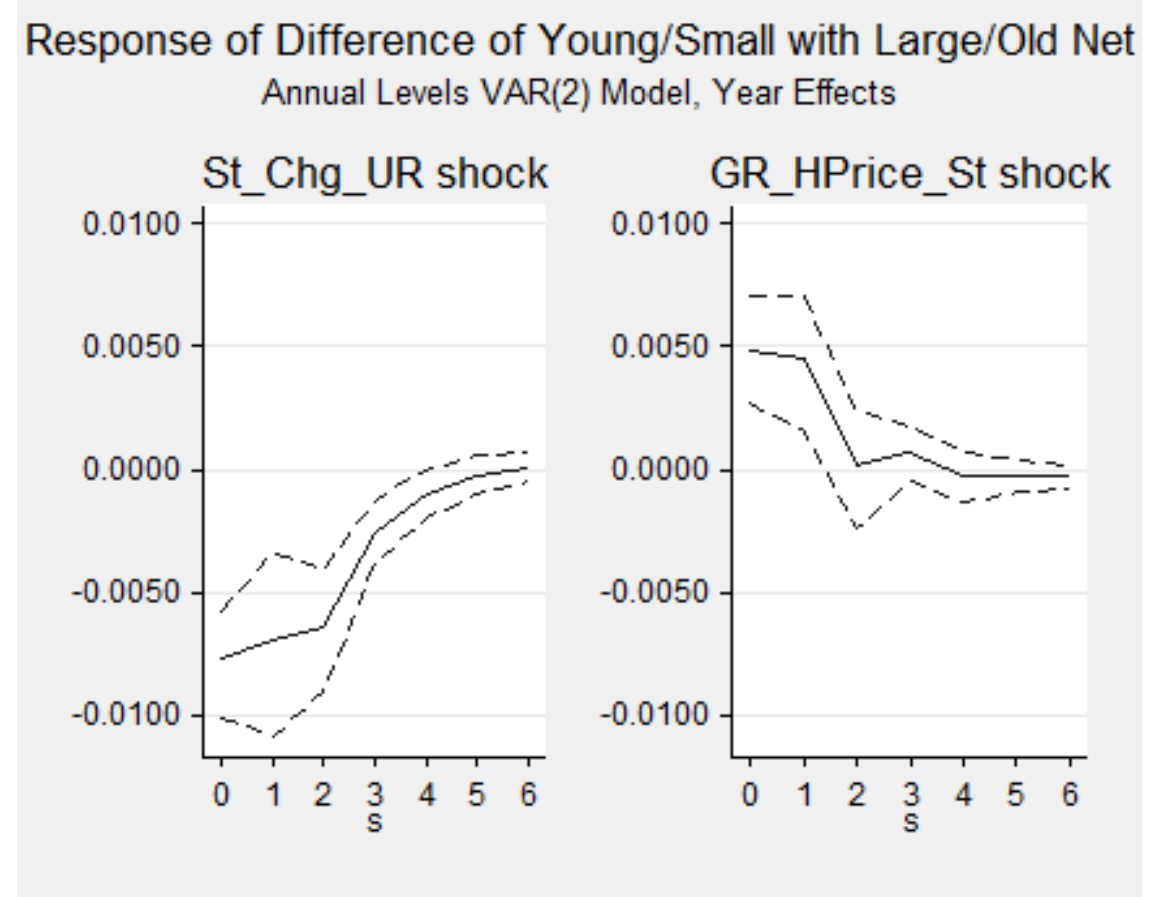

Notes: See Notes to Figure 5.1 
Figure 9.g Net Differential Response for Transportation and Public Utilities

\section{Response of Difference of Young/Small with Large/Old Net Annual Levels VAR(2) Model, Year Effects}
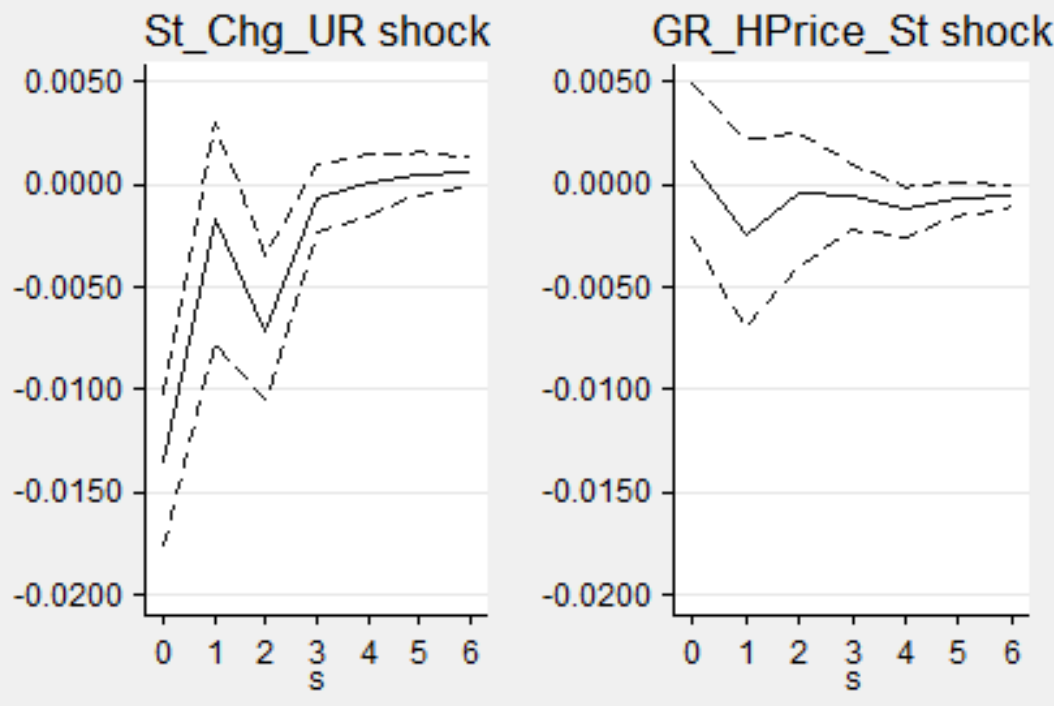

Notes: See Notes to Figure 5.1 
Robustness and Sensitivity Appendix

This appendix provides robustness and sensitivity analysis for the paper "How Firms Respond to Business Cycles: The Role of Firm Age and Firm Size" by Teresa Fort, John Haltiwanger, Ron Jarmin and Javier Miranda. The figures and tables are discussed in the main text of that paper (mostly in footnotes) but are provided here for the sake of brevity.

Figure A.1.1 Components of Net Employment Growth by Broad Firm Size and Age Classes

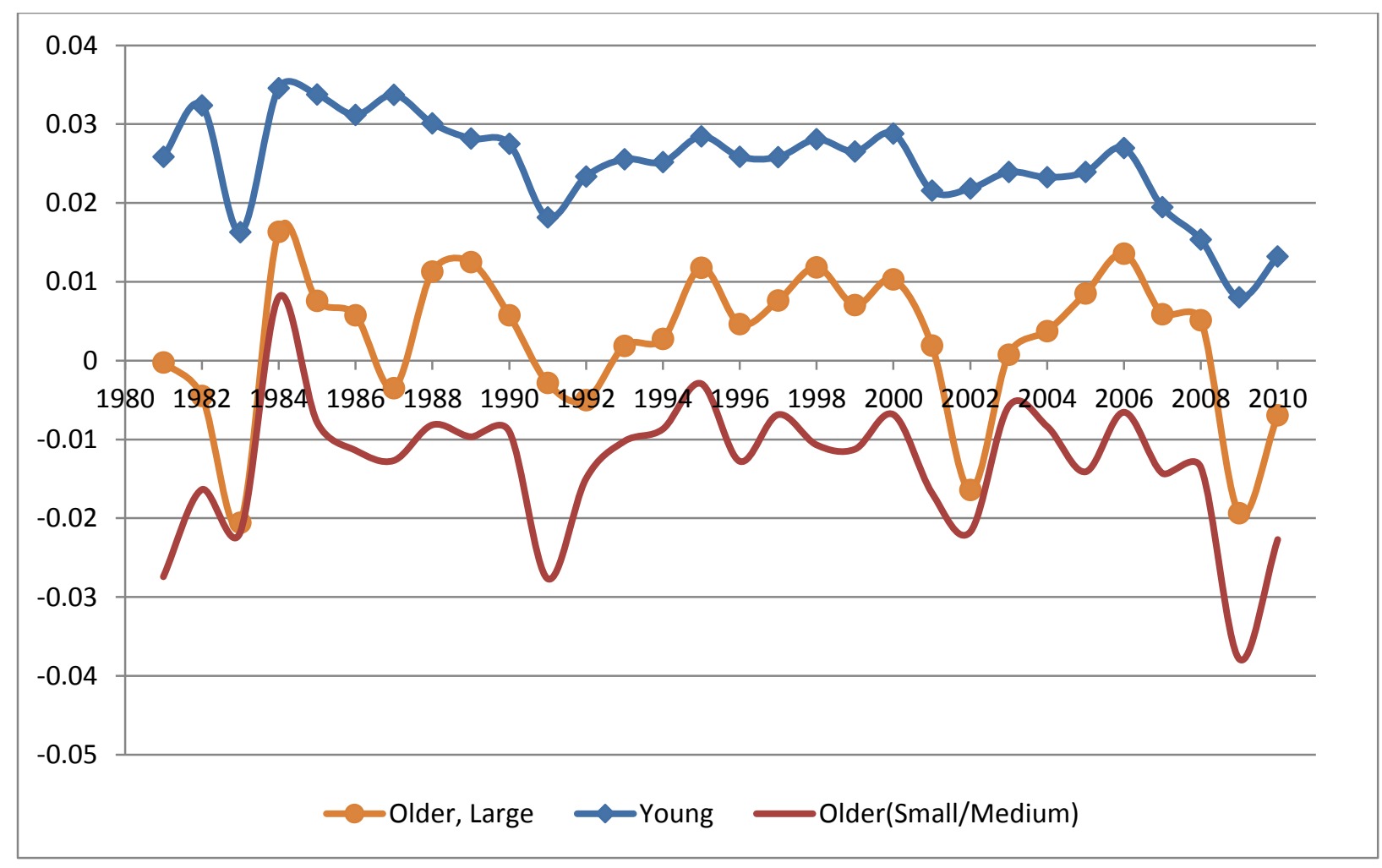

Note: These components are defined as the ratio of net employment for the reported group divided by economy-wide employment (using the DHS denominator). This implies that the components sum to aggregate net employment growth. Each component is equivalent to the net growth rate of the reported group multiplied by the employment share for the group. Young is for firms less than five years old, Small/Medium is less than 500 employees. Older, Large is for firms 5 or more years old and with 500 or more employees. 
Figure A.1.2 Components of Net Employment Growth by Broad Firm Size and Age Classes where Young is Defined as Firms Less than 10 Years Old

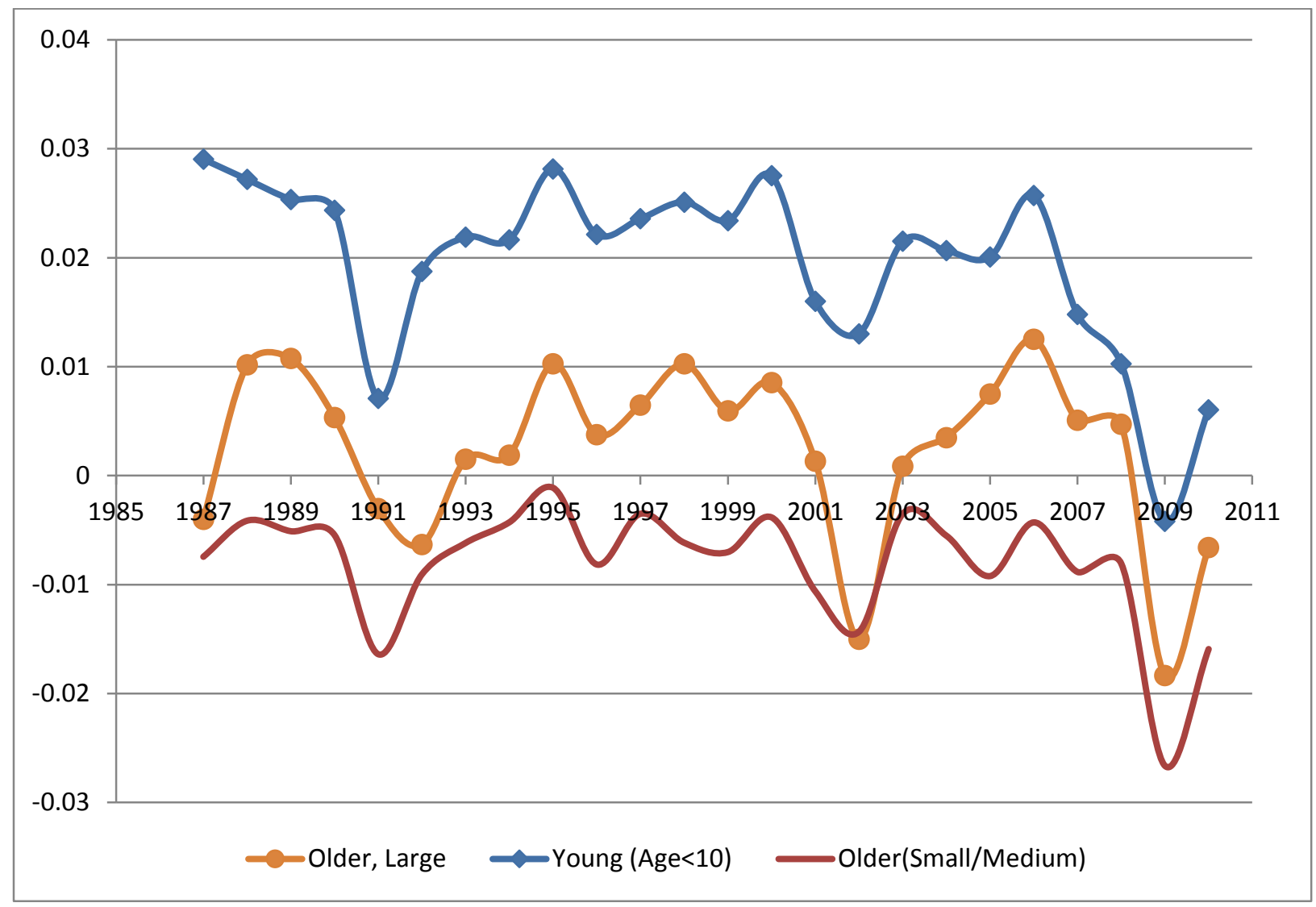

Note: These components are defined as the ratio of net employment for the reported group divided by economy-wide employment (using the DHS denominator). This implies that the components sum to aggregate net employment growth. Each component is equivalent to the net growth rate of the reported group multiplied by the employment share for the group. Note that size groups are defined as in main text (Small<20, Medium 20 to 499, Large 500+) but young represents firms 10 years or less years old. 
Figure A.2.1 Using State Net Employment Growth as Cyclical Indicator

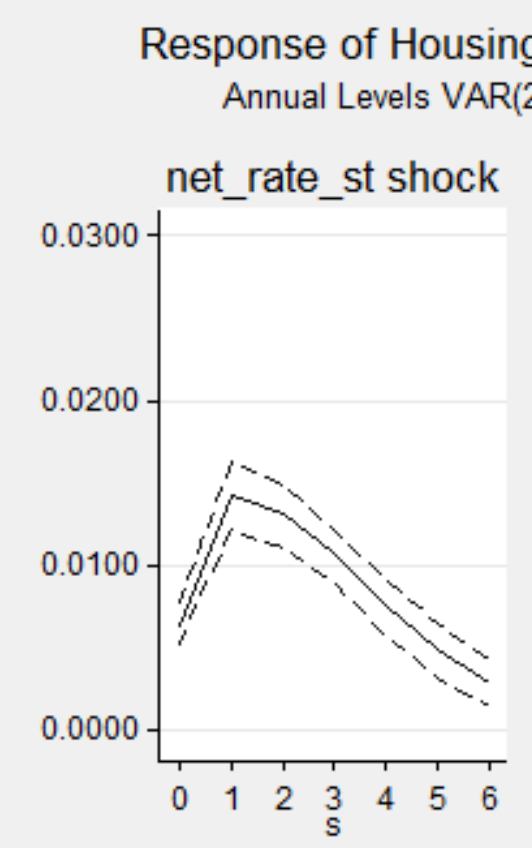

\section{Prices at State Level}


Figure A.2.2 Using Net Employment Growth Rate for Cyclical Shock

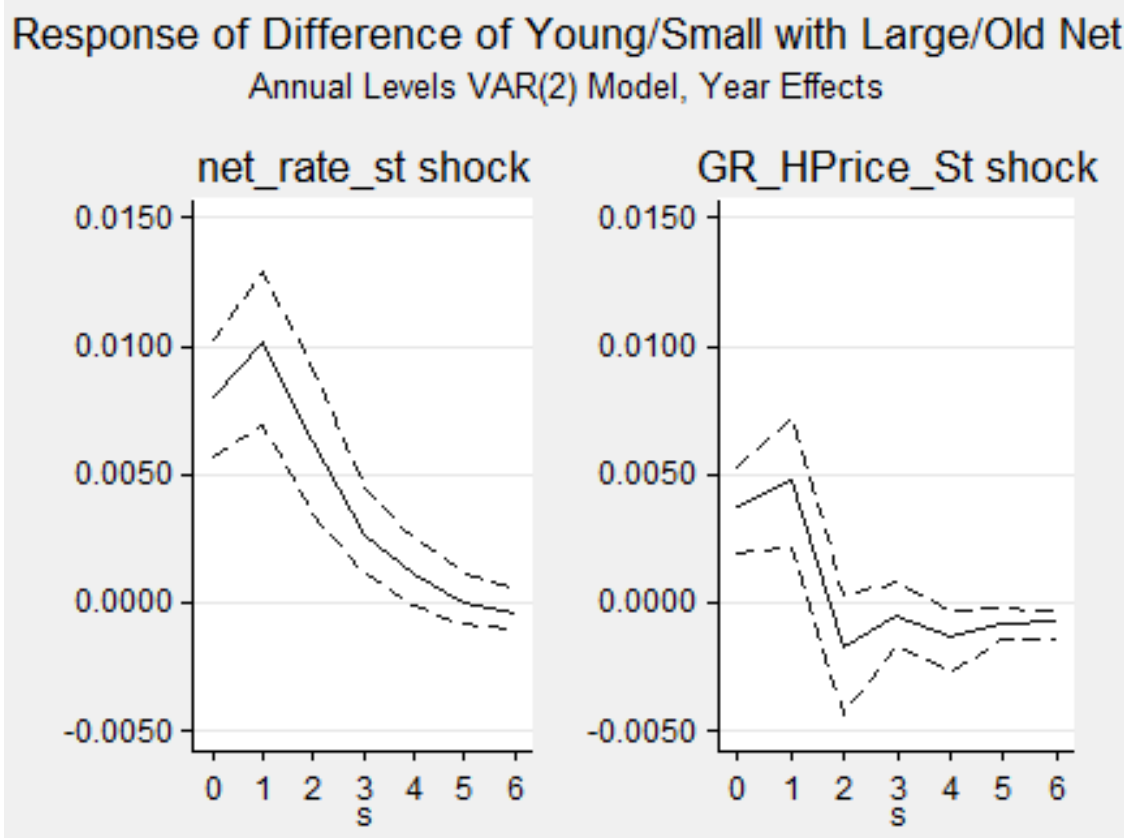

Figure A.2.3 Using Net Employment Growth Rate for Cyclical Shock

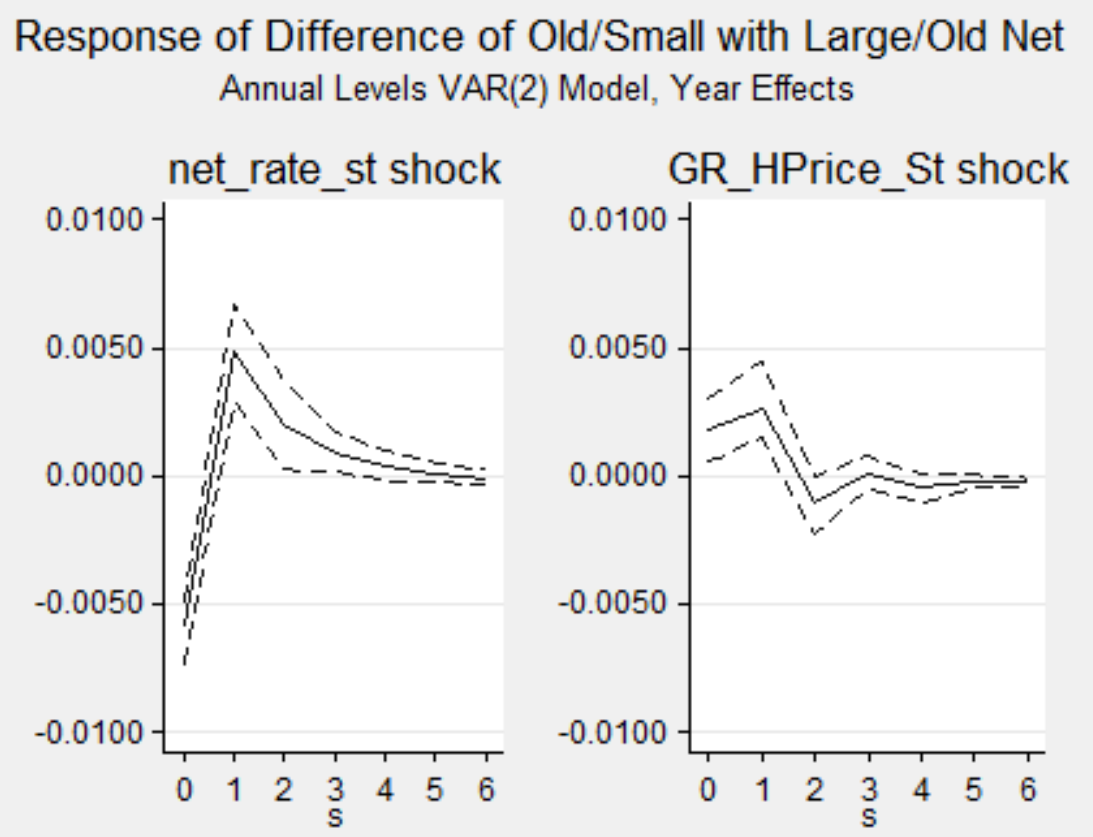


Figure A.2.4 Using HP-filtered State Unemployment Rate

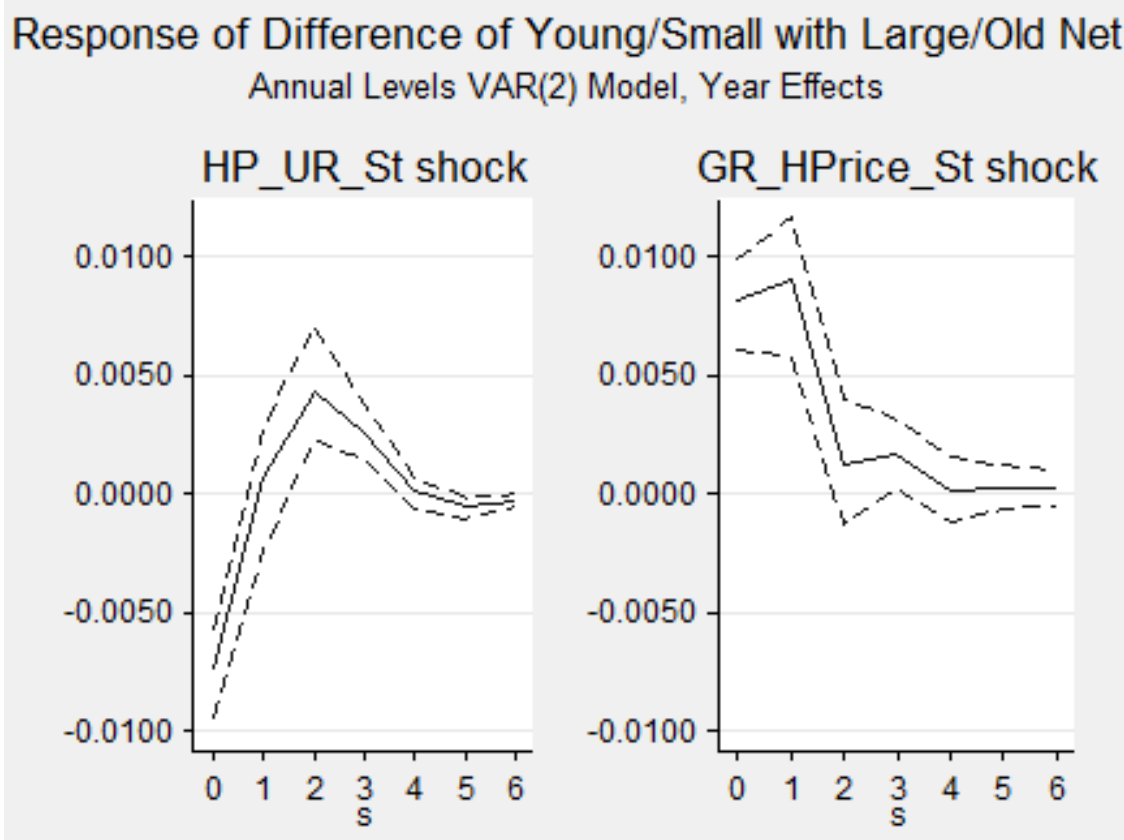

Figure A.2.5 Using HP-filtered State Unemployment Rate

Response of Difference of Old/Small with Large/Old Net Annual Levels VAR(2) Model, Year Effects
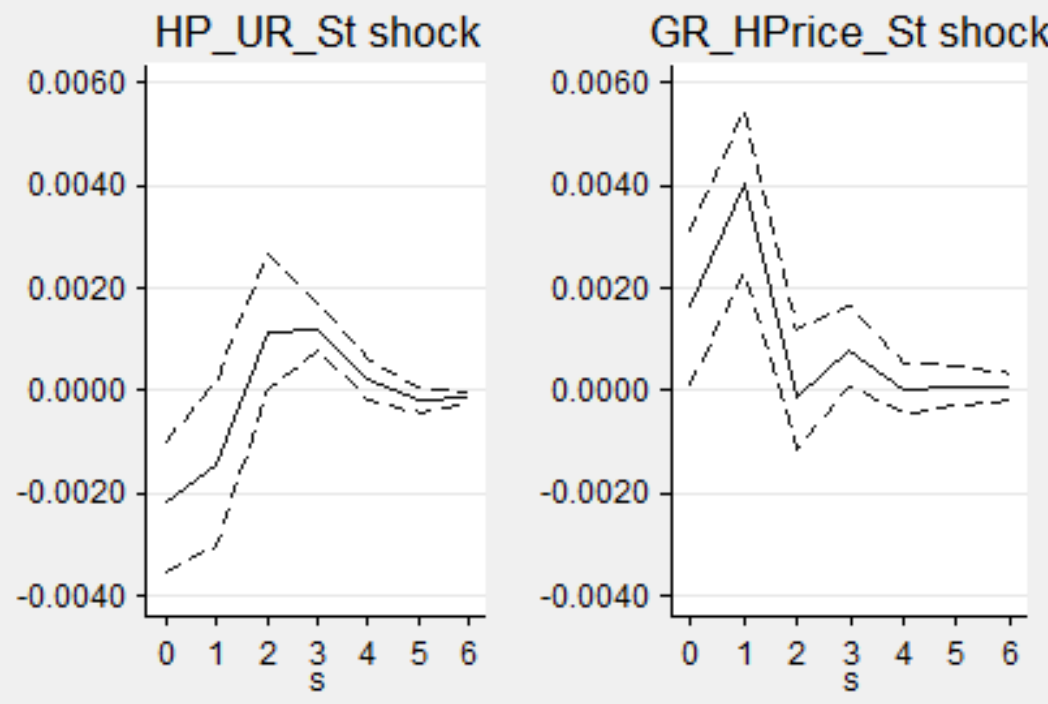
Figure A.2.6.a Putting State Housing Prices Last in Causal Ordering

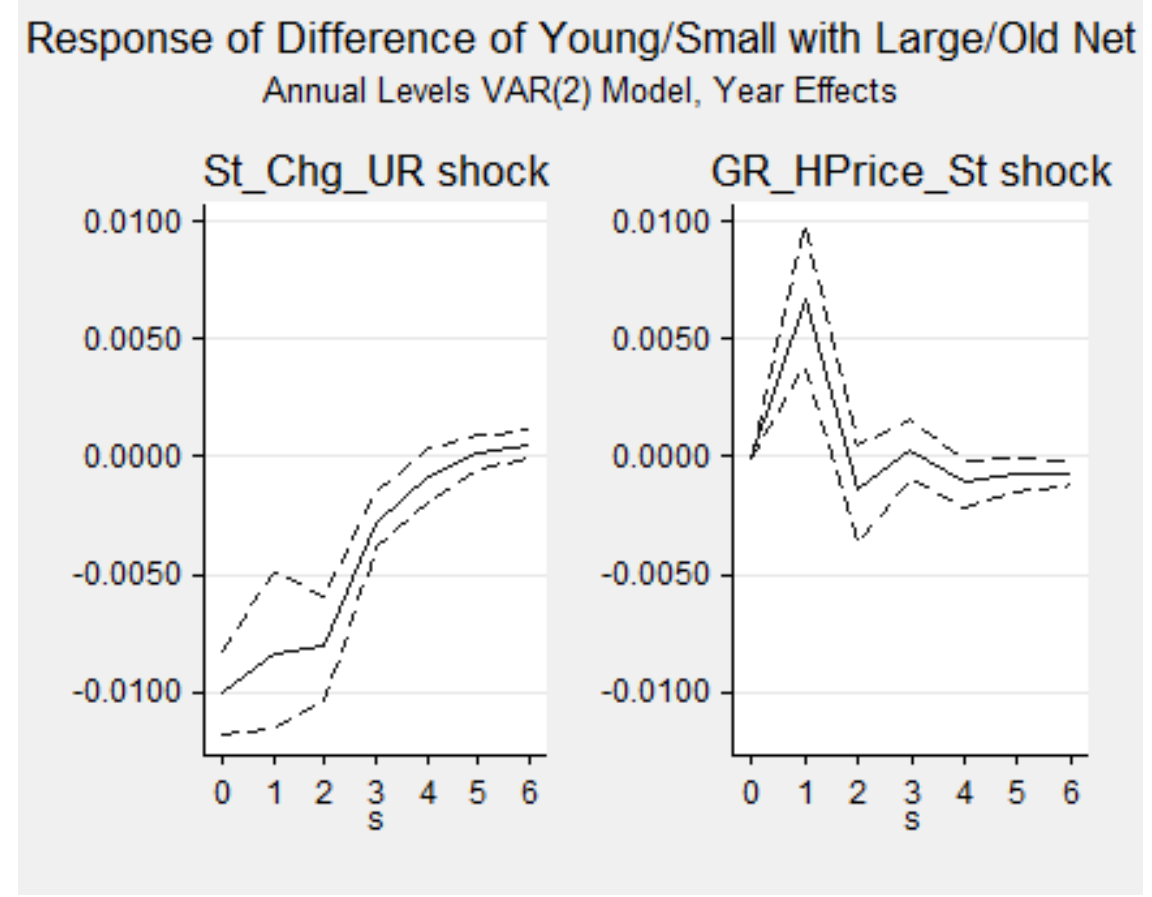

Figure A.2.6.b Putting State Housing Prices Last in Causal Ordering

Response of Difference of Old/Small with Large/Old Net Annual Levels VAR(2) Model, Year Effects
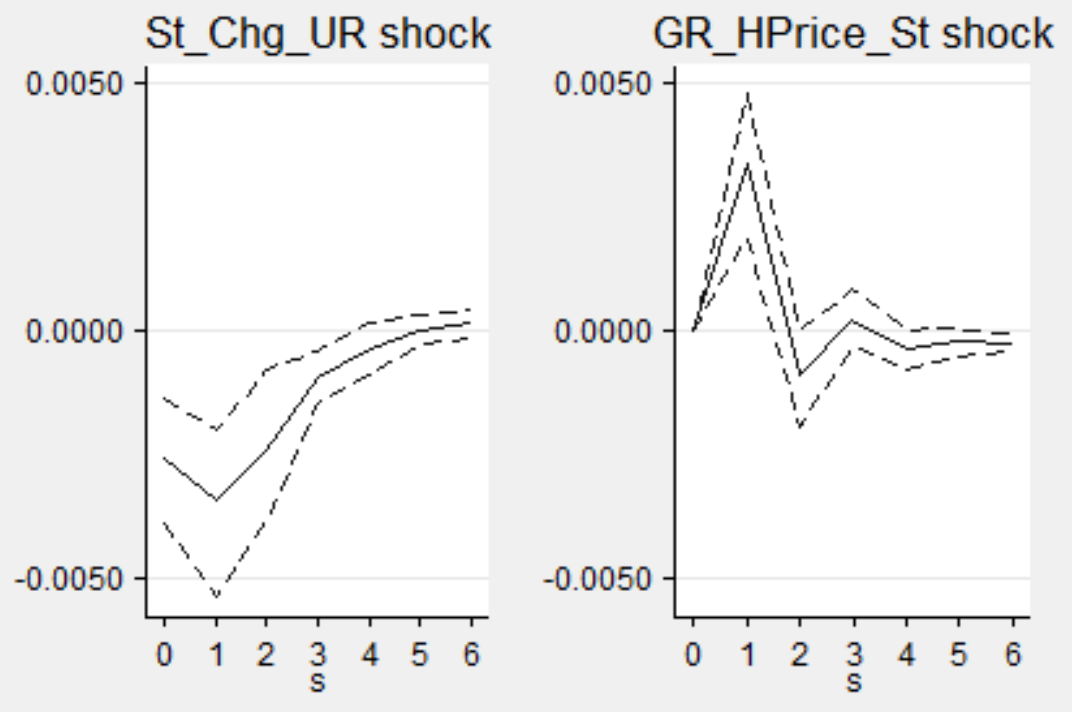
Figure A.2.7 Using Initial Size

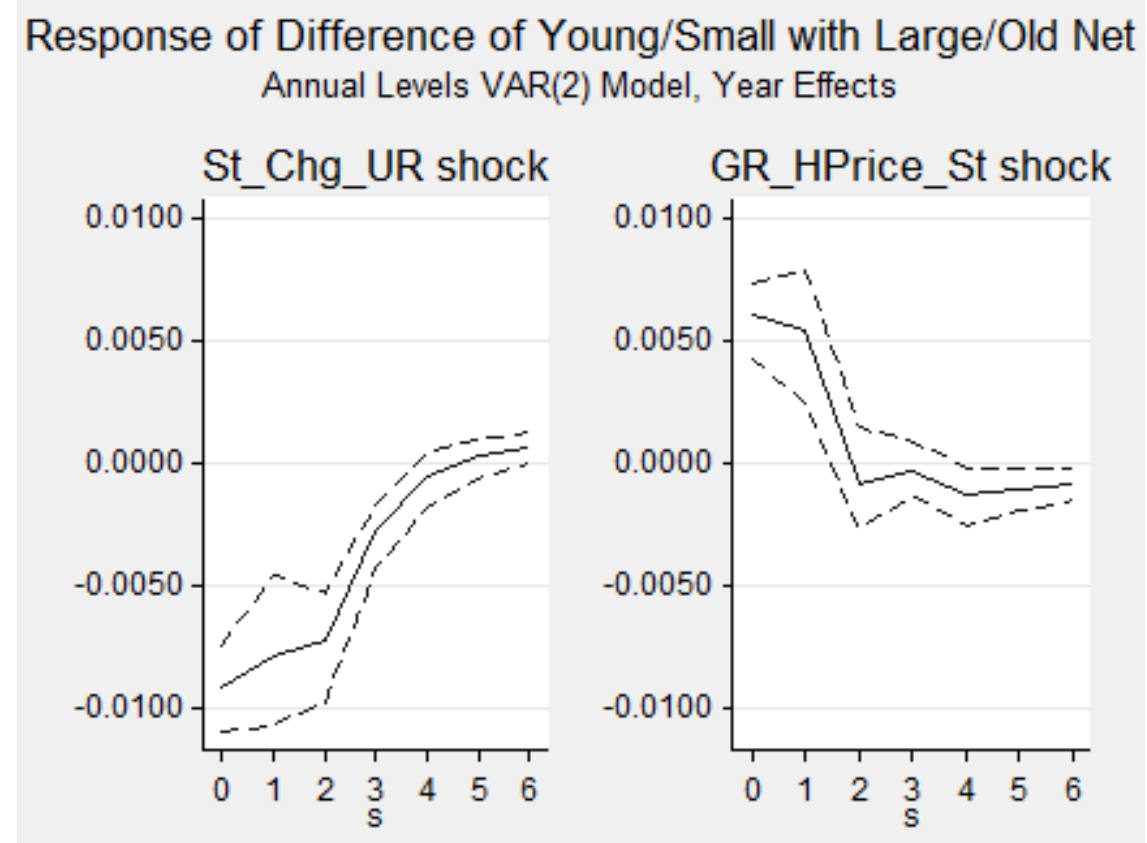

Figure A.2.8 Job Creation Differential Response for Young/Small

Response of Difference of Young/Small with Large/Old Net Annual Levels VAR(2) Model, Year Effects
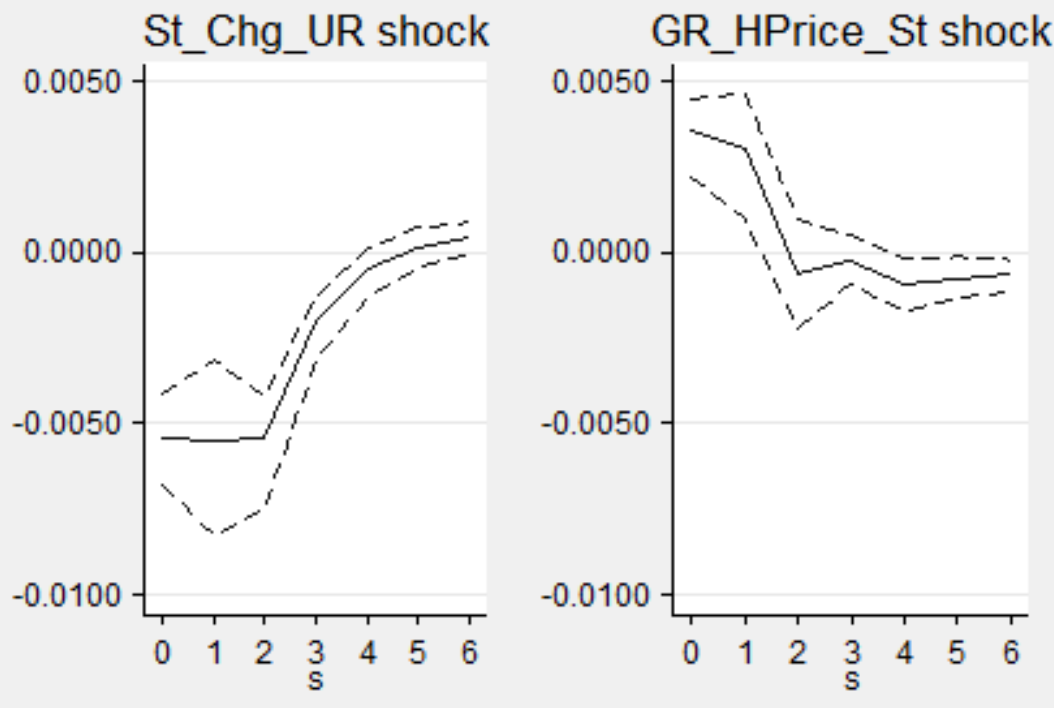

Notes: See Notes to Figure 5.1 
Figure A.2.9 Job Destruction Differential Response for Young/Small
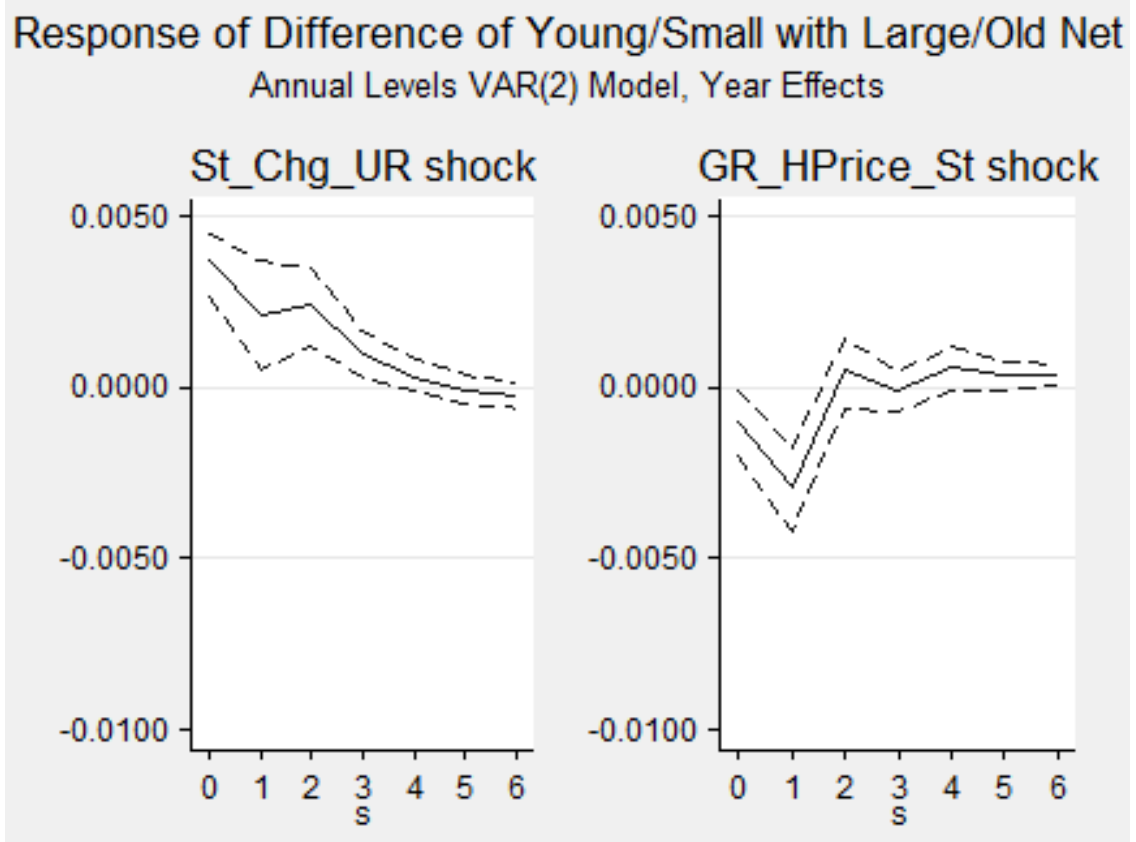

Figure A.2.10 Job Creation Differential Response for Young/Medium

Reponse of Difference of Young/Medium with Large/Old Nel Annual Levels VAR(2) Model, Year Effects
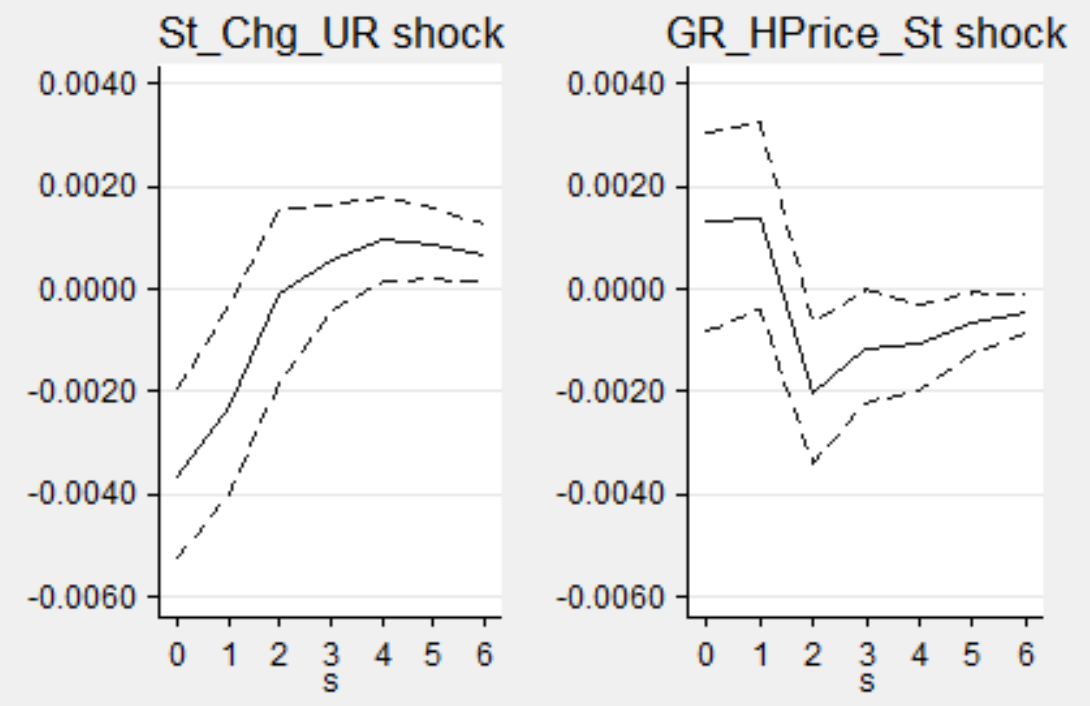
Figure A.2.11 Job Destruction Differential Response for Young/Medium

Reponse of Difference of Young/Medium with Large/Old Nel Annual Levels VAR(2) Model, Year Effects
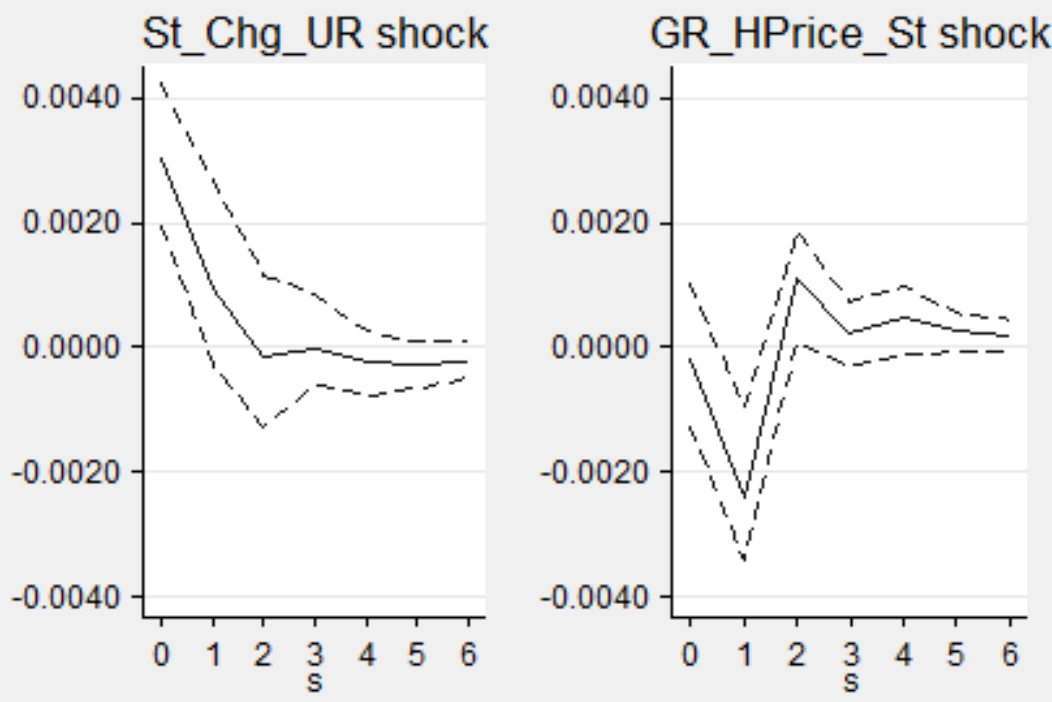
Figure A.2.12 Using only Firm Age, Net Differential Response for Young (<5) Minus Old (5+)

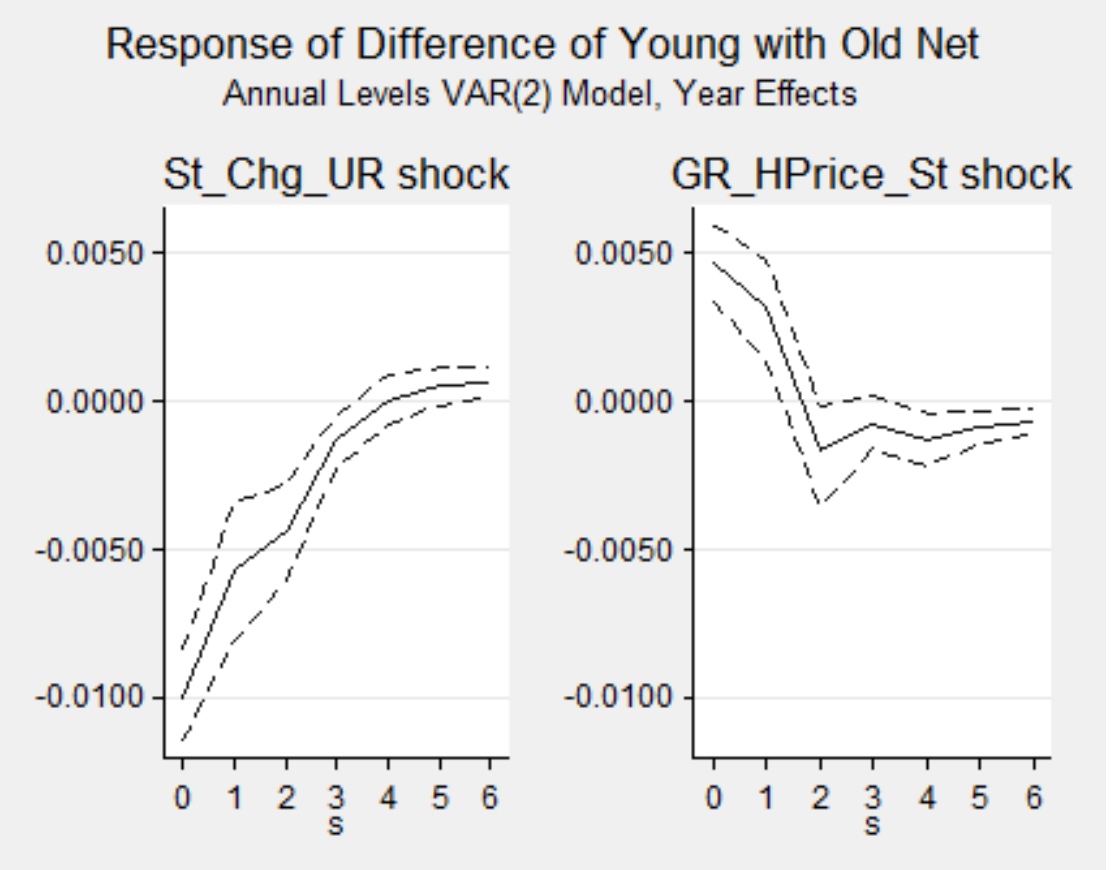

Figure A.2.13 Using only Firm Size, Net Differential Response for Small/Medium $(<500)$ Minus Large $(500+)$

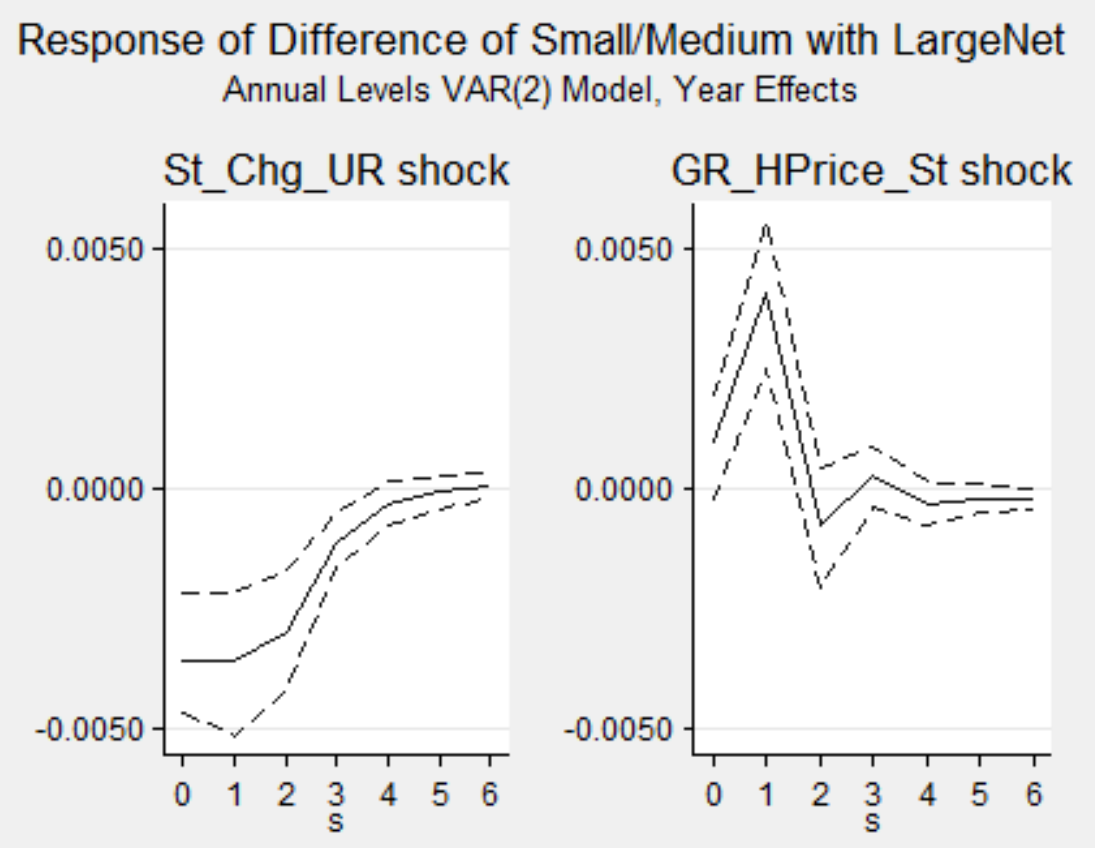


Figure A.2.14 Using Real GDP Growth Rates

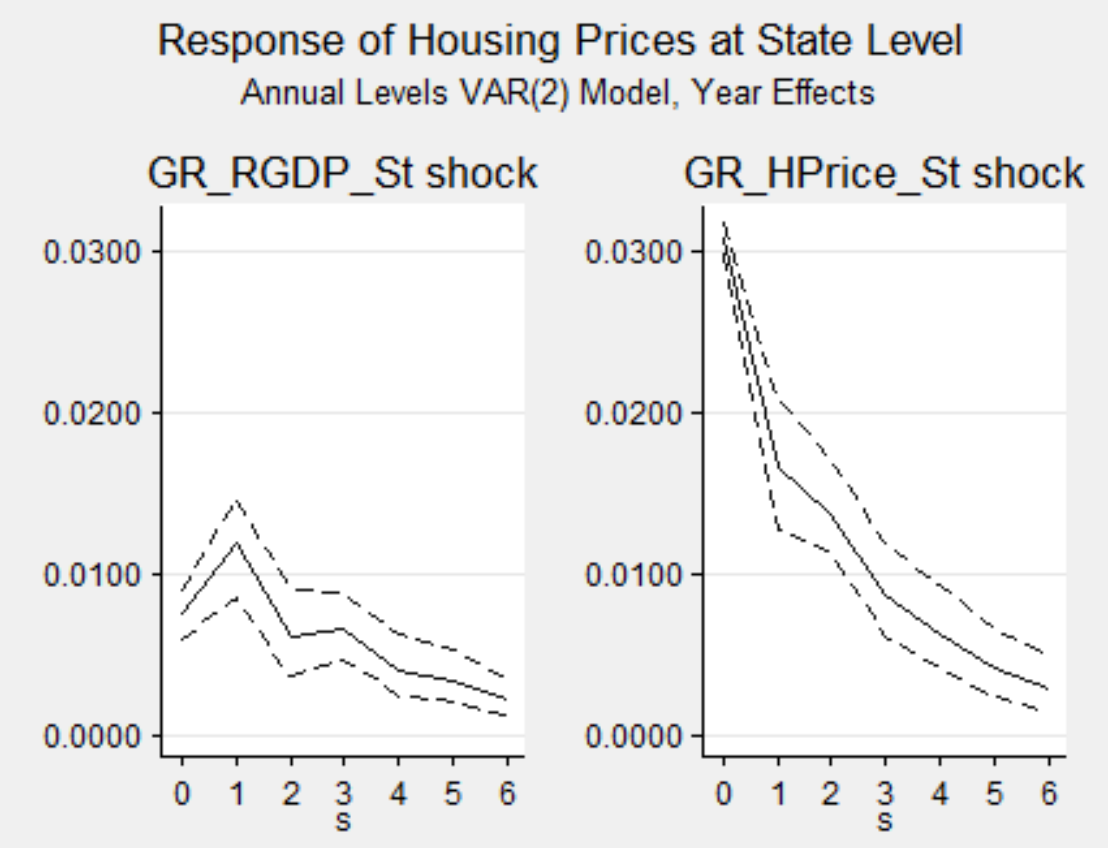


Figure A.2.15 Using Real GDP Growth Rates

\section{Response of Difference of Young/Small with Large/Old Net}

Annual Levels VAR(2) Model, Year Effects
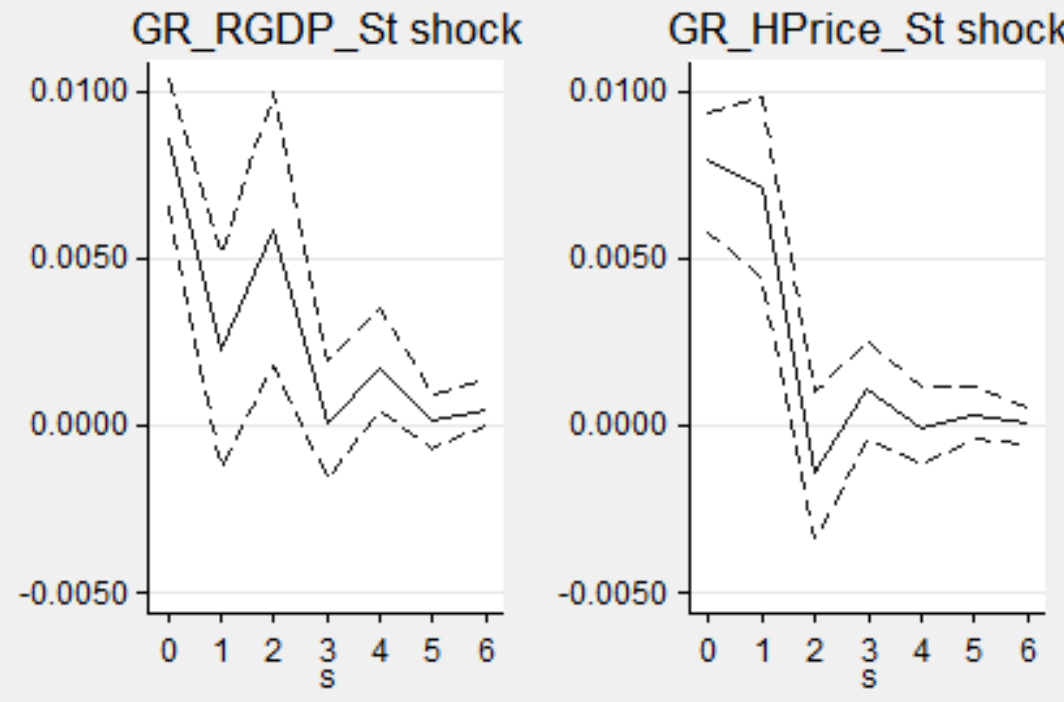

Figure A.2.16 Using Real GDP Growth Rates

Response of Difference of Old/Small with Large/Old Net Annual Levels VAR(2) Model, Year Effects
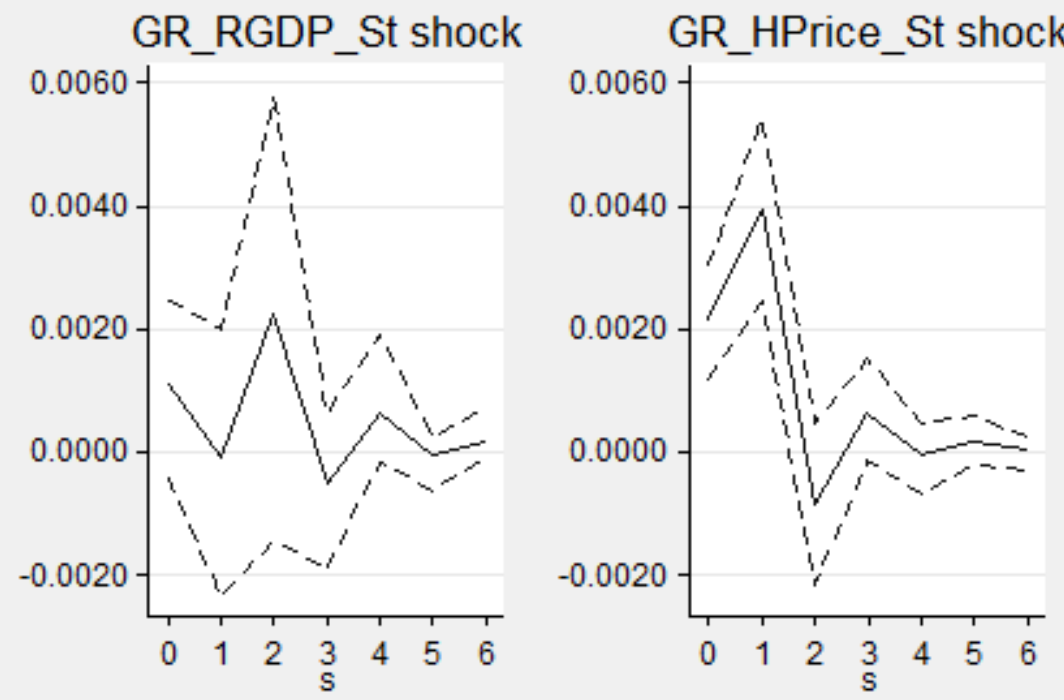
Figure A.2.17 Using Real Personal Income Growth Rates

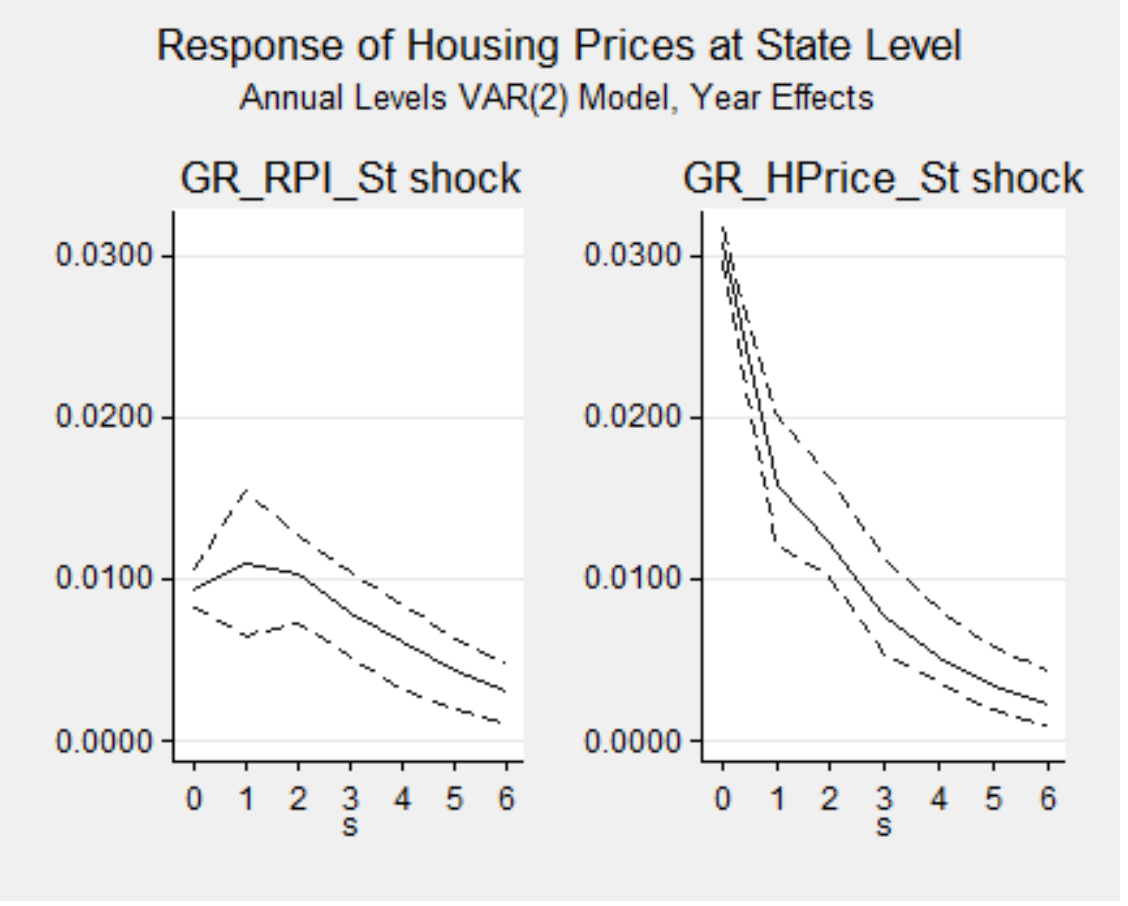

Figure A.2.18 Using Real Personal Income Growth Rates

Response of Difference of Young/Small with Large/Old Net Annual Levels VAR(2) Model, Year Effects
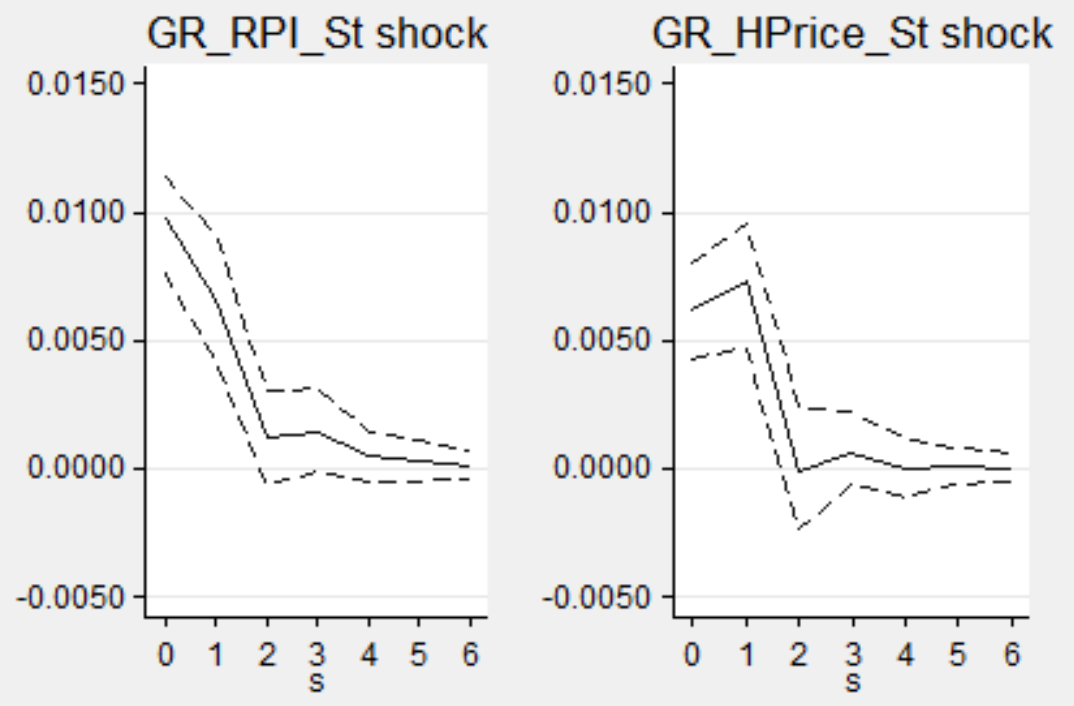
Figure A.2.19 Using Growth Rates in Real Personal Income

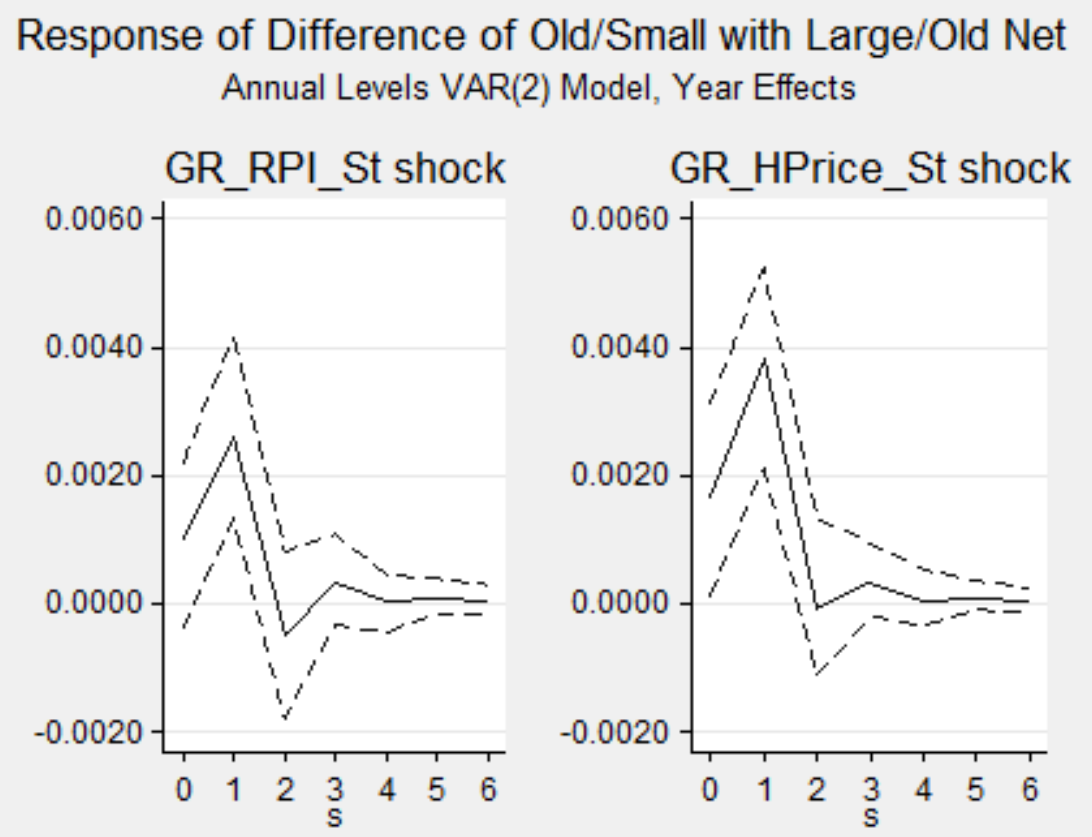


Table A.1. Descriptive Regressions at the National Level Using Real GDP

\begin{tabular}{|c|c|c|c|c|c|c|}
\hline & (1) & (2) & (3) & (4) & (5) & (6) \\
\hline & Net_Rate_All & net_rate_11 & net_rate_21 & net_rate_12 & net_rate_22 & net_rate_32 \\
\hline \multirow{3}{*}{$\begin{array}{l}\text { Real GDP } \\
\text { Growth }\end{array}$} & $0.821^{* * *}$ & $1.087^{* * *}$ & $0.880^{* *}$ & $0.480^{*}$ & $0.820^{* * *}$ & $0.710^{* * *}$ \\
\hline & & & & $(\rho 170)$ & $(0,150)$ & $(0120)$ \\
\hline & $(0.108)$ & $(0.269)$ & $(0.285)$ & $(0.179)$ & $(0.158)$ & $(0.130)$ \\
\hline \multirow[t]{2}{*}{ Int_Rt_Sprd } & $-0.481^{*}$ & -0.317 & $-1.037^{*}$ & -0.227 & $-0.603^{*}$ & $-0.475^{*}$ \\
\hline & $(0.185)$ & $(0.460)$ & $(0.487)$ & $(0.306)$ & $(0.271)$ & $(0.222)$ \\
\hline \multirow[t]{2}{*}{ GR_HPrice_st } & 0.023 & $0.466^{* *}$ & $0.308^{*}$ & 0.117 & 0.038 & -0.024 \\
\hline & $(0.052)$ & $(0.130)$ & $(0.137)$ & $(0.086)$ & $(0.076)$ & $(0.063)$ \\
\hline$N$ & 30 & 30 & 30 & 30 & 30 & 30 \\
\hline
\end{tabular}

Standard errors in parentheses

${ }^{*} p<0.05,{ }^{* *} p<0.01,{ }^{* * *} p<0.001$

Table A.2 Correlations Between Cyclical Indicators and Net Differential Employment Growth Rates (Using Initial Size)

\begin{tabular}{|c|c|c|c|c|c|c|c|c|}
\hline & \multirow{2}{*}{\multicolumn{2}{|c|}{ Change in Unemp Rate }} & \multirow{2}{*}{\multicolumn{2}{|c|}{ Net Emp. Growth Rate }} & \multirow{2}{*}{\multicolumn{2}{|c|}{ Real GDP Growth }} & \multirow{2}{*}{\multicolumn{2}{|c|}{ HP Filtered Unemp Rate }} \\
\hline & & & & & & & & \\
\hline & $1981-2010$ & 1981-2006 & 1981-2010 & 1981-2006 & $1981-2010$ & $1981-2006$ & $1981-2010$ & $1981-2006$ \\
\hline \multirow[t]{2}{*}{ Young/Small-Older/Large } & -0.448 & -0.302 & 0.557 & 0.272 & 0.548 & 0.345 & 0.268 & 0.232 \\
\hline & $(0.013)$ & $(0.134)$ & $(0.001)$ & $(0.180)$ & $(0.002)$ & $(0.085)$ & $(0.152)$ & $(0.255)$ \\
\hline \multirow[t]{2}{*}{ Young/Medium-Older/Large } & -0.322 & -0.247 & 0.453 & 0.249 & 0.327 & 0.306 & 0.121 & -0.051 \\
\hline & $(0.083)$ & $(0.224)$ & $(0.012)$ & $(0.220)$ & $(0.078)$ & $(0.129)$ & $(0.523)$ & $(0.805)$ \\
\hline \multirow[t]{2}{*}{ Older/Small-Older/Large } & 0.163 & 0.312 & 0.037 & -0.237 & 0.030 & -0.185 & 0.564 & 0.594 \\
\hline & $(0.389)$ & $(0.121)$ & $(0.845)$ & $(0.244)$ & $(0.875)$ & $(0.365)$ & $(0.001)$ & $(0.001)$ \\
\hline \multirow[t]{2}{*}{ Older/Medium-Older/Large } & -0.21 & -0.085 & 0.395 & 0.243 & 0.437 & 0.187 & 0.415 & 0.544 \\
\hline & $(0.266)$ & $(0.680)$ & $(0.031)$ & $(0.233)$ & $(0.016)$ & 0.361 & $(0.023)$ & $(0.004)$ \\
\hline \multicolumn{2}{|c|}{ Note: P-values in parentheses. } & & & & & & & \\
\hline
\end{tabular}


Table A.3 Descriptive Regressions at State Level, Using the Net Employment Growth Rate at state level as the cyclical indicator (Controlling for State and Year Fixed Effects)

Bivariate

\begin{tabular}{|c|c|c|c|c|}
\hline & $(1)$ & $(2)$ & $(3)$ & $(4)$ \\
\hline & diff_net_rate_11 & diff_net_rate_21 & diff_net_rate_12 & diff_net_rate_22 \\
\hline net_rate_st & $0.559^{* * * *}$ & $0.224^{* * *}$ & $-0.241^{* * *}$ & $-0.209^{* * *}$ \\
\hline & $(0.058)$ & $(0.068)$ & $(0.038)$ & $(0.038)$ \\
\hline
\end{tabular}

Multivariate

\begin{tabular}{|l|c|c|c|c|}
\hline & $(1)$ & $(2)$ & $(3)$ & $(4)$ \\
\hline & diff_net_rate_11 & diff_net_rate_21 & diff_net_rate_12 & diff_net_rate_22 \\
\hline net_rate_st & $0.444^{* * *}$ & $0.182^{*}$ & $-0.320^{* * * *}$ & $-0.263^{* * *}$ \\
\hline & $(0.061)$ & $(0.072)$ & $(0.040)$ & $(0.040)$ \\
\hline GR_HPrice_st & $0.165^{* * *}$ & 0.061 & $0.115^{* * *}$ & $0.078^{* * *}$ \\
\hline & $(0.028)$ & $(0.034)$ & $(0.019)$ & $(0.019)$ \\
\hline$N$ & 1530 & 1530 & 1530 & 1530 \\
\hline
\end{tabular}

Standard errors in parentheses

${ }^{*} p<0.05,{ }^{* *} p<0.01,{ }^{* * *} p<0.001$ Note 11=Young/Small, 21=Young/Medium, 12=Old/Small, 22=Old/Medium.

All net differentials are with respect to Old/Large.

Table A.4 Descriptive Regressions at State Level, Using the Change in Unemployment Rate at state level as the cyclical indicator (Controlling for State Fixed Effects Only)

Bivariate

\begin{tabular}{|l|c|c|c|c|}
\hline & $(1)$ & $(2)$ & $(3)$ & $(4)$ \\
\hline & diff_net_rate_11 & diff_net_rate_21 & diff_net_rate_12 & diff_net_rate_22 \\
\hline Chg_UR_st & $-1.719^{* * * *}$ & $-1.046^{* * *}$ & $0.219^{*}$ & $-0.409^{* * *}$ \\
\hline & $(0.135)$ & $(0.147)$ & $(0.088)$ & $(0.074)$ \\
\hline
\end{tabular}

Multivariate

\begin{tabular}{|l|c|c|c|c|}
\hline & $(1)$ & $(2)$ & $(3)$ & $(4)$ \\
\hline & diff_net_rate_11 & diff_net_rate_21 & diff_net_rate_12 & diff_net_rate_22 \\
\hline Chg_UR_st & $-1.131^{* * *}$ & $-0.699^{* * *}$ & $0.421^{* * *}$ & $-0.303^{* * *}$ \\
\hline & $(0.138)$ & $(0.156)$ & $(0.093)$ & $(0.079)$ \\
\hline GR_HPrice_st & $0.309^{* * *}$ & $0.182^{* * *}$ & $0.106^{* * *}$ & $0.055^{* * *}$ \\
\hline & $(0.026)$ & $(0.030)$ & $(0.018)$ & $(0.015)$ \\
\hline$N$ & 1530 & 1530 & 1530 & 1530 \\
\hline
\end{tabular}

Standard errors in parentheses

${ }^{*} p<0.05,{ }^{* *} p<0.01,{ }^{* * *} p<0.001$ Note 11=Young/Small, 21=Young/Medium, 12=Old/Small, 22=Old/Medium.

All net differentials are with respect to Old/Large. 
Table A.5 Descriptive Regressions at State Level (Controlling for State and Year Fixed Effects) - Using State-Level Change in Unemployment Rate as Cyclical Indicator and Initial Firm Size

Bivariate

\begin{tabular}{|l|c|c|c|c|}
\hline & $(1)$ & $(2)$ & $(3)$ & $(4)$ \\
\hline & diff_net_rate_11 & diff_net_rate_21 & diff_net_rate_12 & diff_net_rate_22 \\
\hline Chg_UR_st & $-2.168^{* * *}$ & $-1.530^{* * *}$ & $-0.600^{* * * *}$ & $-0.659^{* * * *}$ \\
\hline & $(0.195)$ & $(0.271)$ & $(0.136)$ & $(0.137)$ \\
\hline
\end{tabular}

Multivariate

\begin{tabular}{|l|c|c|c|c|}
\hline & $(1)$ & $(2)$ & $(3)$ & $(4)$ \\
\hline & diff_net_rate_11 & diff_net_rate_21 & diff_net_rate_12 & diff_net_rate_22 \\
\hline Chg_UR_st & $-1.846^{* * *}$ & $-1.496^{* * *}$ & $-0.495^{* * * *}$ & $-0.596^{* * * *}$ \\
\hline & $(0.195)$ & $(0.277)$ & $(0.139)$ & $(0.140)$ \\
\hline GR_HPrice_st & $0.203^{* * *}$ & 0.022 & $0.066^{* * *}$ & $0.039^{*}$ \\
\hline & $(0.025)$ & $(0.035)$ & $(0.018)$ & $(0.018)$ \\
\hline$N$ & 1530 & 1530 & 1530 & 1530 \\
\hline
\end{tabular}

Standard errors in parentheses

${ }^{*} p<0.05,{ }^{* *} p<0.01,{ }^{* * *} p<0.001$ Note 11=Young/Small, 21=Young/Medium, 12=Old/Small, 22=Old/Medium. All net differentials are with respect to Old/Large.

Table A.6 Descriptive Regressions at State Level, Using the Real GDP Growth Rate at state level as the cyclical indicator (Controlling for State and Year Fixed Effects)

Bivariate

\begin{tabular}{|l|c|c|c|c|}
\hline & $(1)$ & $(2)$ & $(3)$ & $(4)$ \\
\hline & diff_net_rate_11 & diff_net_rate_21 & diff_net_rate_12 & diff_net_rate_22 \\
\hline GR_GDP_st & $0.338^{* * *}$ & $0.158^{* * *}$ & 0.029 & 0.036 \\
\hline & $(0.040)$ & $(0.047)$ & $(0.027)$ & $(0.026)$ \\
\hline
\end{tabular}

Multivariate

\begin{tabular}{|l|c|c|c|c|}
\hline & $(1)$ & $(2)$ & $(3)$ & $(4)$ \\
\hline & diff_net_rate_11 & diff_net_rate_21 & diff_net_rate_12 & diff_net_rate_22 \\
\hline GR_GDP_st & $0.246^{* * *}$ & $0.127^{*}$ & -0.008 & 0.018 \\
\hline & $(0.042)$ & $(0.050)$ & $(0.028)$ & $(0.028)$ \\
\hline GR_HPrice_st & $0.171^{* * *}$ & 0.057 & $0.068^{* * * *}$ & 0.033 \\
\hline & $(0.029)$ & $(0.034)$ & $(0.019)$ & $(0.019)$ \\
\hline$N$ & 1530 & 1530 & 1530 & 1530 \\
\hline
\end{tabular}

Standard errors in parentheses

${ }^{*} p<0.05,{ }^{* *} p<0.01,{ }^{* * *} p<0.001$ Note 11=Young/Small, 21=Young/Medium, 12=Old/Small,

$22=\mathrm{Old} /$ Medium. All net differentials are with respect to Old/Large. 
Table A.7 Descriptive Regressions at State Level, Using the Real Personal Income Growth Rate at state level as the cyclical indicator (Controlling for State and Year Fixed Effects)

Bivariate

\begin{tabular}{|l|c|c|c|c|}
\hline & $(1)$ & $(2)$ & $(3)$ & $(4)$ \\
\hline & diff_net_rate_11 & diff_net_rate_21 & diff_net_rate_12 & diff_net_rate_22 \\
\hline GR_RPI_st & $0.658^{* * *}$ & $0.391^{* * *}$ & $0.114^{*}$ & 0.068 \\
\hline & $(0.066)$ & $(0.078)$ & $(0.044)$ & $(0.044)$ \\
\hline
\end{tabular}

Multivariate

\begin{tabular}{|l|c|c|c|c|}
\hline & $(1)$ & $(2)$ & $(3)$ & $(4)$ \\
\hline & diff_net_rate_11 & diff_net_rate_21 & diff_net_rate_12 & diff_net_rate_22 \\
\hline GR_RPI_st & $0.499^{* * *}$ & $0.375^{* * *}$ & 0.045 & 0.030 \\
\hline & $(0.076)$ & $(0.089)$ & $(0.051)$ & $(0.050)$ \\
\hline GR_HPrice_st & $0.133^{* * *}$ & 0.014 & $0.057^{* *}$ & 0.032 \\
\hline & $(0.031)$ & $(0.036)$ & $(0.021)$ & $(0.020)$ \\
\hline$N$ & 1530 & 1530 & 1530 & 1530 \\
\hline
\end{tabular}

Standard errors in parentheses

${ }^{*} p<0.05,{ }^{* *} p<0.01,{ }^{* * *} p<0.001$ Note 11=Young/Small, 21=Young/Medium, 12=Old/Small,

$22=\mathrm{Old} /$ Medium. All net differentials are with respect to Old/Large.

Table A.8 Descriptive Regressions at State Level (Controlling for State and Year Fixed Effects) - Using State-Level Change in Unemployment Rate as Cyclical Indicator, Post-2006 data excluded

Bivariate

\begin{tabular}{|l|c|c|c|c|}
\hline & $(1)$ & $(2)$ & $(3)$ & $(4)$ \\
\hline & diff_net_rate_11 & diff_net_rate_21 & diff_net_rate_12 & diff_net_rate_22 \\
\hline Chg_UR_st & $-2.145^{* * *}$ & $-1.389^{* * *}$ & $-0.405^{*}$ & $-0.384^{*}$ \\
\hline & $(0.241)$ & $(0.275)$ & $(0.161)$ & $(0.157)$ \\
\hline
\end{tabular}

Multivariate

\begin{tabular}{|l|c|c|c|c|}
\hline & $(1)$ & $(2)$ & $(3)$ & $(4)$ \\
\hline & diff_net_rate_11 & diff_net_rate_21 & diff_net_rate_12 & diff_net_rate_22 \\
\hline Chg_UR_st & $-1.928^{* * *}$ & $-1.330^{* * *}$ & $-0.356^{*}$ & $-0.370^{*}$ \\
\hline & $(0.240)$ & $(0.278)$ & $(0.162)$ & $(0.159)$ \\
\hline GR_HPrice_st & $0.196^{* * *}$ & 0.054 & $0.044^{*}$ & 0.013 \\
\hline & $(0.031)$ & $(0.036)$ & $(0.021)$ & $(0.020)$ \\
\hline$N$ & 1326 & 1326 & 1326 & 1326 \\
\hline
\end{tabular}

The dependent variable is the differential net employment growth rate for the group specified. All net differentials are with respect to Old/Large. Ch_UR_st is the state unemployment growth rate; GR_HPrice_st is the growth rate of the state's real FHFA housing price index. Standard errors in parentheses.

${ }^{*} p<0.05,{ }^{* *} p<0.01,{ }^{* * *} p<0.001$ Note 11=Young/Small, 21=Young/Medium, 12=Old/Small, 22=Old/Medium. 